JEFFERSON CHAVES FERREIRA

\title{
MODELAGEM E SIMULAÇÃO DE REDES EM CHIP SEM FIO
}

Dissertação apresentada à Escola Po-

litécnica da Universidade de São Paulo para obtenção do Título de Mestre em Ciências. 
JEFFERSON CHAVES FERREIRA

\section{MODELAGEM E SIMULAÇÃO DE REDES EM CHIP SEM FIO}

Dissertação apresentada à Escola Politécnica da Universidade de São Paulo para obtenção do Título de Mestre em Ciências.

Área de Concentração:

Engenharia de Computação

Orientador:

$\operatorname{Prof}^{a}$. Dr ${ }^{a}$. Cíntia Borges Margi 
Este exemplar foi revisado e corrigido em relação à versão original, sob responsabilidade única do autor e com a anuência de seu orientador.

São Paulo, de de

Assinatura do autor:

Assinatura do orientador:

Catalogação-na-publicação

Ferreira, Jefferson Chaves

Modelagem e Simulação de Redes em Chip sem Fio / J. C. Ferreira -versão corr. -- São Paulo, 2015.

$132 \mathrm{p}$.

Dissertação (Mestrado) - Escola Politécnica da Universidade de São Paulo. Departamento de Engenharia de Computação e Sistemas Digitais.

1.Redes em chip sem fio (Modelagem; Simulação) 2.Redes hierárquicas 3.Sistemas multinível I.Universidade de São Paulo. Escola Politécnica. Departamento de Engenharia de Computação e Sistemas Digitais II.t. 
Dedico este trabalho à minha mãe, que sempre acreditou em mim. 


\section{AGRADECIMENTOS}

Os agradecimentos são direcionados à minha orientadora, professora Cíntia Borges Margi, por sua paciência e disciplina em me guiar neste trabalho.

Também agradeço ao professor Bruno de Carvalho Albertini pelas suas contribuições e por seus conselhos, os quais foram essenciais para o progresso desta pesquisa.

Finalmente agradeço aos membros do Security and EMBedded systems Engineerlng group (SEMBEI) por terem me apoiado inúmeras vezes, especialmente diante das lutas e dificuldades que se sucederam durante toda esta jornada. 


\section{RESUMO}

O paradigma das redes em chip (NoCs) surgiu a fim de permitir alto grau de integração entre vários núcleos de sistemas em chip (SoCs), cuja comunicação é tradicionalmente baseada em barramentos. As NoCs são definidas como uma estrutura de switches e canais ponto a ponto que interconectam núcleos de propriedades intelectuais (IPs) de um SoC, provendo uma plataforma de comunicação entre os mesmos. As redes em chip sem fio (WiNoCs) são uma abordagem evolucionária do conceito de rede em chip (NoC), a qual possibilita a adoção dos mecanismos de roteamento das NoCs com o uso de tecnologias sem fio, propondo a otimização dos fluxos de tráfego, a redução de conectores e a atuação em conjunto com as NoCs tradicionais, reduzindo a carga nos barramentos. $O$ uso do roteamento dinâmico dentro das redes em chip sem fio permite o desligamento seletivo de partes do hardware, o que reduz a energia consumida. Contudo, a escolha de onde empregar um link sem fio em uma NoC é uma tarefa complexa, dado que os nós são pontes de tráfego os quais não podem ser desligados sem potencialmente quebrar uma rota preestabelecida. Além de fornecer uma visão sobre as arquiteturas de NoCs e do estado da arte do paradigma emergente de WiNoC, este trabalho também propõe um método de avaliação baseado no já consolidado simulador ns-2, cujo objetivo é testar cenários híbridos de NoC e WiNoC. A partir desta abordagem é possível avaliar diferentes parâmetros das WiNoCs associados a aspectos de roteamento, aplicação e número de nós envolvidos em redes hierárquicas. Por meio da análise de tais simulações também é possível investigar qual estratégia de roteamento é mais recomendada para um determinado cenário de utilização, o que é relevante ao se escolher a disposição espacial dos nós em uma NoC. Os experimentos realizados são o estudo da dinâmica de funcionamento dos protocolos ad hoc de roteamento sem fio em uma topologia hierárquica de WiNoC, seguido da análise de tamanho da rede e dos padrões de tráfego na WiNoC.

Palavras-chave: redes em chip sem fio, redes hierárquicas, simulação, sistemas multinível 


\section{ABSTRACT}

The network on chip (NoC) paradigm was conceived in order to allow a high-level integration among several system-on-chip (SoC) cores whose communication is traditionally based on buses. NoCs are defined as a switch structure with communication channels, which interconnect SoC Intellectual Property cores allowing data transfer among them. Wireless networks on chip (Wi$\mathrm{NoC}$ ) are an evolutionary approach from the network on chip (NoC) concept, proposing the traffic flow optimization among different modules by providing wireless shortcuts over a traditional NoC, reducing the bus load. Using dynamic routing within the WiNoC enables selective hardware power management, reducing power consumption. However, choosing where to deploy a wireless link over a NoC is a complex task given that those nodes are gateways that cannot be turned off without potentially breaking an established route. Besides providing an overview of NoC architectures and about the emerging WiNoC paradigm, this work proposes a method to use well known ns-2 network simulator to test mixed NoC-WiNoC scenarios. With this approach it is possible to evaluate different WiNoC parameters associated to routing, application and total number of nodes in hierarchical topologies. Simulation study can also point-out which routing strategy is more suitable for a given scenario, what is considered important when choosing wireless node placement over a NoC. We performed experiments to understand the dynamics of wireless ad hoc routing protocol functioning in a WiNoC hierarchical topology, followed by an analysis of network size and traffic patterns over WiNoC.

Key-words: WiNoC, simulation, network on chip, hierarchical systems, multilevel systems 


\section{LISTA DE FIGURAS}

1 Estrutura de uma rede em chip. . . . . . . . . . . . . . . . 21

2 Estrutura geral de uma topologia em malha de uma NoC . . . 28

3 Topologias em anel . . . . . . . . . . . . . . . . 28

4 Topologias butterfly e flattened butterfly . . . . . . . . . . . 29

5 Topologia flattened butterfly bidimensional . . . . . . . . . . 30

6 Diferenças entre topologia cúbica e flattened butterfly . . . . . 32

7 Arquitetura de canais virtuais $\ldots \ldots \ldots \ldots$. . . . . 33

8 Roteamento em um switch sem buffers . . . . . . . . . 35

9 Arquitetura CHIPPER . . . . . . . . . . . . . . . 39

10 Arquitetura MinBD. . . . . . . . . . . . . . . . . . 40

11 Transceptor UWB . . . . . . . . . . . . . . . . . . 45

12 Antena zigue-zague em um substrato de $20-\Omega-\mathrm{cm} \ldots \ldots$

13 Circuito transmissor $(20-\mathrm{GHz})$ fabricado em CMOS (130nm) . . 48

14 Chip receptor UWB . . . . . . . . . . . . . . . . . . . . . . 49

15 Iterações da Curva de Koch . . . . . . . . . . . . . . . 50

16 Dipolo tapete e triângulo de Sierpinski . . . . . . . . . . . . 51

17 Antena fractal de Kumar e Gaikwad (2013) . . . . . . . . . . . 52

18 Pacote circular e retangular de nanotubos de carbono . . . . . 53

19 Comparação de resultados experimentais e de simulação . . . . 55

20 Operação básica de um nanoreceptor . . . . . . . . . . . . . 56

21 Máquina de estados da plataforma de simulação . . . . . . . . 68

22 Diagrama da topologia simulada . . . . . . . . . . . . 70

23 Fluxo principal de simulação. . . . . . . . . . . . . . . . . 72 
24 Exemplo de topologia com fio e sua topologia sem fio equivalente 73

25 Ilustração dos conceitos de nós em tráfego interno e externo . . 75

26 Diagrama de componentes do simulador . . . . . . . . . . . . . 79

27 Exemplo de trace de componente no Gem5 . . . . . . . . . . . . 80

28 Arquitetura do switch modelado no Orion . . . . . . . . . . . 81

29 Resultados das métricas para os três protocolos simulados . . . 85

30 Resultados das métricas para diversos clusters . . . . . . . . . . 87 


\section{LISTA DE TABELAS}

1 Comparação entre barramentos tradicionais e redes em chip . . 14

2 BLESS: políticas de priorização de pacotes . . . . . . . . . . . 38

3 Topologias apresentadas - principais aspectos . . . . . . . . . . 41

4 Arquiteturas apresentadas - principais aspectos . . . . . . . . . 42

$5 \quad$ Antenas em chip - estado da arte . . . . . . . . . . . . . 6 65

6 Modelagem e simulação de WiNoCs - trabalhos relacionados . . 65

7 Protocolos ad hoc sem fio - principais aspectos . . . . . . . . 66

8 Plataforma de simulação - principais aspectos . . . . . . . . . 82

9 Análise de resultados - pontos principais . . . . . . . . . . . . 90

10 Emprego de protocolos ad hoc sem fio em WiNoCs - pontos

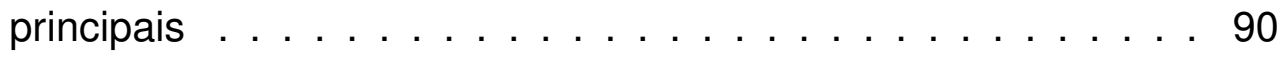




\section{LISTA DE ABREVIATURAS E SIGLAS}

\begin{tabular}{ll} 
AODV & Ad hoc On-Demand Distance Vector \\
API & Application Programming Interface \\
BER & Bit Error Rate \\
BLESS & Bufferless Routing Algorithm \\
CHIPPER & Cheap-Interconnect Partially Permuting Router \\
CMOS & Complementary Metal Oxide Semiconductor \\
CPU & Computer Processing Unit \\
DSP & Digital Signal Processing \\
DSDV & Destination-Sequenced Distance Vector Routing \\
DSR & Dynamic Source Routing \\
FPGA & Field-Programmable Gate Array \\
IP & Intellectual Property \\
LNA & Low Noise Amplifier \\
PLL & Phase Locked Loop \\
MinBD & Minimally-Buffered Deflection \\
NoC & Network on Chip \\
ROTE & Razão de Onda de Tensão Estacionária \\
RNI & Resource Network Interface \\
SoC & System-on-Chip \\
TCL & Static Random Access Memory \\
\hline
\end{tabular}


USP Universidade de São Paulo

VINT Virtual InterNetwork Testbed

WiNoC Wireless Network on Chip

XML Extended Markup Language 


\section{SUMÁRIO}

1 Introdução 13

1.1 Motivação . . . . . . . . . . . . . . . . . . . 15

1.2 Objetivos ........................ 17

1.3 Justificativa . . . . . . . . . . . . . . . . . . 17

1.4 Método . . . . . . . . . . . . . . . . . . 18

1.5 Organização do documento . . . . . . . . . . . . . . . 18

2 Aspectos gerais das redes em chip 20

2.1 Descrição funcional . . . . . . . . . . . . . . . . . . 20

2.2 Componentes de um switch de uma NoC . . . . . . . . . . 22

2.3 Custo de uma NoC . . . . . . . . . . . . . . . . . . . 22

2.4 Desempenho de uma NoC . . . . . . . . . . . . . . 25

2.5 Topologias . . . . . . . . . . . . . . . . 26

2.5 .1 Malha . . . . . . . . . . . . . . 27

2.5 .2 Small-world . . . . . . . . . . . . . . . . . 28

2.5.3 Flattened butterfly . . . . . . . . . . . . . . . . 29

2.5 .4 Cúbica. . . . . . . . . . . . . . . . . . . . 31

2.6 Arquitetura Clássica . . . . . . . . . . . . . . . . . . . 32

2.7 Arquiteturas sem buffers . . . . . . . . . . . . . . . . . . . 34

2.7 .1 BLESS . . . . . . . . . . . . . . . . 36

2.7 .2 CHIPPER . . . . . . . . . . . . . . 39

2.7.3 MinBD . . . . . . . . . . . . . . . . 40

2.8 Sinopse . . . . . . . . . . . . . . . . . . . . . . . . 41 
3.1 Abordagens de transmissão sem fio . . . . . . . . . . . . . 43

3.1.1 O emprego de Ultra Wide Band . . . . . . . . . . . 44

3.1 .2 Antenas zigue-zague $\ldots \ldots \ldots \ldots$

3.1.3 Antenas fractais . . . . . . . . . . . . 50

3.1.4 Nanotubos de carbono . . . . . . . . . . . . . . 52

3.2 Trabalhos relacionados de transmissão sem fio aplicada a redes em chip . . . . . . . . . . . . . . . . . . . 57

3.3 Uso de protocolos de roteamento dinâmico para a economia de energia . . . . . . . . . . . . . . . 62

3.4 Protocolos ad hoc de roteamento sem fio $\ldots . . \ldots 63$

3.5 Sinopse . . . . . . . . . . . . . . . . . 64

4 Plataforma de simulação $\quad 67$

4.1 Modelagem . . . . . . . . . . . . . . . 71

4.1.1 Fluxo principal da plataforma de simulação . . . . . . . 71

4.1 .2 Parâmetros . . . . . . . . . . . . . . 73

4.1 .3 Métricas . . . . . . . . . . . . . . . . . 75

4.1.4 Algoritmo de convergência . . . . . . . . . 76

4.2 Desenvolvimento . . . . . . . . . . . . . . . . 77

4.3 Sinopse $\ldots \ldots \ldots \ldots \ldots \ldots \ldots$. . . . . . . . . . 81

5 Experimentos e análise de resultados 83

5.1 Desempenho de protocolos . . . . . . . . . . . . . . 83

5.1.1 Perfis de tráfego interno e externos . . . . . . . . . . 84

5.1.2 Tamanho da rede e número de saltos $\ldots \ldots$. . . 86

5.2 Empregando protocolos ad hoc sem fio em WiNoCs . . . . . 88 
5.3 Sinopse . . . . . . . . . . . . . . . . . . 89

6 Considerações Finais $\quad 91$

6.1 Publicações . . . . . . . . . . . . . . . . . . . . . . . 92

6.2 Trabalhos futuros . . . . . . . . . . . . . . . . 92

$\begin{array}{lr}\text { Referências } & 94\end{array}$

Apêndice A - Exemplo de script da simulação com fio 101

Apêndice B - Exemplo de script de simulação sem fio 114

Apêndice C - Exemplo para os parâmetros de entrada 123

Apêndice D - Código fonte das abordagens de convergência 125 


\section{INTRODUÇÃO}

Os sistemas em chip (SoCs - System on Chip) são definidos como um conjunto de componentes eletrônicos acoplados em um único dispositivo o qual possui função dedicada (WILTON; SALEH, 2001). Não são raras as vezes em que tais componentes necessitam de recursos de comunicação. Portanto lidando-se com um contexto de miniaturização de componentes, de uso de sistemas embarcados dotados de sensores e do seu emprego em aplicações distribuídas, há uma demanda por sistemas de comunicação que sejam compatíveis com tais requisitos e que suportem uma comunicação complexa. Visando a substituição da infraestrutura de comunicação tradicional dos SoCs baseada em barramentos, as redes em chip (NoCs - Network on Chip) emergem como um novo paradigma cujo alvo é a melhoria do desempenho da comunicação entre os núcleos embarcados fornecendo uma plataforma de comunicação escalável e que possa ser reutilizada em um grande número de SoCs (BENINI; MICHELI, 2002). A Tabela 1 compara os barramentos tradicionais com o paradigma das redes em chip, destacando as vantagens desta nova abordagem de comunicação distribuída sobre a comunicação tradicional.

Uma NoC é definida como uma estrutura de switches e canais ponto-a ponto que interconectam núcleos de um sistema, provendo uma plataforma de comunicação entre eles. Os dados são transmitidos pela rede na forma de pacotes, que podem ser quebrados em unidades menores, denominadas flits, as quais são efetivamente transportadas segundo uma arquitetura e um protocolo específico.

No que tange ao seu emprego em sistemas embarcados, superfície e consumo de energia são primordiais. Dessa forma deve-se privilegiar o emprego de arquiteturas de switches mais simples e econômicas. De acordo com Moscibroda e Mutlu (2009) consegue-se reduzir o consumo energético e a su- 
Tabela 1: Comparação entre Barramentos tradicionais e Redes em Chip. O sinal "+" identifica uma vantagem ao passo que o sinal "-" identifica uma desvantagem.

\begin{tabular}{ccc}
\hline $\begin{array}{c}\text { Barramentos Tradicionais } \\
\text { vantagens e desvantagens }\end{array}$ & $\begin{array}{c}\text { Redes em Chip } \\
\text { vantagens e desvantagens }\end{array}$ \\
\hline $\begin{array}{c}\text { Cada IP anexada adiciona } \\
\text { capacitância parasita, portanto } \\
\text { o desempenho elétrico se degrada } \\
\text { com o aumento de IPs. }\end{array}$ & -+ & $\begin{array}{c}\text { Somente ligações únicas } \\
\text { ponto-a-ponto empregando fios } \\
\text { são usadas, independente da } \\
\text { escala da rede. }\end{array}$ \\
$\begin{array}{c}\text { Sincronização de barramentos } \\
\text { é um processo submicrônico } \\
\text { profundo. }\end{array}$ & -+ & $\begin{array}{c}\text { As ligações da rede podem ser } \\
\text { dispostas em pipeline por }\end{array}$ \\
$\begin{array}{c}\text { Testes envolvendo os barramentos } \\
\text { são complexos e lentos. }\end{array}$ & -+ & $\begin{array}{c}\text { Testes locais dedicados de } \\
\text { interfaces são mais rápidos } \\
\text { e oferecem boa cobertura. }\end{array}$ \\
$\begin{array}{c}\text { O atraso da arbitragem aumenta } \\
\text { com o número de IPs. }\end{array}$ & -+ & $\begin{array}{c}\text { As decisões de roteamento são } \\
\text { distribuídas. }\end{array}$ \\
$\begin{array}{c}\text { A arbitragem do barramento é } \\
\text { específica para cada } \\
\text { instância de SoC. }\end{array}$ & -+ & $\begin{array}{c}\text { O mesmo switch pode ser } \\
\text { instanciado para todos os } \\
\text { tamanhos de rede. }\end{array}$ \\
$\begin{array}{c}\text { A capacidade de transmissão de } \\
\text { dados é limitada e compartilhada } \\
\text { por todas as IPs conectadas ao } \\
\text { barramento. }\end{array}$ & $-\quad+\quad \begin{array}{c}\text { A capacidade de transmissão de } \\
\text { dados aumenta com a escala da } \\
\text { rede. }\end{array}$
\end{tabular}

Dado que uma IP tenha acesso ao barramento, sua latência é somente $o$ atraso relacionado à transmissão de dados.
Barramentos ocupam pouca + - Dependendo da topologia, superfície em hardware. as redes podem ocupar maior superfície em hardware.

Qualquer barramento é, via de regra, diretamente compatível com a maioria das IPs , disponíveis como também com o software empregado nas CPUs.

Os conceitos são simples e $\quad+\quad-$ bem disseminados.
+ - Mecanismos internos de contenção de rede podem originar latência.

+ - IPs orientadas à barramentos necessitam de wrappers.

O software das IPs necessita de sincronização em sistemas multiprocessados.

Os projetistas de sistemas necessitam reeducar-se para assimilar novos conceitos. 
perfície de um componente em até $40 \%$ por meio de redes de switches sem buffers.

Ogras, Hu e Marculescu (2005) enumeram alguns exemplos de problemas relevantes em NoCs, tais como o desenvolvimento de topologias eficientes que sejam capazes de conciliar desempenho, miniaturização e simplicidade de projeto, a concepção de mecanismos de gerenciamento de filas, a questão do tamanho de canal, a questão da existência ou não de buffers e seu impacto na superfície e latência da rede, que demonstram o potencial de desenvolvimento de pesquisas nesta área do conhecimento.

As redes em chip são uma parte integral do projeto de um SoC e de sua respectiva arquitetura, o que incentiva um vasto espaço de opções de implementação e de decisões a serem tomadas. Portanto com o objetivo de obter resultados otimizados, a modelagem e a simulação tornam-se primordiais para uma concepção e um fluxo de desenvolvimento bem-sucedido. A partir deste cenário, pesquisas envolvendo metodologias de projeto e modelos comportamentais de tráfego capazes de relacionar a dinâmica do sistema com os requisitos de redes em chip são desejadas e necessárias para a consolidação deste novo paradigma.

\subsection{Motivação}

Com a evolução da tecnologia de radiofrequência, as redes em chip dotadas de características sem fio despontam como indutoras do aumento de desempenho e escalabilidade das redes em chip. Numerosas arquiteturas de semicondutores metal óxido complementares (CMOS) empregando antenas (dipolo e loop), por exemplo, foram desenvolvidas com resultados promissores (O. et al., 2005) ${ }^{1}$. Tais arquiteturas podem ser aplicadas em mecanismos propagadores de sinais de relógio ou de barramento de controle (FLOYD, 2001), ser utilizadas em mecanismos de redução de conectores (WU; WANG; ZHAO, 2010) e até mesmo atuar em conjunto com as redes em chip tradicionais na transmissão de informações (ZHAO; WU, 2012).

O uso da tecnologia Ultra Wide Band (UWB) associada ao emprego de

\footnotetext{
${ }^{1}$ Dr. Kenneth Kyongyop O
} 
antenas zigue-zague, às antenas fractais ou mesmo às compostas por nanotubos de carbono despontam como potenciais candidatos ao uso em WiNoCs. Isto abre a possibilidade para antenas de tamanho reduzido, e seu consequente uso em arquiteturas de hardware para redes em chip.

A análise de desempenho do emprego de mecanismos de radiotransmissão proposta por Deb et al. (2012) demonstra que as arquiteturas em chip sem fio possuem um desempenho significativamente superior quando comparadas com as arquiteturas hierárquicas com fio equivalentes. Dessa forma, ressaltase a necessidade de análises mais detalhadas a respeito das arquiteturas dos circuitos e dos pontos críticos no emprego das redes sem fio em NoCs.

Além destes aspectos, a tecnologia sem fio em NoCs ainda é incipiente. Não há muitos estudos a respeito do emprego de protocolos ad hoc de redes sem fio, como o DSR (JOHNSON; MALTZ, 1996), o DSDV (PERKINS; BHAGWAT, 1994) ou o AODV (PERKINS; ROYER, 1999), apesar das similaridades dos requisitos em seu emprego tais como a dinâmica de autoorganização e controle de congestionamento de tráfego. Dessa forma, este trabalho inclui um estudo comparativo detalhado a respeito do funcionamento dos protocolos de rede sem fio destinado a saber qual paradigma de protocolo de roteamento é o mais indicado para o uso em roteamento sem fio em NoCs tanto em abordagens intra chip quanto na comunicação externa.

Diante de um contexto de busca de melhores abordagens que conciliem o tempo de resposta, o consumo energético e a área ocupada por uma NoC, este trabalho tem como principal motivação um estudo inicial a respeito de topologias e arquiteturas as quais podem ser utilizadas com a combinação de redes sem fio com NoCs (WiNoCs). Trata-se da especificação de uma rede mista, adaptativa e auto gerenciável que busque a conexão de diversos dispositivos embarcados como sensores e coprocessadores para a realização de uma determinada macro tarefa.

As aplicações deste tipo de rede são variadas. Tal dispositivo pode ser utilizado como rede de comunicação para casas inteligentes, como também em dispositivos de comunicação não vitais em automóveis e até mesmo em aeronaves (MOTAMEDI et al., 2009). 


\subsection{Objetivos}

O objetivo desse trabalho é a análise da dinâmica de funcionamento de redes em chip sem fio (WiNoC) por meio do emprego de uma topologia hierárquica dividida clusters, a partir de uma abordagem evolucionária do estado da arte da pesquisa em WiNoCs. Para isto foi projetada e desenvolvida uma plataforma de simulação baseada no simulador ns-2 (ISI, 2011b), na qual é possível a análise do desempenho dos switches e da dinâmica de funcionamento de redes em chip sem fio em diversos cenários experimentais.

A análise se estende acerca de quais paradigmas de protocolos de roteamento ad hoc de redes sem fio possuem melhores resultados quando aplicados a redes em chip sem fio como também nos efeitos de diferentes perfis de tráfego e tamanhos de rede no desempenho geral da topologia. Outro aspecto importante desta análise é o uso do paradigma de protocolos de roteamento dinâmico a fim de realizar economia de energia e os procedimentos para o uso dos protocolos de roteamento ad hoc sem fio em WiNoCs vislumbrando sua implementação em redes em chip sem fio hierárquicas.

\subsection{Justificativa}

O paradigma de redes em chip sem fio necessita de investigações extensivas para tornar-se uma alternativa viável para as infraestruturas de conexão existentes (DEB et al., 2012). Na maioria dos trabalhos na literatura, os mecanismos de avaliação das arquiteturas de NoCs e WiNoCs são baseados em simuladores próprios, o que gera dificuldades na hora de realizar comparações. Dessa forma, este trabalho propõe o uso de um simulador consagrado como o ns-2 (ISI, 2011b) como base para a simulação de redes em chip sem fio provendo uniformidade na avaliação dos agentes, arquiteturas e protocolos de roteamento.

Além disso, os estudos relacionados à camada física em WiNoCs direcionam-se para prover capacidades sem fio plenas em qualquer nó sem fio. Por outro lado, a radiotransmissão é ainda custosa em termos de consumo de energia o que incentiva os pesquisadores a elaborar estudos a respeito da 
complexidade dos switches e acerca das dinâmicas de rede, a fim de minimizar os custos enquanto se mantém um desempenho aceitável para a rede.

\subsection{Método}

A metodologia adotada consiste na concepção de uma plataforma de simulação baseada no simulador de redes ns-2 (ISI, 2011b). O uso deste simulador como base para a plataforma de simulação de WiNoCs abre a possibilidade para a elaboração de estudos acerca da modelagem da dinâmica de comunicação dos nós em rede com foco, não somente na arquitetura do switch, como também nos impactos da topologia e dos protocolos de roteamento no desempenho geral da rede.

Por meio desta plataforma de simulação foram realizados dois grupos de experimentos em uma topologia de WiNoC hierárquica. O primeiro grupo analisa a dinâmica funcionamento e desempenho de um conjunto de três protocolos de redes ad hoc sem fio em diversos cenários de tráfego interno e externo. O segundo grupo analisa os efeitos da variação do tamanho da rede e de diferentes perfis de tráfego no desempenho da WiNoC.

É interessante ressaltar que, por questões de complexidade, alguns conceitos das redes sem fio tradicionais relacionados ao roteamento dinâmico ou ao acesso ao meio levarão algum tempo para chegar às WiNoCs em sua completude, contudo é possível prospectar aspectos importantes a partir de simulações tais como o comportamento dos paradigmas de roteamento (reativo ou ativo) usados nos protocolos de redes sem fio, os mecanismos de acesso ao meio e a proporção de nós dotados de canais sem fio no total da rede. Estes aspectos dão uma contribuição significativa para o projeto em chip de WiNoCs além de fornecer aspectos importantes em um cenário de co-simulação.

\subsection{Organização do documento}

O restante deste documento está organizado da seguinte forma:

- O capítulo 2 apresenta os conceitos teóricos essenciais ao entendi- 
mento deste trabalho, necessários para a contextualização do tema. Destacam-se os cálculos de custo (seção 2.3) e de desempenho (seção 2.4) de uma NoC, as topologias mais frequentes (seção 2.5) e as arquiteturas de switches com buffers (seção 2.6) e sem buffers (seção 2.7);

- O capítulo 3 apresenta uma visão geral acerca do estado da arte na concepção de antenas em chip (seção 3.1) além de elucidar algumas abordagens e conceitos relevantes para a modelagem e simulação de redes em chip sem fio (seções 3.2 e 3.3);

- O capítulo 4 especifica os aspectos necessários para a simulação de topologias hierárquicas de redes em chip sem fio, apresentando toda a metodologia e as técnicas utilizadas para medir seu desempenho;

- O capítulo 5 especifica os experimentos realizados neste trabalho e analisa os resultados obtidos em cada um deles. Há também uma análise de como implementar os protocolos estudados neste trabalho em hardware visando o uso em WiNoC na seção 5.2;

- Finalmente o capítulo 6 apresenta as conclusões originadas por este trabalho bem como a descrição dos trabalhos futuros a serem tomados para a continuidade e consolidação total deste trabalho de pesquisa. 


\section{ASPECTOS GERAIS DAS REDES EM CHIP}

Este capítulo tem como objetivo especificar os principais fatores que servem como base para a compreensão do funcionamento e da metodologia de avaliação das redes em chip. Incia-se com uma descrição dos principais componentes e estruturas de uma NoC (seções 2.1 e 2.2), seguida de métodos para avaliação de seu custo e desempenho (seções $2.3,2.4$ ) e também da descrição de topologias (seção 2.5) e arquiteturas (seções 2.6 e 2.7) relevantes. Finalmente encerra-se o capítulo com a sinopse das topologias e arquiteturas discutidas (seção 2.8).

\subsection{Descrição funcional}

Uma arquitetura em chip é um arranjo de switches e recursos posicionados em slots conectados pelos switches.

Um recurso é definido como um módulo de Propriedade Intelectual (IP -Intellectual Property) o qual possui uma função específica. Exemplos de recursos são processadores, memórias, FPGAs, hardware customizado ou qualquer outro módulo que possibilite sua inserção nos slots da NoC. Cada recurso possui acesso a pelo menos um switch.

Os switches são conectados a recursos e a outros switches vizinhos. A comunicação interna dos recursos é síncrona e os mesmos devem ser capazes de se comunicar com a NoC por meio de uma interface da rede de recursos (RNI - Resource Network Interface). Tal interface possui quatro níveis (KUMAR et al., 2002):

- A camada física, que determina o número de fios conectando recursos e switches; 
- A camada de transferência de dados, a qual define o protocolo para transmitir uma unidade de dados entre um recurso e um switch ou entre dois switches. Tanto a camada física quanto a camada de transferência de dados são dependentes da topologia. Portanto, para cada nova geração tecnológica, estas duas camadas são definidas;

- A camada de rede define como um pacote ou flit (divisão de um pacote) é transferido pela rede a partir de um emissor arbitrário para um receptor arbitrário direcionado por seu respectivo endereço. Esta camada é dependente da tecnologia empregada;

- A camada de transporte também é dependente de tecnologia. O tamanho da mensagem pode ser variável. A RNI deve empacotar as mensagens da camada de transporte em pacotes da camada de rede.

Figura 1: Estrutura de uma rede em chip.

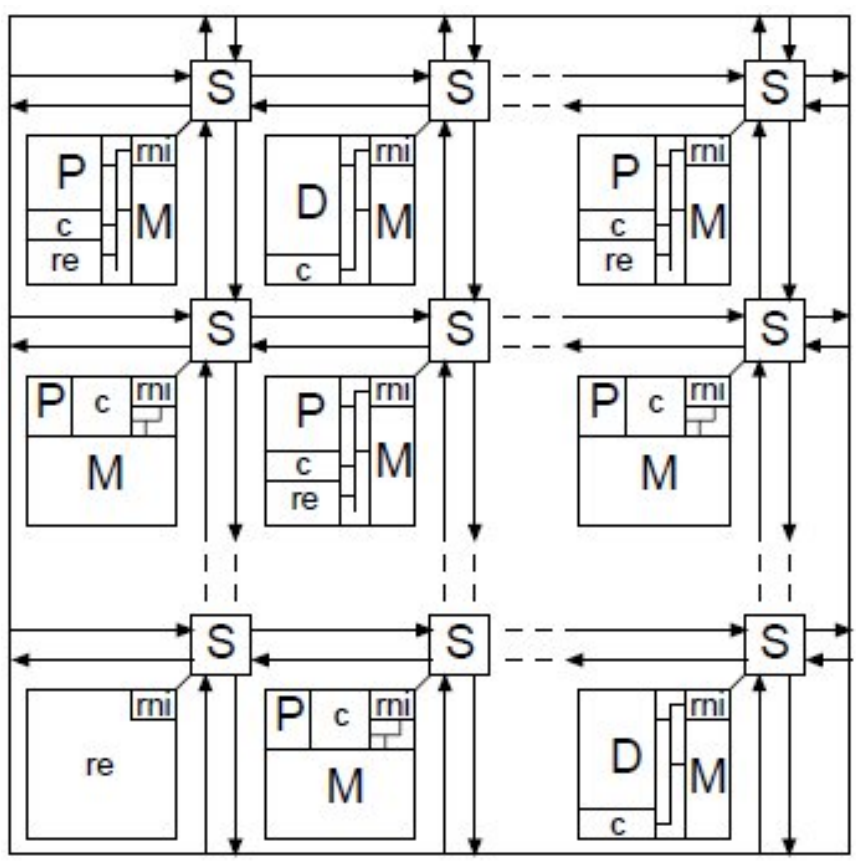

Fonte: Kumar et al. (2002)

A Figura 1 ilustra os componentes principais de uma NoC: "S" são os switches, "RNI" são os módulos de interface da rede de recursos, "P" são os núcleos de processamento, "D" são os núcleos de processamento de sinais, "M" ilustra a memória, "c" ilustra o cache e "re" são os blocos reconfiguráveis. 


\subsection{Componentes de um switch de uma NoC}

Em uma NoC os switches são componentes os quais possuem destaque. Eles são responsáveis por gerenciar e encaminhar os flits possibilitando a comunicação entre os diversos recursos da rede. Apesar da diversidade de arquiteturas de switches

(FALLIN; CRAIK; MUTLU, 2011; MOSCIBRODA; MUTLU, 2009; FALLIN et al., 2012) a maior parte deles possuem componentes em comum, a saber (KIM, 2009):

- Crossbar - é a parte do switch a qual regula o redirecionamento dos flits das portas de entrada para as portas de saída. Em arquiteturas convencionais (seção 2.6) seu impacto na superfície do circuito pode chegar a $64 \%$ da superfície total do switch (KIM, 2009). Suas dimensões no circuito são de $O\left(p^{2} w^{2}\right)$ onde $p$ é o número de portas do switch e $w$ é o comprimento do datapath;

- Arbitragem - é o módulo no qual estão os controles para a comunicação do recurso com a rede. Dessa forma, uma parte significativa da latência é determinada pelos mecanismos de arbitragem;

- Buffers - são componentes utilizados como mecanismos de simplificação do controle do fluxo de tráfego já que podem armazenar uma quantidade limitada de flits em seu interior. Contudo os buffers representam uma porção significativa da área e da energia de um switch de uma rede em chip sem fio (MOSCIBRODA; MUTLU, 2009). Diante do impacto dessas estruturas, além da arquiteturas baseadas na existência de buffers surgem as redes em chip sem buffers (seção 2.7), as quais utilizam mecanismos de deflexão de flits no caso de disputas para o uso do mesmo canal no mesmo intervalo de tempo.

\subsection{Custo de uma NoC}

O custo de uma rede em chip pode ser traduzido em duas principais dimensões: a da energia consumida pela arquitetura e a superfície no chip ocupada pela mesma. 
O consumo energético dos switches de uma NoC é diretamente relacionado com sua arquitetura, sendo que os buffers possuem um papel significativo neste quesito. Segundo Kumar et al. (2007), os buffers podem responder por até $46 \%$ do consumo energético da NoC. O segundo maior consumo energético provém do crossbar, o qual responde por até $34 \%$ da energia consumida, evidenciando a atenção que deve ser dada a estes componentes em um projeto de uma nova arquitetura de rede em chip. O consumo energético também é influenciado pelo perfil de tráfego ao qual a NoC é submetida. Perfis de tráfego que impliquem em maior número de saltos entre nós, por exemplo, exigem maior energia para que a transmissão seja executada. Para estimar-se a energia de uma NoC é necessário mapear o perfil dos caminhos seguidos pelos flits na rede e, a partir dessa informação, somar a energia consumida por cada um dos caminhos conforme as equações 2.1 a 2.4 (GROT et al., 2009):

$$
\begin{gathered}
E_{\text {links }_{j}}=E_{\text {fiomm }} \cdot w \cdot \sum_{i=1}^{H_{j}} \delta_{i} \\
E_{\text {switches }_{j}}=\sum_{i=1}^{H_{j}}\left(E_{\text {buffers }}+E_{\text {crossbar }}+E_{\text {arbitragem }}\right) \\
E_{\text {caminho }_{j}}=E_{\text {links }_{j}}+E_{\text {switches }_{j}} \\
E_{\text {NoC }}=\sum_{j=1}^{F} E_{\text {caminho }_{j}} \cdot n_{j}
\end{gathered}
$$

Onde:

$E_{f i o_{m m}}$ : energia por milímetro de fio

$w$ : largura do canal $(\mathrm{mm})$

$\delta_{i}$ : comprimento do fio por salto $(\mathrm{mm})$

$H_{j}$ : total de saltos de um determinado percurso

$E_{\text {buffers }}:$ contribuição energética dos buffers para um salto 
$E_{\text {crossbar }}$ : contribuição energética do crossbar para um salto

$E_{\text {arbitragem }}$ : energia do componente de arbitragem para um salto

$F$ : número total de fluxos de tráfego dos flits de uma NoC

$n_{j}$ frequência de um determinado fluxo de tráfego em uma NoC

No quesito da área, os buffers também são responsáveis por uma parte significativa do circuito chegando a ocupar até $17 \%$ da superfície total de um switch para abordagens baseadas em SRAM. Arquiteturas de switches com buffers baseados em flip-flop possuem até $51 \%$ de sua área total ocupada pelos buffers (KIM, 2009). Como a lógica de controle não possui peso significativo na área da NoC, a área de uma rede em chip pode ser estimada conforme equações 2.5 a 2.7 (GROT et al., 2009):

$$
\begin{gathered}
A_{\text {links }}=A_{\text {fiomm }} \cdot w \cdot \sum_{i=1}^{C} \delta_{i} \\
A_{\text {switches }}=\left(A_{\text {buffers }}+A_{\text {crossbar }}+A_{\text {arbitragem }}\right) \cdot N \\
A_{N o C}=A_{\text {links }}+A_{\text {switches }}
\end{gathered}
$$

Onde:

$A_{f i o_{m m}}$ : Área ocupada por milímetro de fio

$w$ : largura do canal $(\mathrm{mm})$

$\delta_{i}$ : comprimento do canal $(\mathrm{mm})$

$C:$ total de canais em um switch

$N$ : número de switches

$A_{\text {buffers: }}$ área dos buffers

$A_{\text {crossbar }}$ : área do crossbar

$A_{\text {arbitragem }}$ área do componente de arbitragem 


\subsection{Desempenho de uma NoC}

O desempenho de uma rede em chip pode ser medido por meio de dois parâmetros: o throughput e a latência.

O throughput, ou vazão, é definido como a taxa média de entregas bem sucedidas em um canal de comunicação em um intervalo de tempo, geralmente curto, tendendo a zero. Unidades comuns de throughput são bits por segundo, pacotes por segundo ou flits por segundo. Dessa forma, maior throughput implica em uma maior velocidade de entrega de pacotes. O throughput médio de uma NoC pode ser definido pela equação 2.8:

$$
\operatorname{Tr}_{N o C}=\frac{\sum_{i=1}^{N} \frac{n_{i}}{T}}{N}
$$

Onde:

\section{$N$ : número de switches}

$n_{i}$ : número de flits que percorrem o switch $i$

$T$ : tempo de avaliação

A latência de uma rede em chip é definida como o intervalo de tempo no qual um pacote (ou flit) leva para chegar ao seu destinatário em uma determinada arquitetura. Associada com o throughput, é uma métrica decisiva na hora de avaliar o desempenho de uma rede sem fio. A latência de um pacote de uma NoC pode ser calculada por meio da equação 2.9, adaptado de Kim, Balfour e Dally (2007):

$$
T=T_{h}+T_{s}+T_{w}=H . t_{r}+\frac{L}{b} \cdot t_{s}+T_{w}
$$

Onde:

$T_{h}$ : latência de cabeçalho

$T_{s}$ : latência de serialização

$T_{w}$ : latência de transmissão 
$H$ : número de saltos

$t_{r}:$ tempo de roteamento

$t_{s}$ : soma dos tempos de serialização e deserialização

$L$ : tamanho do pacote

b: largura do canal

No contexto de simulação de dinâmicas de comunicação em rede, outro parâmetro relevante para o desempenho da rede é o atraso médio, o qual mede o tempo médio que os flits dispendem para chegar às suas respectivas destinações. O cálculo consiste na soma do tempo levado por cada pacote para chegar ao seu destino (equação 2.9) em todos os fluxos de tráfego da NoC dividido pelo número total de fluxos de tráfego, calculado conforme a equação 2.10:

$$
T_{\text {NoC }}=\frac{\sum_{i=1}^{N_{\text {flows }}} \sum_{j=1}^{n p_{\text {flow }}} T_{\text {flow }_{i j}}}{N_{\text {flows }}}
$$

Onde:

$N_{\text {flows }}:$ número de fluxos de tráfego

$n p_{\text {flowi }}$ : número de flits que percorrem um fluxo de tráfego $i$

$T_{\text {flow }_{i j}}$ : tempo dispendido para o flit $j$ percorrer o fluxo de tráfego $i$

\subsection{Topologias}

Outro aspecto relevante em uma arquitetura de NoC é a topologia estabelecida pelos switches. Uma topologia é definida como a disposição espacial dos nós em uma rede. No caso de redes em chip, as topologias buscam aproveitar o máximo da superfície do hardware. Há também topologias que buscam aumentar o número de conexões entre os nós com o intuito de diminuir o número de saltos na rede, reduzindo consequentemente a latência da NoC. Por outro lado, redes complexas combinadas com as restrições impostas por 
substratos planares de silício afetam significativamente a escolha de uma topologia para NoCs. Topologias de dimensões simples, como anel ou malhas dimensionais, são interessantes para uso em NoCs já que a regularidade de suas estruturas e a baixa complexidade de seus switches combinam com o processo de síntese de circuitos em hardware. Topologias mais complexas podem ter sua escalabilidade limitada, além do risco de sua síntese possuir canais com comprimentos exagerados, o que pode impactar negativamente na latência de transmissão, no consumo energético e na forma na qual os diversos módulos serão alocados na plataforma de hardware.

A fim de propiciar maior escalabilidade e diminuir a complexidade das topologias surge o conceito de concentração $k$, o qual pode ser traduzido como o número de nós por switch da rede. Uma NoC mais concentrada é aquela na qual é possível acessar mais recursos com um menor número de transições na rede, o que reduz também a complexidade das ligações entre seus diversos elementos. As seções a seguir enumeram e especificam as topologias mais encontradas nas redes em chip.

\subsubsection{Malha}

A Figura 2 ilustra a topologia mais frequentemente adotada nas redes em chip (NYCHIS et al., 2012). Um conjunto de switches e ligações ponto-a-ponto que os interconectam é organizada segundo uma estrutura em malha. Cada switch possui alguns módulos de IPs que são responsáveis pela execução das tarefas. Estas tarefas, executadas em diferentes IPs, comunicam-se por meio da interconexão em chip na qual há, em cada direção, dois canais unidirecionais para cada sentido.

O mecanismo de gestão das interconexões utiliza a técnica dos canais virtuais (seção 2.6), a qual desacopla a alocação de recursos provendo múltiplos buffers para cada ligação física na rede (DALLY, 1992). Cada um destes buffers é considerado um canal virtual e é capaz de armazenar um ou mais flits de um pacote. 
Figura 2: Estrutura geral de uma topologia em malha de uma NoC

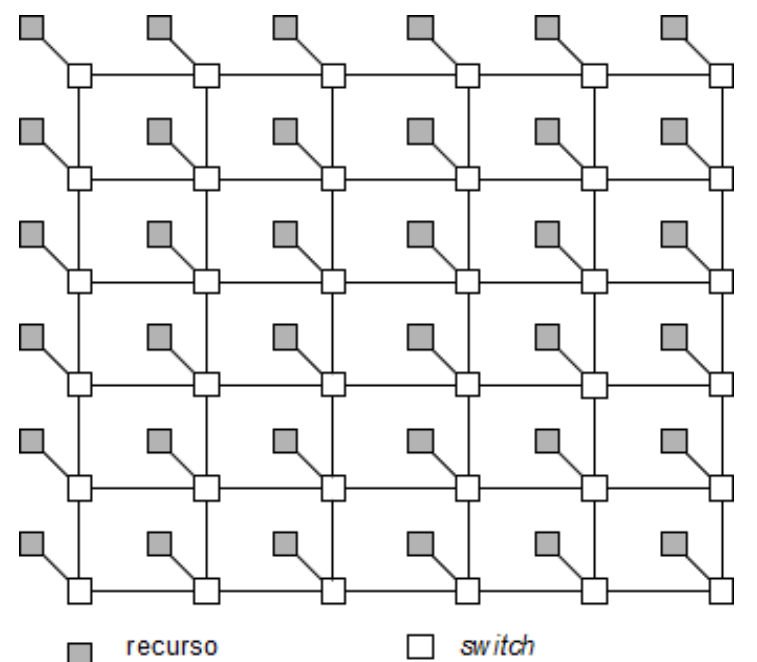

\subsubsection{Small-world}

As redes organizadas em uma topologia small-world possuem um número médio de saltos relativamente pequeno. $O$ caminho médio é da ordem de $\log N_{s w}$, onde $N_{s w}$ são os nós envolvidos na topologia e, dessa forma tal organização torna-se atrativa para a implantação de topologias em NoCs com número elevado de nós (GANGULY et al., 2011a). A Internet e as redes sociais, por exemplo, exibem propriedades modeláveis por small-world (WATTS; STROGATZ, 1998).

Figura 3: A Figura (a) ilustra uma topologia em anel. As outras três Figuras ilustram exemplos de redes small-world para um (b), três (c) e quatorze (d) atalhos.

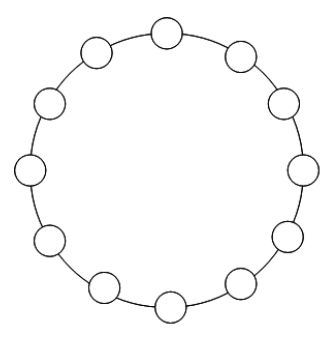

(a)

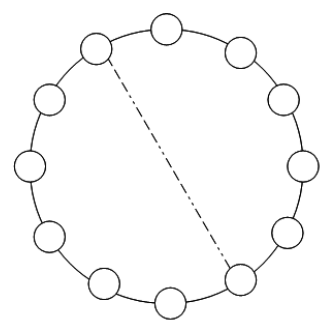

(b)

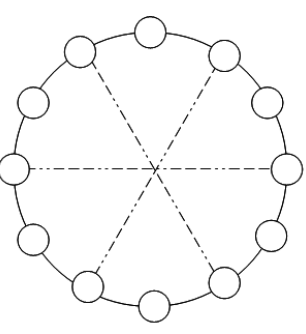

(c)

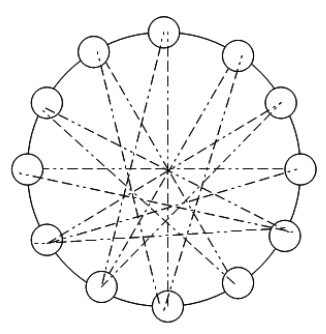

(d)

Adaptado de Ganguly et al. (2011a)

A topologia small-world pode ser construída a partir de uma topologia em anel (Figura 3-a) por meio da especificação de conexões entre os nós de tal forma que se criem atalhos. Tais conexões podem seguir distribuições probabilísticas parametrizadas por parâmetros como, por exemplo, a distância entre 
os nós da topologia em anel inicial. Ainda segundo Ganguly et al. (2011a), estes atalhos permitem melhorar significativamente o desempenho em comparação às redes em malhas tradicionais e com menos recursos que um sistema totalmente interconectado.

\subsubsection{Flattened butterfly}

A topologia flattened butterfly é uma abordagem evolutiva da topologia butterfly. Tal nome advém da forma das interconexões entre os switches a qual se assemelham às asas de uma borboleta (Figura 4-a). Na Figura 4 também há a ilustração do processo de derivação de uma topologia flattened butterfly a partir de uma topologia butterfly.

Figura 4: Diagrama de blocos de uma topologia butterfly de uma dimensão e $\mathrm{k}=4$ (a) e a topologia flattened butterfly correspondente (b). Em (c) há uma topologia butterfly de 3 dimensões e $k=2$ e sua topologia flattened butterfly correspondente está em (d).

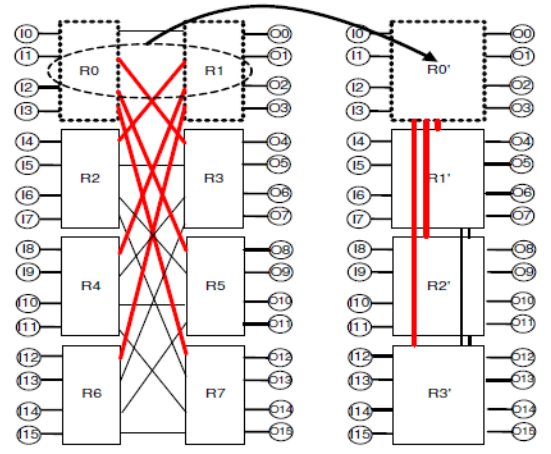

(b)

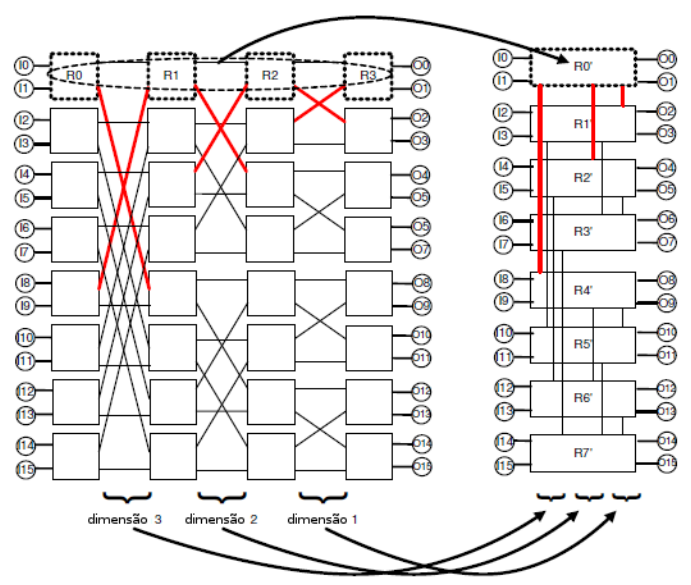

(c) (d)

Fonte: Kim, Dally e Abts (2007)

A partir de uma topologia butterfly tradicional, combina-se os roteadores em cada linha em um único roteador. A Figura 4-a ilustra a combinação dos switches R0 e R1, destacados na parte superior da topologia em butterfly, em um único switch R0' da topologia flattened butterfly (Figura 4-b). De maneira similar os roteadores R0, R1, R2 e R3 da Figura 4-c são combinados em R0' na Figura 4-d. Os canais entre os switches agrupados em cada linha são eliminados. Os outros canais são mantidos na topologia flattened butterfly. Por exemplo, o canal R0-R7 na Figura 4-a é equivalente ao canal R0'-R3' da 
Figura 4-b. É importante ressaltar que os canais das topologias butterfly nas Figuras 4-a e 4-c são unidirecionais ao passo que os canais das topologias flattened butterfly nas Figuras 4-b e 4-d são bidirecionais.

A topologia flattened butterfly busca primordialmente a redução do número de saltos na troca de informações entre os recursos da rede em chip. Nos casos mais simples há somente dois saltos na comunicação entre dois recursos. Trata-se de uma topologia a qual pode ser combinada com switches dotados de um elevado número de portas de troca de dados. A redução do número de saltos é acompanhada pela redução do consumo energético e da latência. Por outro lado, na topologia flattened butterfly, os caminhos percorridos são maiores dos que o da topologia em malha. As perdas de desempenho por conta do tamanho dos fios da topologia em butterfly são compensadas por meio da adoção de repetidores e de registradores de pipeline a fim de preservar a integridade do canal (KIM; BALFOUR; DALLY, 2007). A Figura 5 esquematiza uma topologia flattened butterfly bidimensional.

Figura 5: Topologia flattened butterfly bidimensional . Em (a) o diagrama de blocos e em (b) a sua respectiva representação espacial.

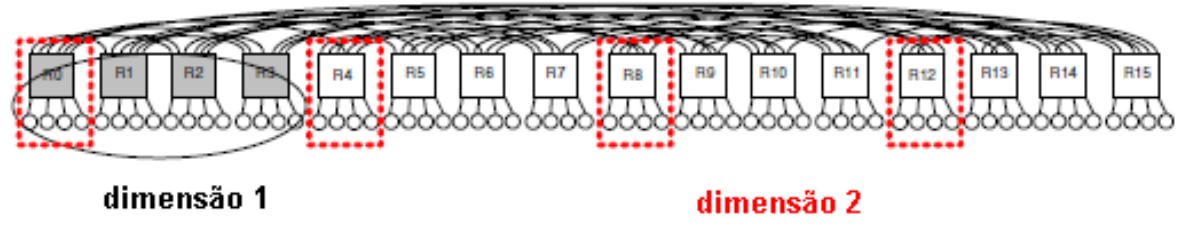

(a)

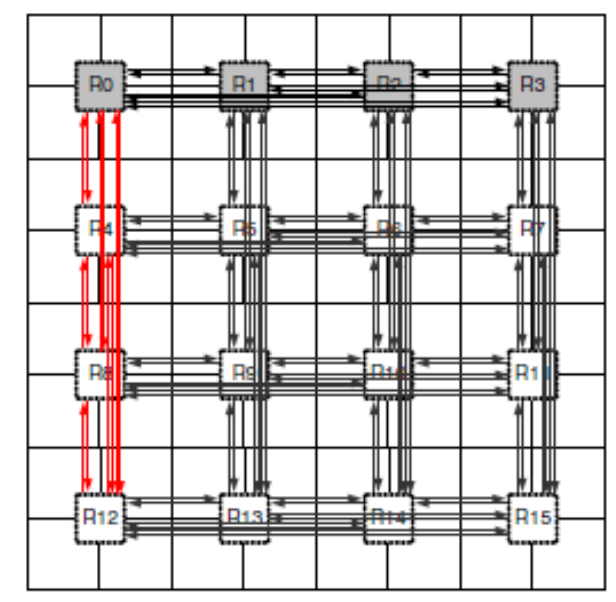

(b)

Fonte: Kim, Balfour e Dally (2007) 
Sabe-se que o consumo de energia dos canais possui papel significativo no consumo geral da NoC. Dessa forma, a redução dos números de canais também reduz o custo da rede. Assim o uso de redes dotadas de switches com número de portas e concentração $k$ elevados, adotando a topologia flattened butterfly, leva à redução dos canais, que por sua vez diminui o diâmetro da rede, e consequentemente reduz a quantia de buffers necessários para o estabelecimento da NoC.

Outros mecanismos de otimização presentes na topologia flattened butterfly são o uso de canais de bypass com mecanismos de arbitragem dotados de priorização para fluxos de tráfego pré-definidos, e controle de fluxo por meio do armazenamento seletivo dos pacotes de controle.

\subsubsection{Cúbica}

Diante dos empecilhos relacionados à escalabilidade das redes em flattened butterfly por conta do número proibitivo de canais para um elevado número de switches, são propostas as topologias cúbicas baseadas em multicanais expressos - MECS (GROT et al., 2009). Trata-se de uma abordagem baseada nas topologias cúbicas tradicionais (DALLY, 1991), mas que possuem canais que se comunicam com diversos destinos (ao invés de somente um como na topologia em flattened butterfly). As MECS mantêm o número máximo de saltos igual ao da topologia em butterfly, contudo, diminuem sensivelmente a complexidade das ligações entre os switches. A Figura 6 ilustra as principais diferenças entre as duas topologias.

As redes cúbicas possuem as seguintes propriedades:

- o número de canais por cada coluna ou linha é igual à raiz da rede, $r$;

- o número de nós acessíveis por meio de um canal é função da localização do nó origem na rede e varia de 1 a $r-1$;

- cada nó possui uma saída por direção da mesma maneira que a topologia em malha;

- o número de entradas é $2(r-1)$ o mesmo da topologia em flattened butterfly. 
Figura 6: Principais diferenças entre a topologia em flattened butterfly (a) e a topologia cúbica com multicanais (b). As duas topologias da Figura possuem $\mathrm{k}=4$ (quatro nós agrupados em cada switch da rede).

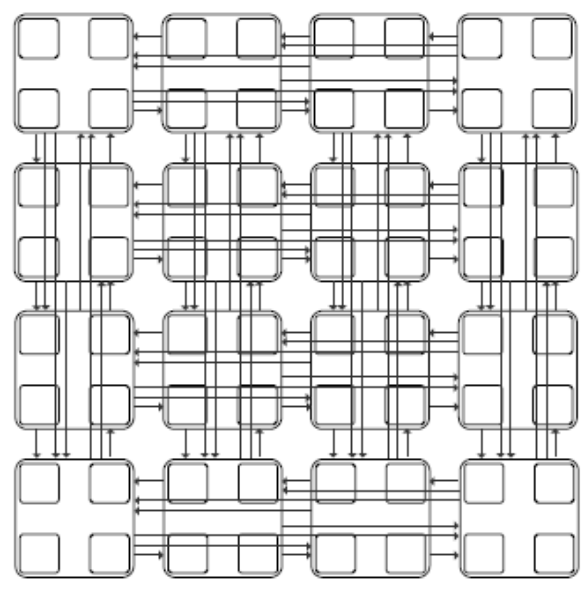

(a) butterfly

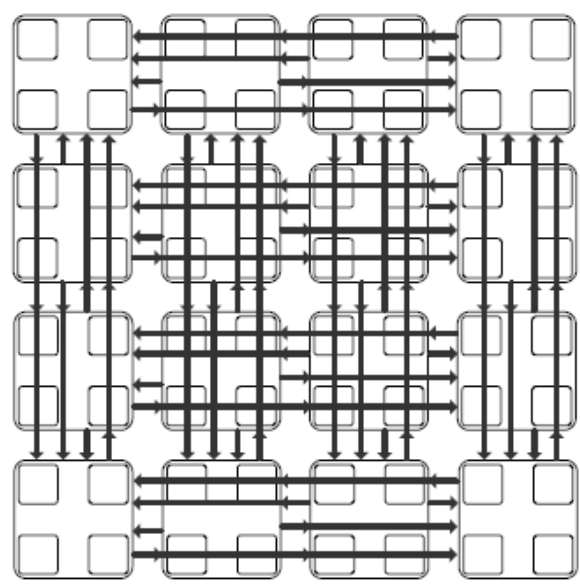

(b) MECS

Fonte: Grot et al. (2009).

\subsection{Arquitetura Clássica}

A topologia de NoC mais frequente é a em malha (NYCHIS et al., 2012) e, segundo Craik e Mutlu (2011), muito do trabalho de roteamento em redes em malha foi baseado na ideia de switches com canal virtual originalmente proposto por Dally (1992). Por conta da possibilidade de dois flits requisitarem a mesma ligação para chegar ao seu destino, o switch primeiro armazena os flits em buffers e, após verificar disponibilidade, os envia para suas respectivas ligações. Isto soluciona o problema de conflitos por recursos entre diferentes fluxos de tráfego, já que se um switch não possuir mais espaço para armazenar os dados dos fluxos que requisitam determinada ligação de saída, ele pode informar os switches emissores de tais fluxos os quais serão responsáveis pela contenção temporária do envio destas informações.

Com o objetivo de assegurar o controle da transmissão de pacotes, um esquema de atribuição e de arbitragem de prioridades torna-se necessário. Dessa forma combina-se tal mecanismo com a técnica dos canais virtuais para que os pacotes sejam transmitidos em tempo hábil. Cada canal virtual atende a um nível de prioridade e é direcionado a um canal físico. Os fluxos de tráfego possuem prioridades associadas a eles. Cada flit gerado por um fluxo herda a sua prioridade e pode requisitar os canais virtuais que possuem 
a mesma prioridade. O pacote mais prioritário sempre tem acesso ao canal físico e pacotes com prioridades superiores são capazes de ultrapassar pacotes com menores prioridades interrompendo seus fluxos de transmissão. $A$ Figura 7 ilustra o mecanismo de prioridades.

Figura 7: Esquema de decisão de acesso a um canal físico utilizando a técnica de canais virtuais.

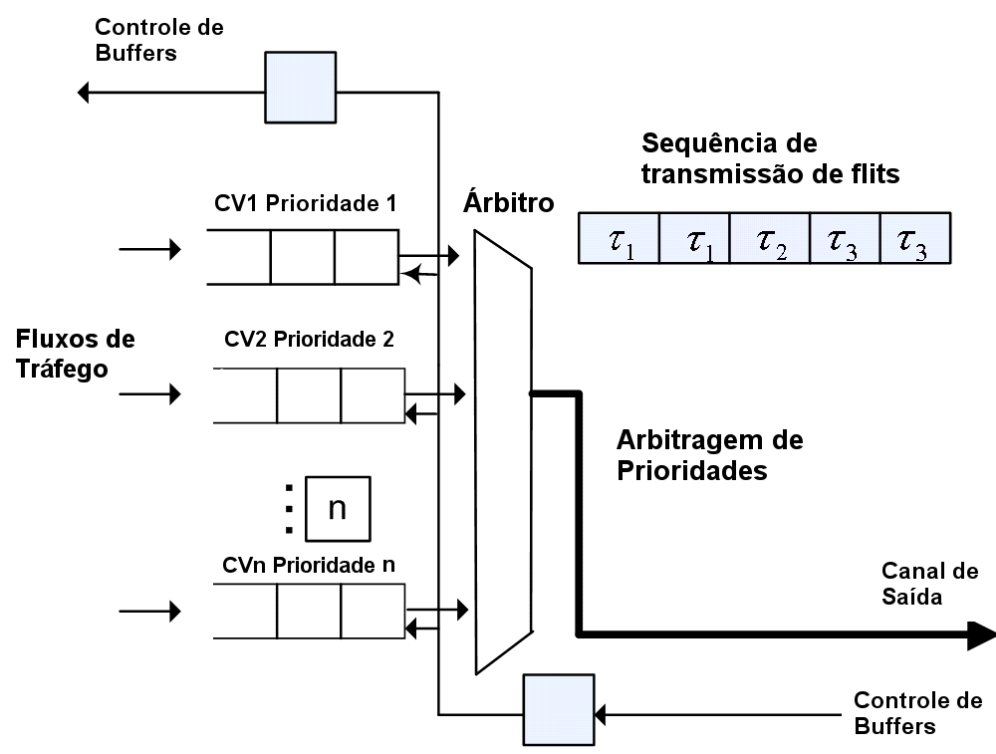

Fonte: Shi e Burns (2008)

Considerando $n$ canais virtuais (no caso de redes em malha $n \geq 2^{b} ; b \in$ $\mathbb{N} \wedge b>1$ ), cada um é associado a um canal físico contendo flits. O mecanismo de gestão de prioridades ajusta os flits em cada buffer de acordo com suas respectivas prioridades. Se um determinado pacote não consegue acessar o canal de saída é porque ele está bloqueado em algum ponto da rede. Diante deste cenário o pacote com a prioridade posterior ao pacote bloqueado consegue acessar o canal físico. O tempo de serviço disponível para um determinado fluxo de tráfego é definido como o intervalo de tempo no qual tal fluxo não compete por um mesmo canal físico com pacotes de prioridades superiores.

No caso do roteamento em pacotes (que são divididos em flits) os canais virtuais empregam a técnica de roteamento em wormhole (NI; MCKINLEY, 1993). Nas redes do tipo wormhole os dados são encapsulados em um formato de pacote para transmissão em rede. Cada pacote é dividido em um número fixo de flits. O flit de cabeçalho contém os dados de roteamento e é 
responsável por decidir a rota do pacote. À medida que o flit de cabeçalho avança, segundo um caminho específico, os flits restantes o seguem em pipeline. Ao encontrar uma ligação entre switches em uso, o flit de cabeçalho é bloqueado até que tal ligação esteja disponível. Nesta situação todos os flits do pacote permanecerão no switch e, dessa forma, um buffer, cujo tamanho equivale ao de um pacote, é necessário em cada switch. Quando um pacote é bloqueado, diminuem-se os recursos disponíveis para os outros pacotes e a eficiência da rede é afetada.

\subsection{Arquiteturas sem buffers}

As arquiteturas clássicas assumem comumente que cada switch na rede contém buffers a fim de armazenar os pacotes ou flits transmitidos dentro da rede. É sabido que tal armazenamento reduz o número de flits perdidos e meIhora a capacidade da rede de entregar os pacotes nas rotas corretas. Por outro lado, a existência de buffers também possui algumas desvantagens. A primeira é o consumo energético significativo de tais módulos mesmo quando não ocupados. A segunda consiste no impacto dos buffers na área ocupada pelo circuito e também na necessidade de estruturas lógicas de controle para seu correto funcionamento, o que aumenta a complexidade da NoC (MOSClBRODA; MUTLU, 2009).

Diante de tais circunstâncias as redes em chip sem buffers apresentam-se como uma alternativa à arquitetura clássica. As tradicionais filas de armazenamento de pacotes dão lugar a uma abordagem na qual as próprias ligações da rede atuam como uma entidade de armazenamento. Quando há concorrência dos pacotes por uma ligação, um mecanismo de arbitragem decide qual dos flits será conduzido de fato à ligação, ao passo que o outro será roteado para outra ligação que não é a mais otimizada, em termos de número de saltos, para a chegada ao seu destino.

Os mecanismos de controle de fluxos de tráfego das arquiteturas sem buffers são simplificados e locais. As arquiteturas clássicas de controle de fluxo necessitam de algum tipo de mecanismo de controle para evitar o sobrecarregamento da rede e evitar que os buffers se sobrecarreguem. Nas redes 
sem buffers não há a necessidade destes mecanismos, já que um switch injeta um flit na rede quando, pelo menos, um canal está disponível. Isto pode ser verificado localmente sem qualquer necessidade de comunicação entre os switches.

Figura 8: Ilustração do processo de roteamento em um switch sem buffers: em um determinado ciclo, quatro pacotes chegam ao switch pelos canais de entrada e desejam acessar o canal de saída da face "N" para chegarem aos seus respectivos destinos. O mecanismo de arbitragem do switch, o qual varia de acordo com a arquitetura, decide que o pacote proveniente do canal de entrada da face "E" acessará o canal de saída da face "N" (ligação em destaque). Os outros três pacotes, por sua vez, serão defletidos para os canais de saída das outras faces, configurando as outras ligações ilustradas.

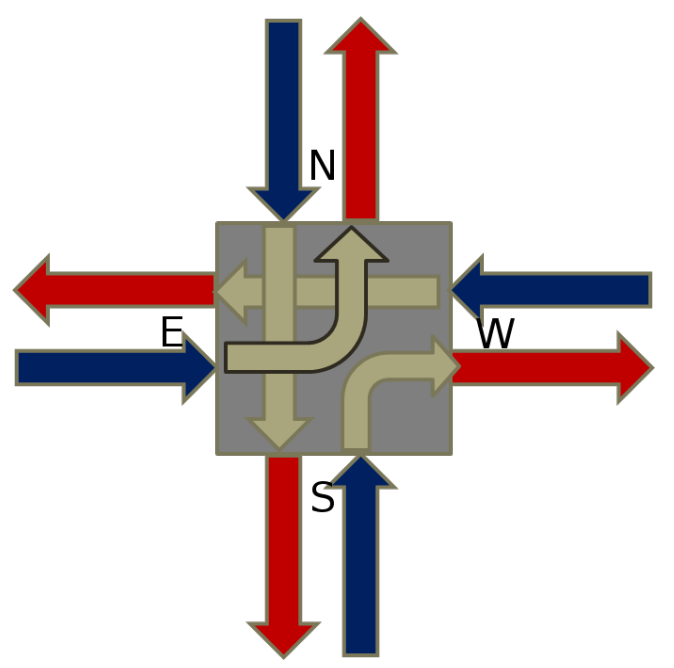

O mecanismo de roteamento nas NoCs sem buffers utiliza o conceito de deflexão. No caso de dois flits necessitarem acessar o mesmo canal de saída para chegar ao seus respectivos destinos, um deles acessará a porta desejada, contudo o outro será defletido para uma outra porta de saída. Dessa forma, nas redes sem buffers, o número de canais de entrada deve ser igual ao de saída, pois não há como armazenar os pacotes que queiram acessar a mesma porta de saída dentro do switch. A figura 8 ilustra este processo de roteamento.

Intuitivamente percebe-se que as redes sem buffers funcionam com meIhor desempenho em cenários de baixo tráfego, pois um número maior de flits será direcionado às rotas mais produtivas a fim de chegar ao destino desejado. Em cenários de tráfego nos quais há flits sendo injetados por todas as portas de entrada, a latência de transmissão dos pacotes aumenta, o que 
aumenta também a necessidade de registradores de entrada e saída nos switches receptores. Os flits que já chegaram no nó de destino devem esperar por aqueles que ainda estão navegando pela rede para que o pacote seja remontado. Por outro lado a eliminação dos buffers de roteamento compensa este aumento nos buffers de saída (MOSCIBRODA; MUTLU, 2009). As subseções a seguir apresentam as principais abordagens sem buffers para as redes em chip.

\subsubsection{BLESS}

A arquitetura BLESS (MOSCIBRODA; MUTLU, 2009) parte da abordagem da eliminação dos buffers da arquitetura de rede tradicional. Dessa forma, não há buffers de entrada e consequentemente não há como utilizar canais virtuais (seção 2.6). Os próprios canais físicos atuam como buffers para a NoC e, para que a abordagem sem buffers seja viável, é necessário que o número de canais de saída seja maior ou igual ao número de canais de entrada. Diferentemente da abordagem clássica na qual os pacotes ou flits que disputam um mesmo canal de saída são armazenados em buffers, a arquitetura BLESS admite um sistema de prioridades no uso dos canais. O pacote mais prioritário utiliza o canal enquanto os outros são redirecionados aos canais restantes de acordo com um mecanismo de prioridades. O critério de prioridade mais efetivo é o oldest-first no qual os pacotes ou flits são dotados de um mecanismo de tempo de vida baseado no timestamp de seus respectivos momentos de criação (MOSCIBRODA; MUTLU, 2009).

Há dois tipos de abordagens BLESS: a baseada em flits denominada de FLIT-BLESS e a baseada em pacotes, a qual utiliza a técnica de roteamento em wormhole (seção 2.6), denominada de WORM-BLESS.

$\mathrm{Na}$ abordagem FLIT-BLESS cada flit é roteado de maneira individual, o que facilita os mecanismos de controle dos switches. Por outro lado, a existência de vários flits têm impacto no tempo de transmissão, afetando a latência da NoC (seção 2.4). Além disso, cada flit necessita de um cabeçalho o que também afeta negativamente a latência e o consumo energético da rede. Finalmente maiores latências implicam em maiores requisitos de buffers de saída para a montagem dos pacotes a partir de seus respectivos flits. As regras de 
priorização de portas para a abordagem FLIT-BLESS são especificadas na Tabela 2. Resumidamente, dado um conjunto de flits que chegam ao switch, os flits que possuem mais tempo imersos na rede serão alocados às portas desejadas (que permitem chegar de maneira eficiente ao destino - regra 1) ao passo que os flits mais novos serão defletidos (regra 2).

A abordagem WORM-BLESS foi concebida como a evolução da abordagem FLIT-BLESS a fim de transpor os desafios da abordagem FLIT-BLESS supracitados. Na WORM-BLESS, a princípio, somente o primeiro flit do pacote necessita de cabeçalho. Os outros flits seguirão o mesmo caminho do primeiro não se espalhando pela rede.

Os mecanismos de injeção de pacotes e de arbitragem na NoC devem ser levemente modificados para que se evitem que determinados fluxos de tráfego monopolizem os canais. Na abordagem WORM-BLESS é utilizado o mecanismo de truncagem de pacotes que pode ser explicado por meio do corte de um pacote em grupos menores. Para seu correto funcionamento é necessário agregar um mecanismo de alocação de portas de saída para cada pacote composto por uma pequena tabela no switch. Em cada divisão de pacotes é necessário agregar um cabeçalho para a segunda parte resultante da divisão.

A combinação do algoritmo de truncagem de pacotes com a priorização de portas a partir do timestamp é importante pois assegura que os flits mais veIhos são sempre roteados para a porta desejada. Assim os flits mais antigos tornam-se prioritários e sempre estarão seguindo um caminho que se aproxima do caminho ótimo para chegar ao seu destino. Na Tabela 2, há as regras de priorização de portas para a abordagem WORM-BLESS. Nota-se que tais regras distinguem flits de cabeçalho de flits de dados. Para um determinado flit de cabeçalho, uma nova porta necessita ser alocada. A porta desejada e não alocada para nenhum outro grupo de flits é a mais prioritária (regra 1). No caso deste tipo de porta de saída não estar disponível, a próxima prioridade são as portas desejadas e que estão atualmente alocadas para um determinado grupo de pacotes (regra 2). Neste caso, a porta é realocada para o novo grupo de flits, sendo que o grupo para o qual a porta estava alocada será truncado. Assim um grupo de flits mais prioritário é capaz de truncar um grupo de pacotes já alocado. O primeiro flit do grupo de pacotes truncados torna-se um 
novo flit de cabeçalho e será realocado para outra porta. Assim haverão dois grupos de flits os quais serão roteados de maneira independente ao destino. No caso de todas as portas já estarem ocupadas por flits de prioridades maiores, o flit de cabeçalho é alocado para uma porta de saída não desejada (ele é defletido - regras 3 e 4). Finalmente se o flit não é de cabeçalho, por definição sua porta de saída já está definida e alocada (regra 5).

Tabela 2: BLESS: políticas de priorização de pacotes

\begin{tabular}{ll}
\hline \multicolumn{1}{c}{ flit BLESS } & \multicolumn{1}{c}{ worm BLESS } \\
\hline & if flit contém cabeçalho then \\
& 1 - atribuir flit para porta não alocada \\
& desejada \\
& 2 - atribuir flit para porta alocada de- \\
& sejada \\
& $\leftarrow$ pacote em transmissão é trun- \\
& cado \\
& 3 - atribuir flit para porta não alocada \\
1 - atribuir flit para porta dese- & e não desejada \\
jada & $\leftarrow$ pacote a transmitir é defletido \\
2 - atribuir flit para porta não de- & 4 - atribuir flit para porta alocada não \\
sejada & desejada \\
$\leftarrow$ pacote a transmitir é defle- & \\
tido & cado \\
& $\leftarrow$ pacote em transmissão é trun- \\
& else a transmitir é defletido \\
& 5 - atribuir o flit para a porta que está \\
& alocada ao seu respectivo pacote \\
end if
\end{tabular}

Nota: O switch arbitra suas portas conforme a ordem de prioridades desta Tabela. Somente portas livres são consideradas, ou seja, portas que não foram assinaladas a flits de maior prioridade (maior tempo na rede) em um mesmo ciclo.

É importante ressaltar que o mecanismo de truncagem ocorre somente para pacotes com níveis de prioridade inferior a do pacote a ser injetado ou retransmitido. No caso de haver mais de uma porta disponível, os algoritmos priorizam a porta que está na mesma direção pela qual o flit adentrou no switch. 


\subsubsection{CHIPPER}

CHIPPER (FALLIN; CRAIK; MUTLU, 2011) é uma abordagem evolucionária da arquitetura BLESS (seção 2.7.1) baseada em uma rede de permutações e em um algoritmo que emprega um pacote com status especial denominado de golden. Antes de entrar na rede, o pacote é dividido em flits e, por meio de uma rede de blocos de arbitragem que os processa em pares, é possível determinar uma sucessão de prioridades para um conjunto de flits. A Figura 9 ilustra a arquitetura a ser modelada.

Figura 9: Arquitetura CHIPPER.

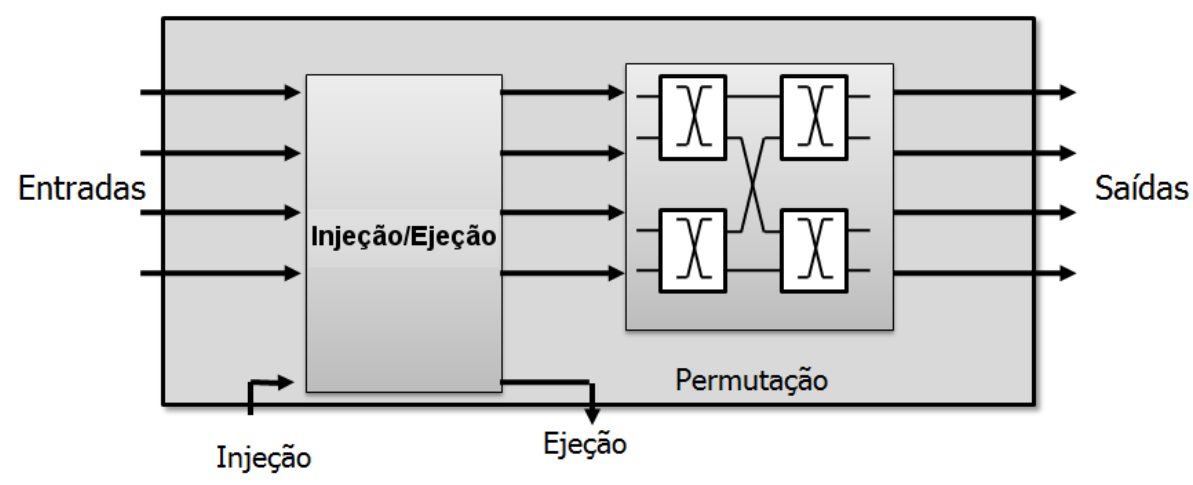

Adaptado de (FALLIN; CRAIK; MUTLU, 2011)

A primeira parte consiste do mecanismo de injeção e ejeção de flits. Basicamente um flit é injetado em um switch CHIPPER quando há espaço livre em uma de suas quatro portas de saída. O espaço livre provém da ejeção de um outro flit que acabou de chegar ao seu switch de destino. Dessa forma, agrupando-se os switches em uma rede, percebe-se que não há buffers entre os mesmos para conter eventuais disputas por uma certa porta de saída. Quando dois flits competem pelo mesmo recurso, um deles necessariamente não conseguirá o acesso e será defletido para uma rota diferente da desejada. O mecanismo de direcionamento dos flits é feito pela rede de blocos de arbitragem. $O$ conjunto de blocos é testado em pares decidindo-se um flit vencedor e um flit perdedor em cada turno.

O critério de decisão dos flits vencedores é dado por meio da atribuição de um status especial, denominado de golden, para um determinado pacote. Este status é atribuído a um pacote em um certo intervalo dentro da rede em chip. Quando um pacote possui o status golden todos os seus flits o possuirão 
e serão prioritários nos momentos nos quais necessitarem competir por uma porta de saída com um outro flit. Este tipo de competição caracteriza a disputa de um flit com status golden e outro com status não golden. Por outro lado, há os casos nos quais há dois flits com status golden ou com status não golden que disputam uma mesma porta de saída. Em ambos os casos, o vencedor é decidido aleatoriamente. Nota-se que mesmo nos momentos nos quais os quatro flits venham a disputar uma mesma porta de saída, um deles obterá tal porta enquanto os outros serão desviados para rotas não desejadas de acordo com os resultados do módulo de arbitragem, o que possibilita o uso de uma arquitetura sem buffers de espera com o custo de aumentar o caminho crítico de um flit no sistema.

\subsubsection{MinBD}

A arquitetura MinBD: Minimally-Buffered Deflection Routing for EnergyEfficient Interconnect (FALLIN et al., 2012) propõe uma abordagem aprimorada para as arquiteturas de redes em chip sem buffers. Partindo do pressuposto que as redes sem buffers baseadas em deflexão são ineficientes em NoCs com um grande número de switches e em cenários de tráfego mais intenso, é proposta a criação de uma rede de deflexão com um buffer lateral mínimo a fim de evitar a circulação desnecessária de flits nos canais da NoC, evitando-se o desperdício de recursos energéticos sem aumentar a complexidade ou área da NoC. A Figura 10 ilustra a arquitetura MinBD.

Figura 10: Arquitetura MinBD.

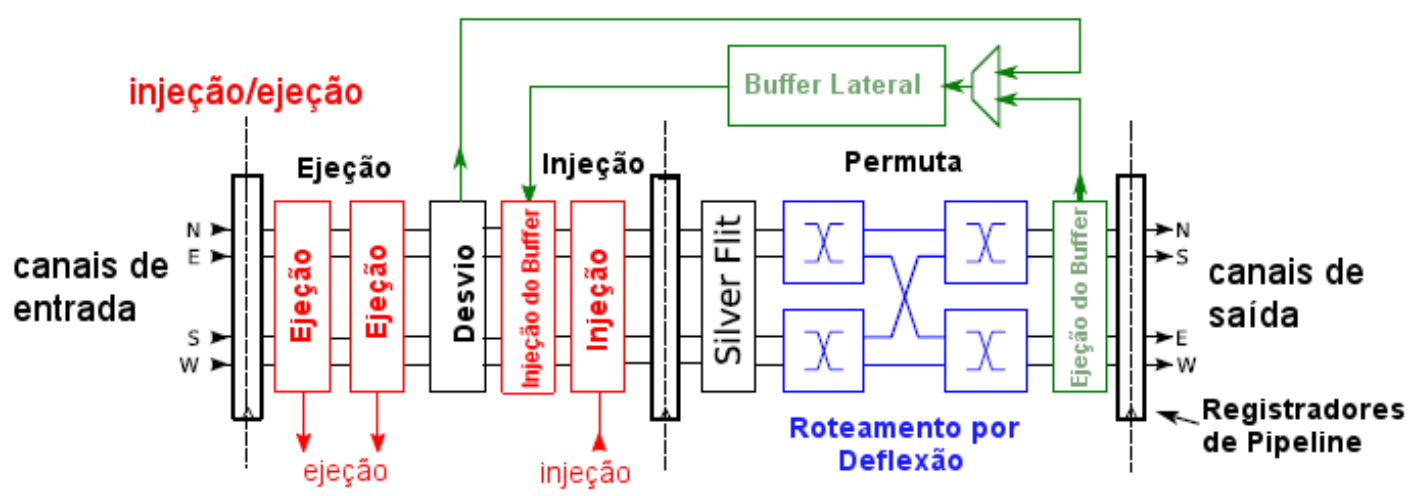

Fonte: Fallin et al. (2012)

A abordagem MinBD é baseada na arquitetura CHIPPER, contudo o me- 
canismo de status golden dos pacotes é modificado de tal forma a possuir um segundo nível de prioridade. O segundo nível é utilizado nos casos nos quais não há um pacote golden no momento da arbitragem. Neste cenário utiliza-se da estratégia de que um pacote não será defletido nos dois estágios de arbitragem, o que garante o destino desejado a um dos pacotes, mesmo em caso de ausência de flits com prioridade golden. Tal mecanismo é denominado de silver priority.

Outra abordagem inovadora foi a existência de dois buffers de ejeção a fim de melhorar o fluxo de flits ejetados (que chegaram ao destino) do switch. A motivação para o uso desta quantia de buffers foi que em $8,5 \%$ dos casos nas simulações adotadas um flit poderia ser ejetado ao invés de ser defletido se não existisse somente um buffer de saída de flits.

\subsection{Sinopse}

Esta seção resume os aspectos principais discutidos neste capítulo.

A Tabela 3 resume as principais topologias discutidas.

Tabela 3: Topologias apresentadas - principais aspectos

\begin{tabular}{|c|c|}
\hline Topologia de NoC & Principais Características \\
\hline malha & estrutura regular, número de saltos significativo \\
\hline small-world & $\begin{array}{l}\text { número baixo de saltos, muitas entradas } \\
\text { e saídas para cada switch }\end{array}$ \\
\hline butterfly & $\begin{array}{l}\text { número baixo de saltos, número elevado de conexões } \\
\text { dentro da topologia }\end{array}$ \\
\hline cúbica & $\begin{array}{c}\text { número baixo de saltos, menor quantidade de conexões } \\
\text { dentro da topologia }\end{array}$ \\
\hline
\end{tabular}

A Tabela 4 resume as principais características acerca das arquiteturas de switch discutidas. 
Tabela 4: Arquiteturas apresentadas - principais aspectos

\begin{tabular}{cc}
\hline Arquitetura de NoC & Principais Características \\
\hline clássica & emprega canais virtuais, facilidade de desenvolvimento \\
BLESS & ausência de buffers \\
CHIPPER & $\begin{array}{c}\text { ausência de buffers, prioridade especial (golden) } \\
\text { minBD }\end{array}$ \\
$\begin{array}{c}\text { presença de um buffer para ejeção temporária } \\
\text { de flits e de um segundo nível de prioridade } \\
\text { denominado (silver) }\end{array}$ \\
\hline
\end{tabular}




\section{EMPREGO DE REDES SEM FIO EM NOCS}

A abordagem das Redes em Chip sem Fio (WiNoC - Wireless Network on Chip) é uma evolução do conceito de NoC. Como são dotadas de mecanismos de roteamento simples associados às tecnologias sem fio, é possível conciliar fluxos de tráfego entre diferentes módulos por meio da redução de barramentos (WU; WANG; ZHAO, 2010) ou mesmo atuando em conjunto com redes em chip tradicionais na transmissão de informações (ZHAO; WU, 2012).

Há pesquisas sendo desenvolvidas com resultados promissores no campo de estudos relacionados ao acesso físico (O. et al., 2005). Juntamente com as melhorias nas tecnologias de radiotransmissão, as WiNoCs emergem como indutores para melhoria de desempenho e escalabilidade em NoCs. As próximas seções enfatizam este aspecto por meio de uma visão geral das principais abordagens para radiotransmissão em chip que estão sendo investigadas (seção 3.1), como também alguns exemplos de abordagens envolvendo modelagem e simulação da dinâmica em rede (seção 3.2), e também aspectos envolvendo o uso de protocolos dinâmicos para a economia energia em redes em chip (seção 3.3). No fim deste capítulo, são enumerados os principais aspectos discutidos por meio de uma sinopse (seção 3.5).

\subsection{Abordagens de transmissão sem fio}

Esta seção tem como objetivo apresentar os principais campos de investigações para antenas em chip (O. et al., 2005) as quais servem como base para uma implementação do canal sem fio em chip. Destacam-se o emprego da tecnologia Ultra Wide Band (seção 3.1.1), as abordagens das antenas em zigue-zague (seção 3.1.2), das antenas fractais (seção 3.1.3) e dos nanotubos de carbono (seção 3.1.4). 


\subsubsection{O emprego de Ultra Wide Band}

O uso da tecnologia Ultra Wide Band (UWB) desponta como um dos campos de pesquisa para a transmissão usando canal sem fio (SAHA; SASAKI; KIKKAWA, 2006; WATANABE; KIMOTO; KIKKAWA, 2004). Segundo Zhao e Wu (2012), o emprego da tecnologia Ultra Wide Band usando modulação impulsiva de gaussianas é uma oportunidade para a comunicação a curtas distâncias com baixo consumo energético e com um diverso espectro de frequências. Além disso, o fato dos sinais serem transmitidos sem portadora simplifica as implementações dos circuitos de radiofrequência. Por conta dessas características tal abordagem é uma solução atrativa para a comunicação entre os núcleos em chip. Como os pulsos possuem curta duração, consegue-se alta transmissão de dados com taxa sinal ruído constante.

Há alguns estudos relacionados à síntese de circuitos que empregam $\mathrm{Ul}$ tra Wide Band em transmissão de sinais. Razavi et al. (2005), por exemplo, desenvolveram um transceptor empregando a tecnologia UWB com característica multibanda (salto de frequências). Embora o trabalho não deixe claro qual foi a abordagem de antenas utilizada, são destacados alguns dos problemas relacionados ao uso da Ultra Wide Band em CMOS. O primeiro deles é associado ao tempo de resposta dos phase locked loops (PLLs) que demoram algumas centenas de ciclos para se estabilizar o que impede um alto dinamismo nos saltos em frequências. Além disso há dificuldades relacionadas à síntese de osciladores locais ágeis, os quais podem gerar interferências e distorções entre as harmônicas dos sinais. Finalmente também há desafios a serem superados em relação às discordâncias de fase e ganho associadas às quadraturas (defasagens de $90^{\circ}$ ) e aos conversores.

A arquitetura proposta por Razavi et al. (2005) é ilustrada na Figura 11-a. O processo de recepção consiste de um amplificador de baixo ruído (LNA) com três entradas para cada uma das três bandas tratadas. Cada entrada é direcionada para um mixer selecionável em quadratura. $O$ sinal resultante é aplicado a um filtro de Sallen-Key (JUNG, 2005) de quarta ordem e a um passa-baixas de primeira ordem. Esta sucessão de filtros permite uma amostragem superior a $512 \mathrm{MHz}$. O caminho de transmissão, por sua vez, também emprega um filtro de Sallen-Key, mixers e um estágio de saídas o qual compartilha a antena 
Figura 11: Transceptor UWB.

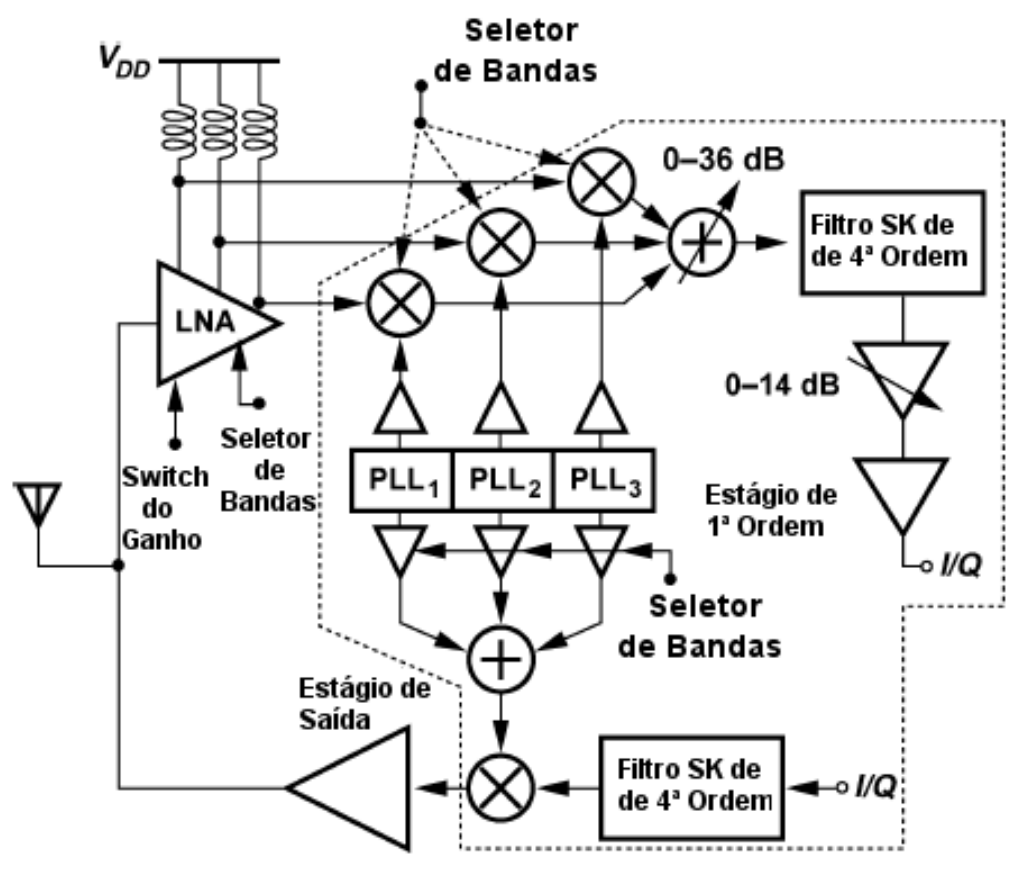

(a) Diagrama de blocos

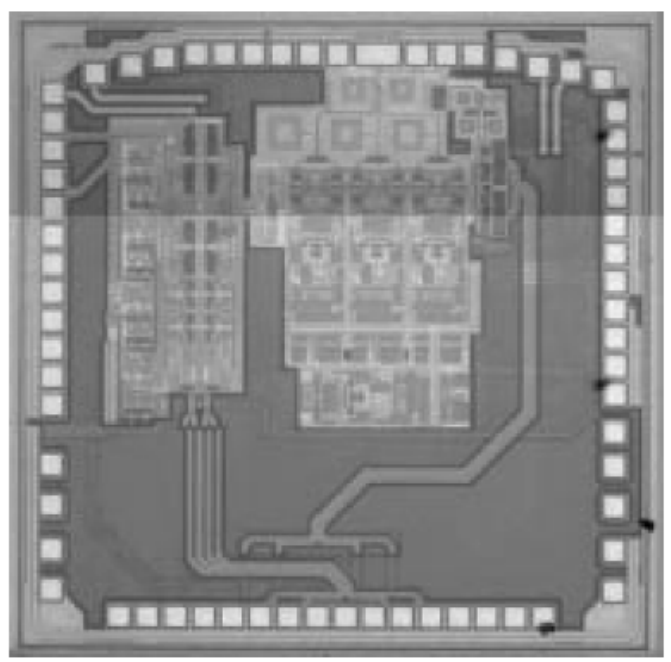

(b) Fotografia da disposição do circuito no silício em uma área ativa de aproximadamente $1 \mathrm{~mm} \times 1 \mathrm{~mm}$ empregando-se tecnologia CMOS de $0.13 \mu \mathrm{m}$

Fonte: Razavi et al. (2005) 
com o amplificador de baixo ruído. As frequências dos osciladores locais (LO) são sintetizadas por meio de três PLLs independentes com o objetivo de evitar a mistura das harmônicas de cada uma das entradas. A Figura 11-b retrata disposição no silício deste circuito cuja potência dissipada total é de $105 \mathrm{~mW}$.

\subsubsection{Antenas zigue-zague}

A integração de antenas em um substrato semicondutor antecede as atividades na pesquisa recente por, pelo menos, dez anos. Algumas implementações menos recentes de antenas em substratos semicondutores utilizaram osciladores de diodo em seu projeto original (BUECHLER et al., 1986). Nos anos 90 substratos de alta resistividade foram empregados para fabricar antenas operando entre 90 a 802 GHz (REBEIZ et al., 1992). Com a evolução da tecnologia de microchips, atualmente é possível produzir tais antenas com um grau de compactação muito maior e a um menor custo. A Figura 12, por exemplo, exibe um dipolo de antena zigue-zague sintetizada em um substrato de silício e sua seção transversal. Para aplicações operando a 24-GHz uma antena típica ocupa 3-4mm×0.15mm (LIN et al., 2007).

Figura 12: Antenas em chip fabricadas em um substrato de $20-\Omega$-cm (a). Secção transversal (b).

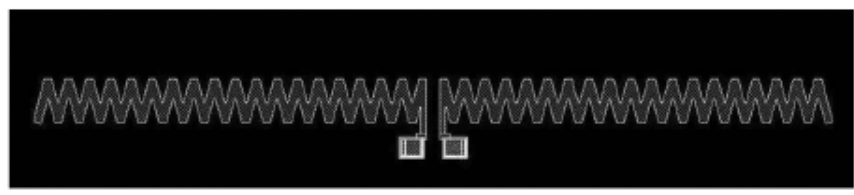

(a)

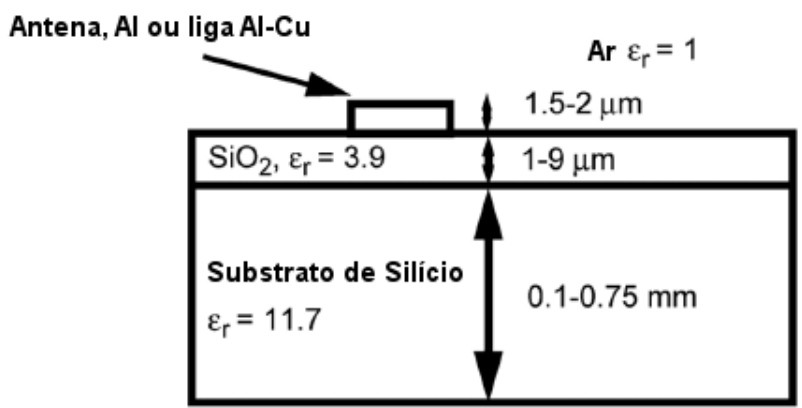

(b)

Fonte: Lin et al. (2007)

Segundo Lin et al. (2007), a frequência $24 \mathrm{GHz}$ foi empregada com o objetivo de compactar a antena e o circuito de transmissão utilizando tecnolo- 
gia CMOS de 130nm. Para a avaliação dos resultados empregou-se o ganho como métrica conforme descrito na equação 3.1:

$$
G a=\frac{|S 21|^{2}}{\left(1-|S 11|^{2}\right)\left(1-|S 22|^{2}\right)}=G t G r\left(\frac{\lambda}{4 \pi R}\right)
$$

O ganho do par de antenas é dado pelos ganhos de transmissão Gt e recepção $G r$ considerando perdas de propagação no meio. $R$ é a separação entre as antenas e $\alpha$ é a constante de atenuação, a qual considera a perda por condução do substrato. Ga é obtido por meio dos parâmetros de espalhamento $S$ para matriz de espalhamento de duas portas. O circuito de transmissão é tratado como uma caixa preta na qual os parâmetros de transmissão são as razões de ondas de tensão que entram e saem das portas. Um parâmetro de espalhamento Sij é definido pela fração da onda de tensão entrando pela porta $j$ e saindo pela porta $i$ (WENTWORTH, 2008).

Verificou-se que desempenho das antenas de 24-GHz, por meio da análise de seu ganho, foi suficiente para satisfazer os requisitos de comunicação dos nós. Lin et al. (2007) também examinaram o desempenho de antenas operando a frequências mais baixas $(5.8 \mathrm{GHz})$ para distâncias de comunicação maiores.

A fim de determinar a viabilidade de se construir um circuito de transmissão de rádio em CMOS (130nm), foi sintetizado um amplificador de baixo ruído (LNA) juntamente com uma célula de Gilbert a qual foi associada à antena em chip conforme descrito na Figura 13.

Acoplando-se a antena de $3 \mathrm{~mm}$ a um gerador de sinais (Agilent 8254A) Lin et al. (2007) conseguiram receber satisfatoriamente o sinal emitido. O aparato de recepção emprega o circuito da Figura 13 e está 5 metros de distância do aparato emissor. Nota-se que por meio deste experimento foi possível estabelecer comunicação incorporando uma antena em chip a uma distância de $5 \mathrm{~m}$ usando um circuito rádio CMOS.

Sasaki et al. (2009), por sua vez, desenvolveram um receptor UWB usando a tecnologia CMOS $0.18 \mu \mathrm{m}$ a qual emprega pulsos monocíclicos gaussianos (equação 3.2) para a transmissão associada a uma antena zigue-zague integrada ao silício. Tal receptor (Figura 14) foi capaz de recuperar 200 Mbps de 
Figura 13: Circuito transmissor (20-GHz) fabricado em CMOS (130nm). Diagrama esquemático do amplificador de baixo rúido (LNA) e da célula de Gilbert (a). Layout do circuito em CMOS associado a uma antena em chip de $3 \mathrm{~mm}$ (b).

(a)

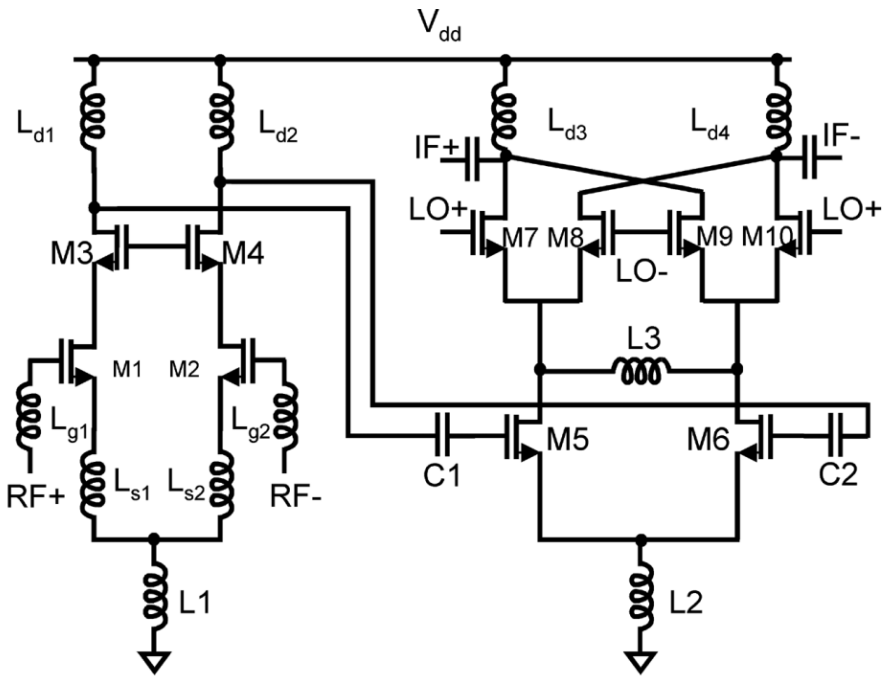

(b)

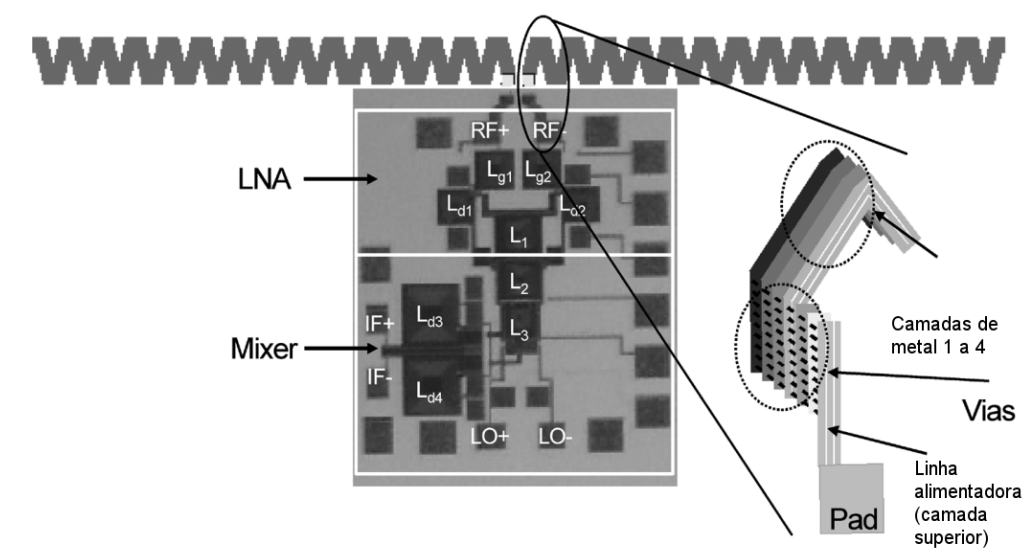

Fonte: Lin et al. (2007) 
dados a uma distância de $0.5 \mathrm{~mm}$ transmitidos por uma antena integrada em outro chip. O PLL é responsável por metade da energia consumida (19mW), buffers, conversores RZ, NRZ e demodulador consomem $13 \mathrm{mV}$ e o template generator consome $6 \mathrm{~mW}$.

$$
y(t)=\sqrt{\epsilon}\left(\frac{2 \pi(t-t 0)}{\tau}\right) e^{-\frac{1}{2}\left(\frac{2 \pi(t-t 0)}{\tau}\right)^{2}}
$$

Onde:

$\tau$ : inverso da frequência central $f c$

$\epsilon$ : permissividade do meio

$t$ : instante de tempo final

t0: instante de tempo inicial

Figura 14: Fotografia do chip de um receptor UWB com suas respectivas dimensões onde o Phase Locked Loop é responsável por sincronizar o sinal de clock de referência com o clock interno e o RZ Return-Zero e NRZ Non-returnto-zero são conversores de sinais binários.

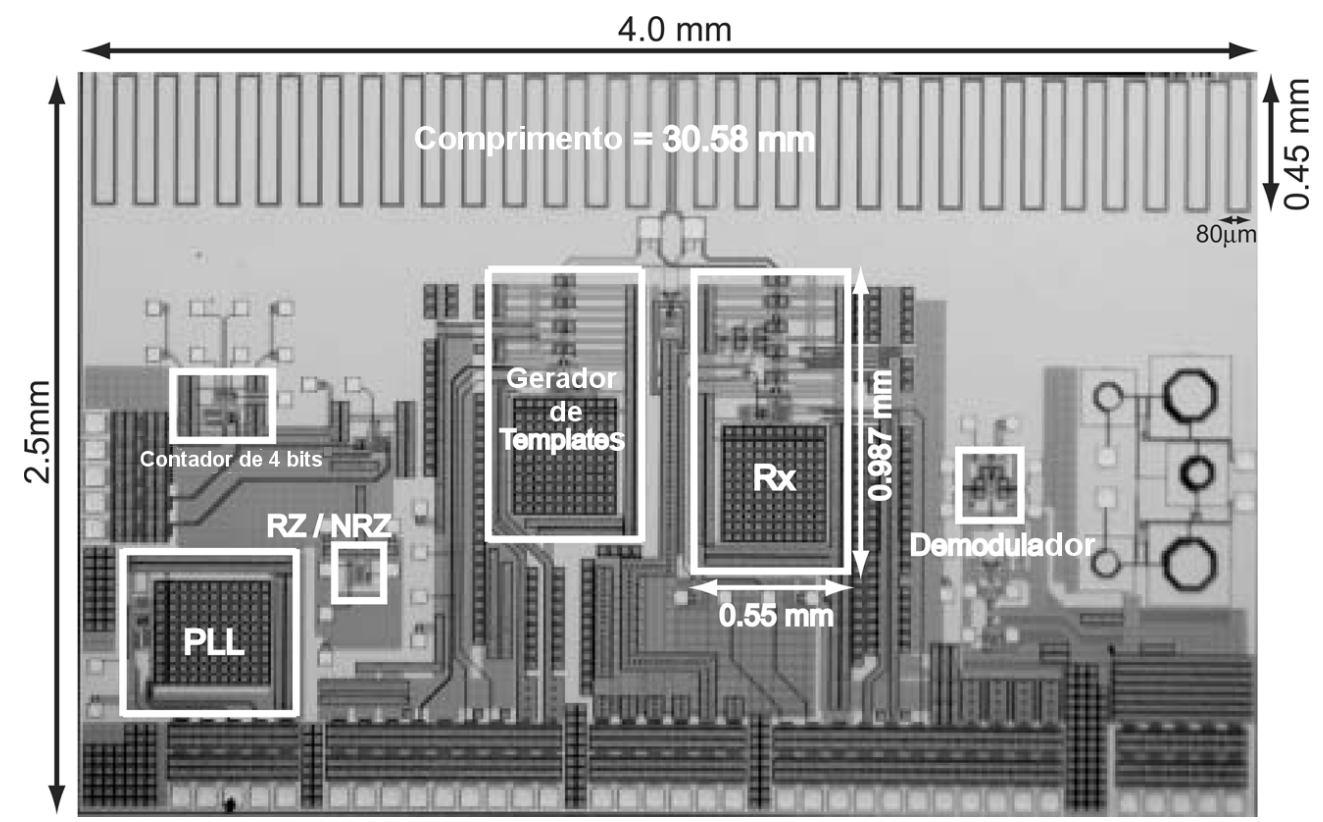

Fonte: Sasaki et al. (2009) 


\subsubsection{Antenas fractais}

Outra abordagem para a síntese de canal sem fio em chip desponta no emprego de antenas fractais. Este tipo de antena se destaca para o emprego em WiNoCs por conta de sua relativa facilidade de síntese em chip (O. et al., 2005).

Os primeiros resultados experimentais acerca do uso das propriedades das estruturas em fractal aplicadas às antenas de tamanho reduzido foram feitos a partir da estrutura clássica da curva de Koch (ADDISON, 1997). Puente et al. (1998), por exemplo, demonstraram, por meio de resultados experimentais e de simulações, como um monopolo de Koch (BALIARDA; ROMEU; CARDAMA, 2000) pode melhorar as características relativas a radiação (ressonância, frequência e banda) em relação a um monopolo linear comum. Os experimentos consistiram na implementação das cinco primeiras iterações da curva de Koch juntamente com um monopolo clássico para comparação (Figura 15). A partir dos resultados experimentais e das simulações concluiu-se que, com o aumento da ordem da curva de Koch, a resistência de radiação aumenta e a reatância diminui, melhorando o desempenho geral da antena.

Figura 15: As cinco primeiras iterações (K1-K5) da curva de Koch em uma configuração de monopolo. K0 é um monopolo linear o qual foi utilizado como base para comparação nos experimentos e simulações.

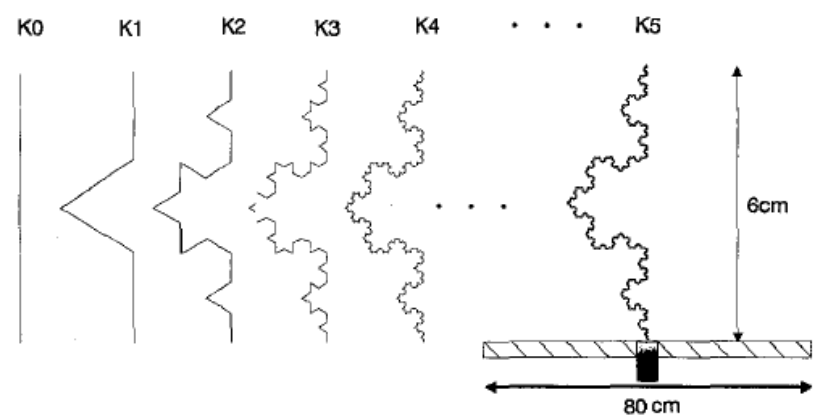

Fonte: Puente et al. (1998)

Além das curvas de Koch, os fractais de Sierpinski também foram estudados. Kimoto et al. (2004) por exemplo, desenvolveram experimentos para aferir o desempenho da transmissão de dados utilizando antenas do tipo Tapete de Sierpinski (Figura 16-a) associado à comunicação UWB (seção 3.1.1). Utilizou-se dois dipolos do tipo Tapete de Sierpinski em três configurações de dimensões $\left(1.0 \times 1.9,2.0 \times 3.8\right.$ e $\left.4.0 \times 7.6 \mathrm{~mm}^{2}\right)$ sobre um substrato de silício 
separados por uma distância variando entre 5.0 até $30.0 \mathrm{~mm}$. Por meio de um acoplador híbrido de $180^{\circ}$ geram-se sinais de diferenciais para os dipolos de antenas. No experimento o desempenho do UWB obteve perdas de retorno inferiores a $10 \mathrm{~dB}$, juntamente com a impedância de entrada cujos resultados apresentaram ROTE<2 - Razão de Onda de Tensão Estacionária (WENTWORTH, 2008) - em todo o domínio de frequências utilizado (626.5GHz). Quanto menor a ROTE mais potência é transmitida para a antena, logo resultados demonstram que o desempenho das antenas foi satisfatório (KIMOTO et al., 2004).

Figura 16: Configuração de um dipolo de Tapete de Sierpinski de 20- $\Omega$-cm (a). Dipolo em triângulo de Sierpinski (b)
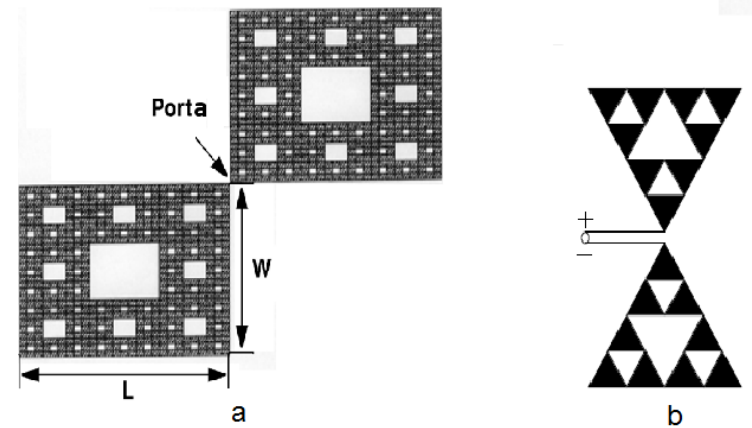

b

Fontes: O. et al. (2005) e Na e Xiao-wei (2005)

As propriedades de alguns tipos de antenas fractais também permitem a operação multibanda (NA; XIAO-WEI, 2005). A vantagem da operação multibanda reside no fato de se conseguir diferentes níveis de acesso ao meio o que aumenta o número de nós da rede em chip envolvidos na comunicação sem fio. Por meio de simulações dos tipos Tapete e Triângulo de Sierpinski (Figura 16-b), Na e Xiao-wei (2005) demonstraram que não é a natureza fractal que necessariamente dá origem ao comportamento multibanda das antenas, mas sim sua forma. A geometria fractal deve interceptar o exterior das regiões no qual a corrente elétrica circula para que o comportamento multibanda seja averiguado. Dessa forma, as antenas do tipo Tapete não são multibanda ao passo que as antenas hexagonais e pentagonais possuem esta característica (NA; XIAO-WEI, 2005).

Kumar e Gaikwad (2013) estudaram a compatibilidade das antenas fractais com o emprego da tecnologia Ultra Wide Band. A antena empregada no estudo é o resultado da concatenação de grupos similares aos triângulos de 
Figura 17: Visão no eixo vertical da antena fractal com quatro iterações sintetizada por Kumar e Gaikwad (2013)

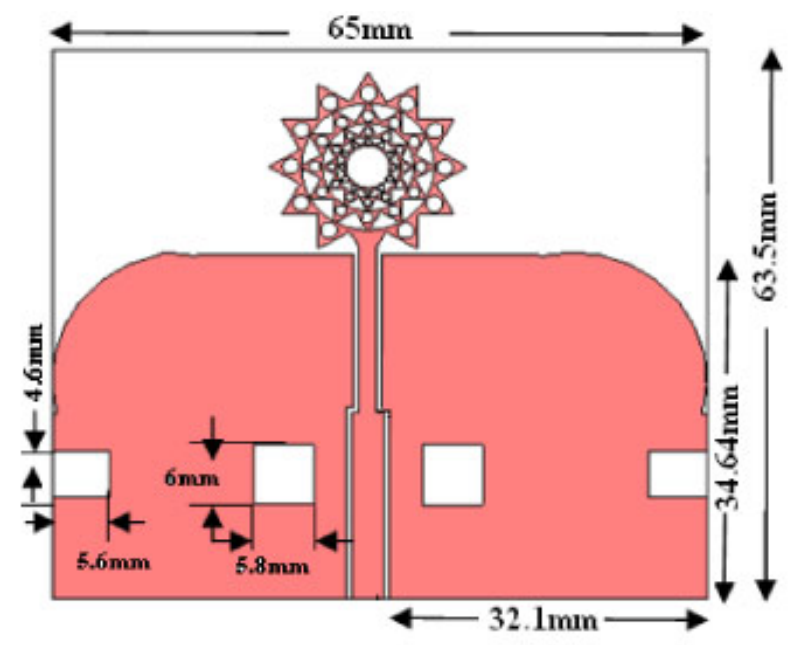

Sierpinski (Figura 16-b) em diversos níveis. O primeiro nível é composto por doze arcos em cujos lados internos foram sintetizados triângulos isósceles. Nos níveis internos subsequentes são sintetizados instâncias cada vez menores até atingir o quarto nível resultando no padrão ilustrado na Figura 17. Por meio de simulações e da síntese da antena ilustrada na Figura 17 avaliaramse os efeitos do número de iterações, das dimensões horizontais e verticais da base da antena. $\mathrm{O}$ aumento do número de iterações possibilita a melhoria do coeficiente de reflexão da antena da mesma maneira que os resultados obtidos por Baliarda, Romeu e Cardama (2000). A antena fractal mostrou-se apta para aplicações utilizando a tecnologia UWB em termos de frequências e padrões de radiação. Por serem compactas, relativamente simples de fabricar as antenas fractais despontam como potencial candidato para a síntese em chip visando seu uso em comunicações sem fio.

\subsubsection{Nanotubos de carbono}

Uma outra abordagem em estudo é a obtenção de antenas feitas a partir de nanotubos de carbono. Burke, Yu e Rutherglen (2005), por exemplo, afirmam que o uso de pacotes de nanotubos, por exemplo, permite a criação de circuitos apropriados para o casamento de impedâncias em sistemas de $50 \Omega$. Além disso, ainda segundo Burke, Yu e Rutherglen (2005), os nanotubos possuem resistividade menor e condutividade maior quando comparados ao 
cobre, o que demonstra o potencial da tecnologia.

Estudos teóricos acerca do desempenho dos nanotubos como antenas também foram desenvolvidos (HUANG; YIN; LIU, 2008). Por meio de predições baseadas em modelos de condutância, de impedância, de distribuição de corrente e de radiação de campo elétrico em pacotes circulares e retangulares de nanotubos (Figura 18), Huang, Yin e Liu (2008) concluem que o uso dos pacotes melhora o desempenho das antenas de nanotubos se comparadas ao uso individual dos mesmos. A eficiência de um pacote de nanotubos chega a ser de 30-40dB mais alta que a de um dipolo composto somente por um nanotubo.

Figura 18: Esquema de pacote circular (a) e retangular (b) de dipolo de nanotubos de carbono. Cada dipolo circular e retangular consiste em dois pacotes de nanotubos conforme ilustrado respectivamente em (b) e (d).

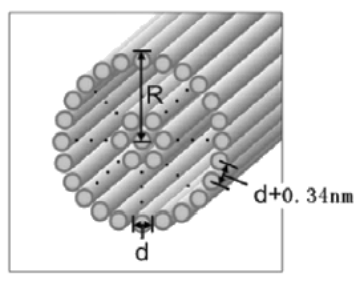

(a)

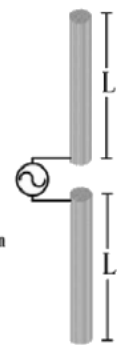

(b)

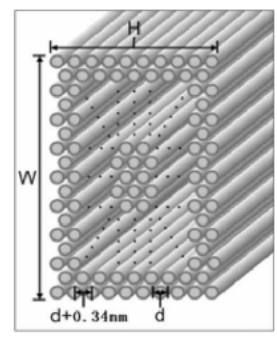

(c)

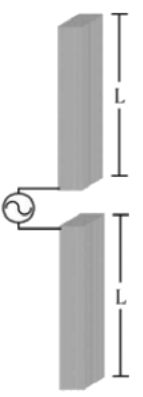

(d)

Fonte: Huang, Yin e Liu (2008)

Além das abordagens teóricas, outros estudos procuraram demonstrar que os nanotubos possuem propriedades relacionadas às das antenas existentes. Wang et al. (2004) demonstraram que os espalhamentos da luz em nanotubos alinhados mostram ser quantitativamente consistentes com os padrões de uma matriz de antenas . Dois efeitos básicos de antenas foram estudados:

1 - o efeito da polarização no qual não há resposta da antena quando o campo elétrico da radiação incidente é polarizado perpendicularmente ao dipolo do eixo da antena.

2 - o efeito do comprimento da antena cuja resposta é maximizada quando seu comprimento é múltiplo do campo de metade do comprimento de onda da radiação do meio. 
Em outro estudo, Kempa et al. (2007) evidencia ainda mais os efeitos dos nanotubos alinhados como antenas quando submetidos a um feixe de laser, demonstrando que sua radiação está em acordo com a teoria de antenas de rádio e sua respectiva modelagem e simulação. $O$ espalhamento do feixe é fundamentalmente em reflexão especular, estando de acordo com as análises teóricas realizadas. Além disso, também foram executadas simulações da resposta de uma antena de diâmetro desprezível em relação ao comprimento (similar a um nanotubo de carbono).

O experimento principal consiste em medir a resposta dos nanotubos a um feixe de laser por meio de um anteparo. Constatou-se que os resultados experimentais e os das simulações são essencialmente idênticos, incluindo intensidade e linhas de interferência. Confirmou-se também que este alinhamento entre a teoria e o experimento continua para outros ângulos de incidência, comprimentos de onda e dos nanotubos. A Figura 19 resume os resultados obtidos.

O trabalho de Koksal e Ekici (2012) explora outra modelagem teórica para um receptor de radiofrequências baseado em um arranjo de nanotubos denominado de floresta. Uma floresta de nanotubos é definida como um grupo de milhares de nanotubos alinhados verticalmente em um mesmo substrato. $O$ modelo do receptor é experimentado em um cenário de baixa relação sinalbanda (a banda do sinal é muito menor que a banda aceita pelos nanotubos) e também em uma abordagem de alta relação sinal-banda (a banda do sinal é maior que a banda aceita pelos nanotubos) nas quais explora-se o fato da taxa de transmissão ser proporcional ao número de nanotubos com uma razão sinal ruído aceitável. Koksal e Ekici (2012) também mencionam aplicações para o regime de baixa relação sinal-banda as quais consistem em sistemas os quais ficam desativados por um longo período de tempo e só devem ser ativados ao receber o respectivo sinal de ativação. A taxa de transmissão é da ordem de poucos kilobits por segundos, o que evidencia ainda mais a aplicação deste regime para sinais de controle nos quais a taxa de erro de comunicação dever ser mínima. A motivação do regime de alta razão sinal-banda é demonstrar que o receptor de nanotubos de carbono pode operar com taxas de transmissão semelhantes aos receptores atuais (Mbps). Apesar do receptor ser feito com a associação de milhares de nanotubos, o grau de miniaturização é de- 
Figura 19: Comparação entre os mapas de radiação experimentais (a, b) e os calculados (c, d) para dois comprimentos diferentes de nanotubos. Em (a) e (c) I $\approx 850 \mathrm{~nm}$ e em (b) e (d) I $\approx 3.5$ um. O comprimento de onda é $\lambda=543.5 \mathrm{~nm}$ e o ângulo de incidência do laser $\theta=40^{\circ}$.

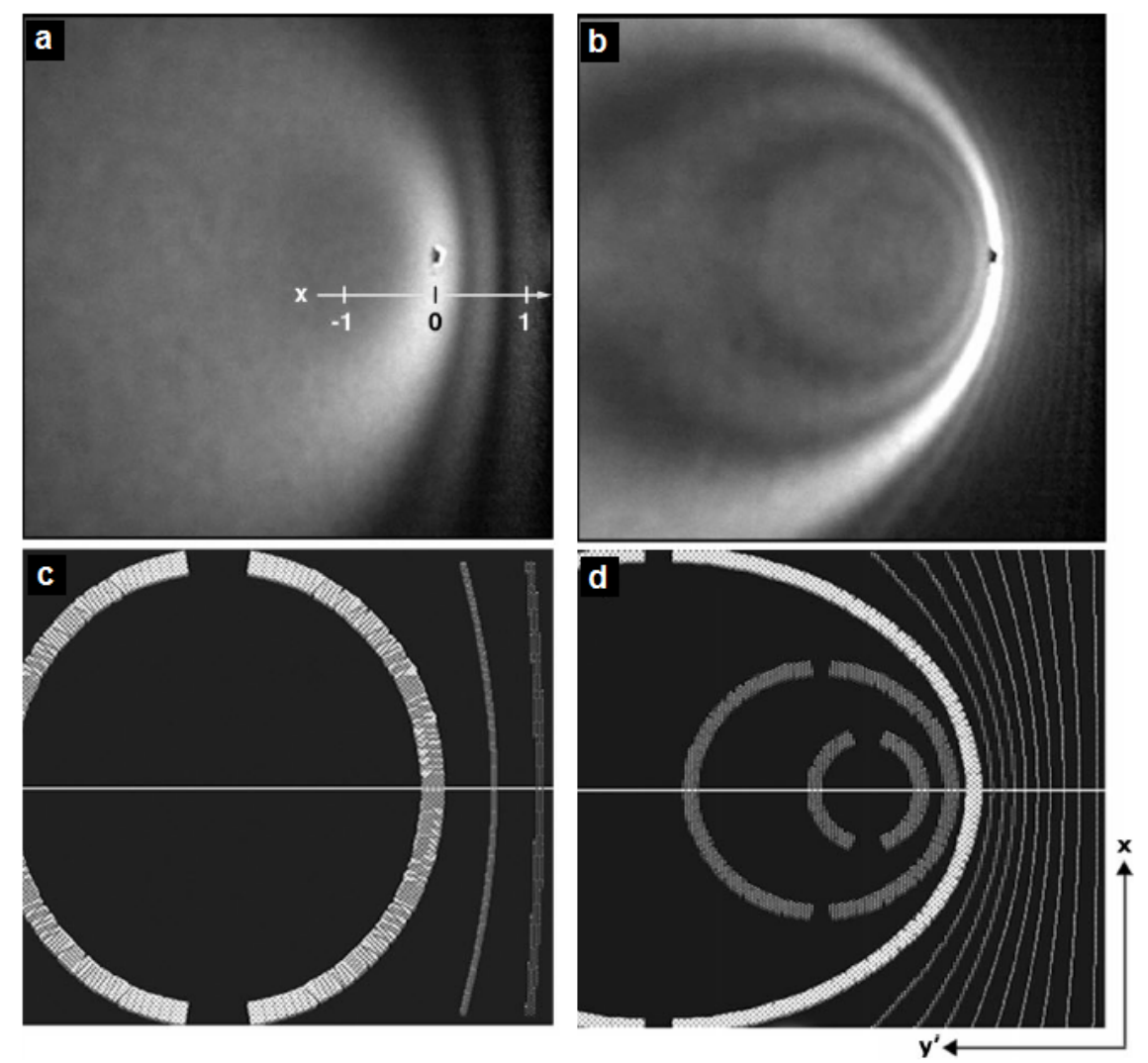

Adaptado de: Kempa et al. (2007) 
fendido pelo fato das estruturas serem menores que antenas de comunicação sem-fio atuais.

Figura 20: Operação básica de um nanoreceptor

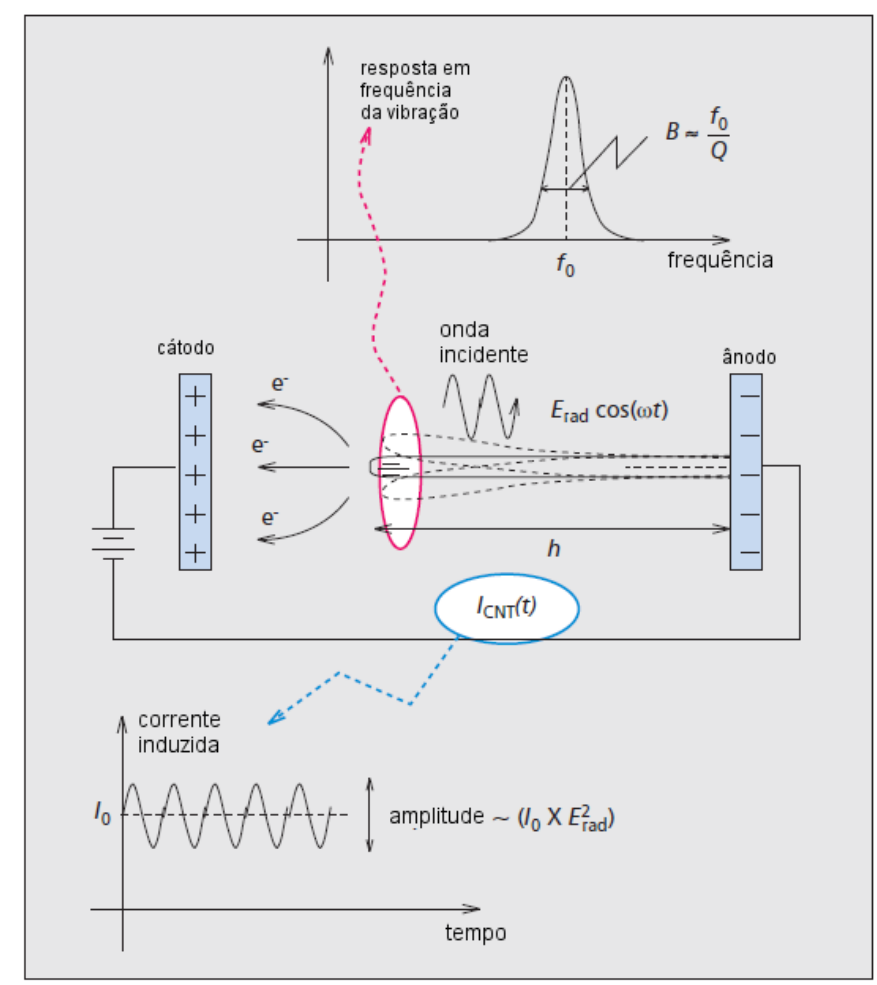

Fonte: Koksal e Ekici (2012)

O modelo físico de cada elemento da floresta de nanotubos é ilustrado na Figura 20. Ele consiste de um nanotubo de carbono acoplado a um ânodo, deixando sua outra extremidade livre para se movimentar. Tal abordagem explora as propriedades elásticas dos nanotubos para induzir o movimento da extremidade livre por meio de um campo elétrico longitudinal ao nanotubo. Por meio desta excitação eletromagnética, há o aumento da densidade de cargas na ponta do natotubo a qual induz seu movimento. Propriedades fundamentais como a massa, o comprimento e o diâmetro do nanotubo determinam a frequência ressonante e o fator de qualidade desta vibração. A resposta da vibração tem seu pico quando a frequência incidente é igual a frequência ressonante e diminui à medida que a diferença entre estas duas frequências aumenta. $\mathrm{O}$ aumento do campo elétrico entre a ponta do nanotubo faz com que as cargas saltem pelo espaço entre a ponta do nanotubo e o cátodo gerando uma corrente de tunelamento a qual está ilustrada na Figura 20. Esta corrente gera um campo elétrico cuja raiz quadrada varia em função da radiação inci- 
dente no nanotubo (KOKSAL; EKICI, 2012), a qual é usada para decodificar os sinais recebidos.

Os experimentos para o regime de baixa relação sinal-banda concentramse no desempenho do receptor ligado às probabilidades de erros de transmissão. Por exemplo, empregando uma floresta de mil nanotubos, a probabilidade de erro neste regime é da ordem de $10^{-5}$. Além disso o número de nanotubos é bastante sensível a relação sinal-ruído: diminuindo $1 \mathrm{~dB}$ desta relação, aumenta-se o número de nanotubos por um fator de 100 a fim de que 0 desempenho (taxa de transmissão e probabilidade de erro) seja mantido.

Para a avaliação do desempenho no regime de alta relação sinal-banda foi utilizada a taxa de bits errados (BER). O número de nanotubos é significativamente maior para que este regime tenha desempenho similar ao de baixa relação sinal-banda em termos de probabilidade de erros. Enquanto o número de nanotubos no regime de baixa relação sinal-banda é da ordem de milhares, este número cresce para a ordem de milhões no regime de alta relação sinalbanda. Isso é causado porque a maior parte da energia do sinal está fora da banda do nanotubo de carbono e acaba sendo filtrada. Esta perda da energia do sinal é compensada com o aumento do número de nanotubos de carbono. Contudo tal abordagem ainda é válida dado que, com o estado atual da tecnologia, é possível dispor $10^{6}$ nanotubos em uma área de $0.1 \mathrm{~mm}^{2}$ (KOKSAL; EKICI, 2012).

\subsection{Trabalhos relacionados de transmissão sem fio aplicada a redes em chip}

Além dos avanços já descritos neste capítulo relacionados à camada física, nesta seção são abordados alguns trabalhos relacionados à modelagem e simulação de redes em chip sem fio. Conforme mencionado no começo deste capítulo, a escalabilidade é fundamental para o sucesso de qualquer arquitetura baseada em redes. Diante do desafio de proporcionar escalabilidade para as redes em chip em cenários de tráfego mais intensos, as tecnologias de transmissão por canais sem fio surgem como uma alternativa viável para o incremento dos fluxos de tráfego imersos na NoC (DEB et al., 2012). 
O estudo de Wu, Wang e Zhao (2010), por exemplo, foca no uso da abordagem de redes em chip sem fio para reduzir a superfície ocupada por cada IP. Para tal, propõem uma arquitetura sem fio pura para transmissão de pacotes em substituição à tradicional arquitetura em malha (seção 2.5) em redes em chip irregulares nas quais cada IP ocupa uma área diferente em hardware. A análise de desempenho é feita por meio da comparação da arquitetura proposta com o roteamento padrão de caminho mais curto orientado a tabelas, e o trabalho de Schafer et al. (2005) que propõe um algoritmo de roteamento para redes em chip irregulares. Os experimentos são executados em uma plataforma de simulação própria focando em aspectos como o throughput, o atraso médio e o grau de irregularidade da topologia. Os resultados mostraram que o roteamento sem fio é $35 \%$ mais rápido e é $28.5 \%$ menos dispendioso em área de tabelas quando comparado com o roteamento tradicional, contudo o trabalho não deixa claro detalhes a respeito de como os fluxos de tráfego são gerenciados.

Outro trabalho pioneiro na análise do uso de redes em chip sem fio é o de Yoon e Park (2005) no qual há a proposta de uma topologia de rede em chip sem fio octogonal. Primeiramente há a modelagem da comunicação de WiNoCs por meio de equações, as quais focam no throughput e latência para, em seguida, haver a justificativa de tal modelo por meio de um simulador próprio implementado em $\mathrm{C}++$. Apesar da simplicidade da topologia proposta, há um estudo de caso que aplica o IEEE 802.11a com o objetivo de analisar o tamanho mínimo dos buffers do switch para que seja possível uma operação confiável sem perda de pacotes.

Apesar de alguns dos campos de pesquisas de transmissão sem fio abordarem capacidades multibanda (RAZAVI et al., 2005; NA; XIAO-WEI, 2005; GANGULY et al., 2011a) as quais permitem que mais de um fluxo de tráfego seja transmitido sem haver colisões no acesso ao meio, é necessária a concepção de mecanismos de controle de acesso a fim de envolver um número maior de nós em topologias de WiNoCs. A partir da tecnologia UWB para distâncias curtas abordada na seção 3.1.1, por exemplo, consegue-se a transmissão simultânea dos canais sem fio, assegurando que os fluxos de tráfego no canal sem fio estejam a uma distância que leve em consideração a taxa de bits errados (BER Bit Error Rate) de tal forma que não interfiram uns 
com os outros. Isso é feito por meio de um mecanismo de arbitragem baseado em permissões de acesso ao canal sem fio associado às posições geográficas dos emissores, receptores e vizinhos (ZHAO et al., 2011). Há também a possibilidade de modelar protocolos de acesso ao meio para evitar colisões durante a transmissão dos canais sem fio. Por meio de uma máquina de estados associada a mecanismos de sincronização (ZHAO; WANG, 2008), é possível identificar os nós sem fio vizinhos e estabelecer diversos fluxos de tráfego sem colisões. O processo de acesso ao meio é dividido em duas fases principais: a da competição e a de transmissão de dados. A fase de competição inicia-se com um período de inicialização da máquina de estados e dos registradores do fluxo de dados. Em seguida vem o período de contenção de canal no qual se decide quais nós serão envolvidos na transmissão em uma determinada zona da rede. Finalmente a fase da competição termina com a autorização para um par de nós utilizar o canal sem fio para transmitir flits durante determinado período de tempo.

Associada a mecanismos de acesso ao meio, a tecnologia sem fio nas redes em chip proporciona o surgimento de uma nova abordagem de transmissão a qual propõe diminuir o número de saltos nas transmissões de informações intra-chip da mesma maneira que a a topologia flattened butterfly (KIM; BALFOUR; DALLY, 2007), descrita na seção 2.5.3, propõe. Os primeiros estudos provém de simulações e análises de topologias dotadas somente de canais com fio. Ogras e Marculescu (2006), por exemplo, propõem o uso de canais de longa distância com fio, que conectam nós não adjacentes, usando o roteamento em wormhole (NI; MCKINLEY, 1993) para NoCs. Os experimentos são baseados em comparar uma malha tradicional com a abordagem de transmissão com links de longa distância em diversos cenários de tráfego sintético. Os resultados mostraram ganhos significativos em termos de latência e throughput da rede, contudo em alguns experimentos os links de longa distância tornaram-se um gargalo na rede por conta do acesso exagerado aos mesmos. O artigo ainda sugere estudos acerca do desenvolvimento de um protocolo de roteamento dinâmico o qual poderia melhorar o impacto dos links de longo alcance tomando a totalidade da rede como referência para a análise do desempenho.

Com a finalidade de otimizar a dinâmica de transmissão dos pacotes, as 
redes sem fio em NoCs funcionam como uma nova camada na qual os flits com destinações mais longínquas são transmitidos entre grupos de switches dentro da rede em chip, diminuindo distâncias e a probabilidade de interferência entre os fluxos de tráfego de maior ordem com os de menor ordem (SHI; BURNS, 2008). No momento da transmissão de um flit por parte de um switch, um mecanismo de arbitragem hierárquica deve decidir por qual canal de transmissão (intra chip ou sem fio) o transporte será efetuado. Diante de tal contexto, mecanismos de zoneamento (ZHAO; WU, 2012) demonstram-se como uma boa alternativa para a transmissão de dados na NoC. A topologia hierárquica de Zhao e Wu (2012) é composta por nós separados em zonas com o objetivo de melhorar a capacidade de comunicação em chip. Por meio desta abordagem foi possível reduzir o atraso fim-a-fim em 33\% em comparação com a tradicional topologia em malha ao passo que o throughput foi melhorado em $51 \%$. As zonas podem ser regulares ou definidas com base nos fluxos de tráfego previamente estimados. De maneira similar, a densidade e a localização dos canais sem fio também pode ser uma função dos fluxos de tráfego na rede (ZHAO et al., 2011).

Há também estudos que focam na dinâmica dos fluxos de tráfego usando redes em chip sem fio. Ganguly et al. (2011a) analisa o comportamento de redes em chip mistas com canais sem fio baseados na topologia small-world (seção 2.5.2). As métricas utilizadas foram latência, throughput e dissipação de energia. O throughput na saturação é quase quatro vezes maior em topologias dotadas de canais sem fio se comparadas com topologias compostas somente de canais com fio. $\mathrm{O}$ artigo também sugere que um novo mecanismo de controle de fluxos deve ser usado com o objetivo de melhorar o desempenho das redes em chip sem fio. Além disso, a análise de Ganguly et al. (2011b) evidencia os benefícios das WiNoCs, focando em um contexto de elevado número de falhas, característico do emprego de novas tecnologias como as da seção 3.1. O trabalho explora os resultados de estudos teóricos os quais afirmam que as redes em topologia small-world são resilientes a problemas de interconexão (ALBERT; JEONG; BARABÁSI, 2000) para propor uma arquitetura de WiNoC tolerante a falhas. Nesta arquitetura há a presença de atalhos nos quais a tecnologia de transmissão sem fio é empregada para aqueles de maiores distâncias ao passo que os atalhos de menor distância são de 
fios tradicionais. Tal análise é baseada em sistemas de até 256 nós com protocolo de roteamento em wormhole baseado na busca exaustiva do menor caminho. Os resultados mostraram que as abordagens hierárquicas possuem desempenho superior à malha tradicional e que o throughput da rede não se altera de maneira considerável mesmo quando $75 \%$ dos nós são aleatoriamente desativados. Dessa forma, inovações na arquitetura podem contribuir para a robustez e eficiência energética mesmo quando projetadas com novos paradigmas, como o das WiNoCs, e diante de um alto grau de falhas.

Finalmente Chang et al. (2012) fazem uma análise mais detalhada da dinâmica de comunicação das WiNoCs comparando topologias organizadas hierarquicamente por meio de um simulador de NoCs próprio no qual o ganho da antena sem fio, dados de atraso e de banda são alimentados a partir de ferramentas externas. $O$ trabalho concentra-se em uma rede com dois níveis hierárquicos. O primeiro nível utiliza somente canais com fio e é composto por clusters, de diferentes topologias, os quais são ligados a uma topologia em anel (segundo nível) por meio de um nó coordenador central em cada cluster. O segundo nível, em anel, possui atalhos sem fio correspondendo a uma topologia small-world conforme o arranjo descrito pela Figura 3-d. O roteamento é estático baseado em um mecanismo de token-flow no qual um nó é roteado pelo canal sem fio somente quando este possui o token. Utiliza-se uma política de broadcast no qual o nó emissor envia o sinal para todos os outros nós de forma que o nó de destino trata os flits enviados. O trabalho avalia a topologia no nível de dinâmica de rede e identifica que há um número ótimo de ligações sem fio para cada configuração de topologia o qual concilia consumo energético com o desempenho do throughput. Para topologias de 128, 256 e 512 nós, o valor ótimo de throughput é atingido com respectivamente 4, 6 e 10 canais sem fio. Isso acontece por conta da abordagem estática de roteamento na qual a latência para conseguir acesso ao canal sem fio aumenta significativamente com o número de canais sem fio. Além disso, quanto maior o número de canais sem fio, mais energia é consumida durante o processo de transmissão baseado em broadcast. 


\subsection{Uso de protocolos de roteamento dinâmico para a economia de energia}

As investigações no meio físico têm como principal objetivo prover capacidades sem fio para qualquer nó em uma NoC. Por outro lado, a transmissão via rádio é ainda custosa em termos energéticos, o que incentiva os pesquisadores a focar também na complexidade do switch da rede em chip (seções 2.6 e 2.7) e na dinâmica da rede. Topologia (seção 2.5), capacidade de roteamento (dinâmico ou fixo), localização e quantidade de nós sem fio dentro de uma NoC tradicional (seção 3.2) são alguns dos parâmetros que os projetistas necessitam tratar a fim de minimizar os custos (seção 2.3) mantendo um desempenho aceitável.

A proposta deste trabalho contribui com os estudos de modelagem e simulação da seção 3.2 por meio da análise das WiNoCs com o objetivo de descobrir trade-offs estratégicos e novas abordagens para os switches. O foco do trabalho é em roteamento dinâmico, broadcasting e técnicas para simulação em multi-rotas. Um cenário atrativo para WiNoCs usando roteamento dinâmico é a possibilidade de se desligar seletivamente porções do chip sem a necessidade de interromper a comunicação, o que não é possível nas análises atuais uma vez que adota-se o roteamento estático (ZHAO; WU, 2012; YOON; PARK, 2005).

Em cenários de roteamento dinâmico, o uso de protocolos ad hoc semfio clássicos como o DSR (JOHNSON; MALTZ, 1996), o AODV (PERKINS; ROYER, 1999) ou o DSDV (PERKINS; BHAGWAT, 1994), detalhados na seção 3.4), embora nunca testados em WiNoCs, pode ser efetivo dado suas similaridades com os requisitos de WiNoC em termos de auto-organização dos nós e aspectos de controle de fluxos. Neste trabalho há uma análise do usos dos três protocolos para redes sem fio supracitados em um ambiente de aplicação em WiNoCs na seção 5.2 além da visão geral da modelagem de consumo energético usando a ferramenta de simulação Orion (WANG et al., 2002). 


\subsection{Protocolos ad hoc de roteamento sem fio}

Esta seção descreve os aspectos principais dos protocolos envolvidos neste trabalho, a saber: DSDV (PERKINS; BHAGWAT, 1994), DSR (JOHNSON; MALTZ, 1996) e AODV (PERKINS; ROYER, 1999).

DSDV (Destination Sequenced Distance Vector) é um protocolo de roteamento proativo no qual cada estação de roteamento transmite mensagens periodicamente a fim de preencher tabelas com os nós de destinos e seus respectivos números de saltos. Cada nó difunde sua tabela de roteamento para os vizinhos de tal forma que seja possível para um nó localizar os outros na rede. Cada tabela de roteamento lista todas as destinações conhecidas e o número de saltos para cada uma, assim como o próximo salto. Além da transferência periódica de informações há também troca de mensagens durante qualquer evento no qual a rede modifica-se de maneira significativa. A fim de diminuir o overhead destas mensagens de controle, o protocolo somente transmite as informações alteradas por conta do evento que ocorreu na rede. As rotas são escolhidas adotando o critério do caminho mais curto usando o algoritmo de Bellman-Ford (MEDHI; RAMASAMY, 2007). O protocolo controla o processo de atualização das rotas por meio da adoção de números sequenciais em cada uma das mensagens.

DSR (Dynamic Source Routing) é um protocolo de roteamento reativo composto por dois mecanismos: descoberta de rotas e manutenção de rota. A descoberta de rota é descrita pela fase na qual o nó de origem recebe uma rota para o nó de destino, ao passo que o mecanismo de manutenção de rotas é usado para verificar a integridade da rota entre os nós de origem e destino. Os dois mecanismos operam segundo a demanda de tráfego, portanto, não necessitam de pacotes periódicos de nenhum tipo na rede. A descoberta de rota é baseada em duas mensagens: route request (RREQ) e route reply (RREP). As mensagens RREQ são enviadas pela fonte a qual demanda de seus nós vizinhos a localização de um destino. Os nós vizinhos adicionam seus endereços às mensagens e as retransmitem aos seus nós adjacentes até o momento no qual o destino é encontrado. As mensagens RREP retornam a sequência de endereços de nós para o emissor a qual será utilizada para roteamento. A manutenção de rota é baseada nas mensagens route error 
(RERR). As mensagens RERR são enviadas, por exemplo, quando o número máximo de retransmissões de um pacote por parte de um nó é atingido. Esta mensagem de erro contém os endereços do nó que detectou o erro, o destino para o qual o pacote estaria sendo enviado. Ao receber a RERR mensagem um nó deve excluir de seu cache a rota na qual se processou o erro. Este protocolo é mais simples que o DSDV já que não necessita de tabelas de roteamento, sendo suficiente um cache das rotas em uso em cada nó emissor. Por outro lado, apresenta um tempo maior de resposta já que as rotas são elaboradas sob demanda por conta do DSR ser um protocolo reativo.

AODV (Ad hoc On-Demand Distance Vector Routing) é um protocolo de roteamento reativo baseado tanto no DSR e no DSDV. Este protocolo emprega um mecanismo de descoberta de rotas baseado no DSR, como também se beneficia das vantagens do estabelecimento de tabelas de rotas em nós intermediários. A diferença é mais visível em topologias maiores devido ao overhead gerado por se transportar informações de rotas em cada pacote. Há quatro tipos diferentes de mensagens: RREQ, RREP, RERR, HELLO. As três primeiras mensagens têm função similar às do DSR. As mensagens HELLO tem como objetivo verificar a comunicação dos links entre os nós vizinhos e também averiguar a entrada e saída de novos nós móveis na rede. Entre os parâmetros de destaque presentes nas tabelas de roteamento do protocolo AODV há o ID do destino, o número sequencial, o número de saltos para atingir o destino, o próximo salto e a lista de nós anteriores. As tabelas de roteamento do protocolo AODV permitem que os pacotes não necessitem manter a rota a ser traçada em seus cabeçalhos. Este protocolo difere do DSR porque cada nó possui uma tabela de roteamento diminuindo o overhead dos cabeçaIhos dos pacotes. Apesar de possuir tabelas de roteamento, elas são menos complexas que as empregadas no DSDV.

\subsection{Sinopse}

Esta seção resume os aspectos principais discutidos neste capítulo.

A Tabela 5 sintetiza o estado da arte das principais vertentes de investigação de antenas em chip. 
Tabela 5: Antenas em chip - estado da arte

\begin{tabular}{|c|c|}
\hline Tecnologia & Estado da Arte \\
\hline antenas zigue-zague & $\begin{array}{l}\text { síntese de circuitos de recepção distâncias longas (m) } \\
\text { (LIN; WU; O, 2005; LIN et al., 2007) e curtas (mm) } \\
\text { (SASAKI et al., 2009) }\end{array}$ \\
\hline antenas fractais & $\begin{array}{c}\text { aferição, modelagem e comprovação de } \\
\text { propriedades em aplicações para comunicação } \\
\text { (NA; XIAO-WEI, 2005; KUMAR; GAIKWAD, 2013) }\end{array}$ \\
\hline nanotubos de carbono & $\begin{array}{c}\text { aferição, modelagem e comprovação de } \\
\text { propriedades em aplicações para } \\
\text { comunicação. Modelagem preliminar de receptores } \\
\text { (KEMPA et al., 2007; KOKSAL; EKICI, 2012) }\end{array}$ \\
\hline
\end{tabular}

A tabela 6 sintetiza os principais trabalhos relacionados com modelagem e simulação de WiNoCs. Destacam-se os estudos focados em redes hierárquicas, que podem ser simuladas utilizando a ferramenta de simulação descrita no capítulo 4.

Tabela 6: Modelagem e simulação de WiNoCs - trabalhos relacionados

\begin{tabular}{cc}
\hline Foco da Pesquisa & Descrição do Estudo \\
\hline redes hierárquicas & $\begin{array}{c}\text { topologias com zoneamento fixo (ZHAO; WU, 2012), } \\
\text { dinâmica de rede baseada em topologias } \\
\text { em small-world (GANGULY et al., 2011a) }\end{array}$ \\
acesso ao meio & $\begin{array}{c}\text { maquinas de estado para priorização } \\
\text { de nós (ZHAO; WANG, 2008), } \\
\text { abordagens focadas na transmissão } \\
\text { entre nós adjacentes (ZHAO et al., 2011) } \\
\text { simuladores } \\
\text { modelagem de WiNoC octogonal } \\
\text { seguida de simulação (YOON; PARK, 2005), } \\
\text { modelagem de WiNoCs usando diferentes } \\
\text { topologias em um conjunto integrado } \\
\text { de ferramentas de simulação (CHANG et al., 2012) }\end{array}$ \\
\hline
\end{tabular}

Finalmente a tabela 7 resume os protocolos ad hoc sem fio de roteamento dinâmico utilizados na plataforma de simulação descrita no capítulo 4 . 
Tabela 7: Protocolos ad hoc sem fio - principais aspectos

\begin{tabular}{cc}
\hline Protocolo & Descrição \\
\hline DSDV & $\begin{array}{c}\text { rotas são elaboradas com base na transferência periódica } \\
\text { das distâncias em número de saltos entre os nós }\end{array}$ \\
DSR & $\begin{array}{c}\text { rotas feitas sob demanda. Baseado em duas mensagens: } \\
\text { RREQ (Route Request) e RREP (Route Reply) }\end{array}$ \\
AODV & $\begin{array}{c}\text { mescla dos conceitos usados no DSDV e DSR: as rotas são } \\
\text { elaboradas sob demanda, contudo cada nó mantém uma tabela } \\
\text { de roteamento menos elaborada, se comparada às do DSDV }\end{array}$ \\
\hline
\end{tabular}




\section{PLATAFORMA DE SIMULAÇÃO}

Com a finalidade de verificar o desempenho e o funcionamento de uma rede em chip sem fio é necessário o desenvolvimento de uma abordagem que permita averiguar estas redes. Apesar dos avanços tecnológicos da seção 3.1, descrever a arquitetura da WiNoC em hardware é ainda uma tarefa custosa. Portanto o emprego de metodologias recentes do projeto em hardware (ERBAS, 2006) permite facilitar esta tarefa e é uma alternativa para conseguir resultados preliminares, em um espaço de tempo menor, sem precisar descrever todo o chip. Para isto primeiramente modela-se arquitetura e as aplicações das IPs, a fim de averiguar quais são os tradeoffs existentes e se a abordagem proposta possui desempenho satisfatório em termos arquiteturais e de sistema. A partir dos resultados anteriores, é possível refinar a arquitetura. Finalmente, partindo de um modelo refinado com desempenho satisfatório, incia-se o desenvolvimento do chip.

Apesar de nos capítulos anteriores o conceito de flit ser muito mencionado, na ferramenta de simulação desenvolvida, o termo pacote será utilizado para determinar as menores unidades de dados transmitidas entres os switches. A plataforma de simulação proposta neste trabalho (FERREIRA; MARGI, 2013) possui três componentes principais: o simulador ns-2, a descrição em baixo nível para a simulação do switch e os subsistemas de integração.

O ns-2 (ISI, 2011b) é um simulador de eventos discretos com o objetivo de estudar a dinâmica do tráfego em rede. O simulador possui suporte para simulações TCP, algoritmos de roteamento e para protocolos (unicast e multicast) de topologias com fio e sem fio. O ns-2 começou como uma variante do simulador de rede REAL em 1989 (KESHAV, 1997) e evoluiu com o passar dos anos. Em 1995, o desenvolvimento do ns-2 foi apoiado pela Defense Advanced Research Projects Agency, através do projeto VINT (USC, 1997), 
Xerox PARC, Universidade da Califórnia Berkeley (UCB) e pelo Instituto de Ciências da Informação da Universidade do Sul da Califórnia (USC). Além disso, há contribuições substanciais de outros pesquisadores, incluindo o código sem fio dos projetos Daedelus da UCB e Monarch (RICE, 2004), e da Sun Microsystems.

Apesar da viabilidade na simulação de NoCs clássicas com fio no ns-2 (MANOHAR et al., 2001) e do simulador possuir uma interface de simulação entre redes com fio e redes sem fio (ISI, 2011a), ela é limitada a simulações entre um domínio com fio e um domínio sem fio. Portanto não é possível a simulação de tráfego entre dois domínios (clusters) com fio intermediados por um domínio sem fio. Alterar o simulador ns-2 não faz parte do escopo deste trabalho e implica em desviar-se dos releases originais, o que desencoraja novas propostas. Diante dessas premissas, concebeu-se uma nova estratégia por meio do uso do ns-2 padrão para projetar uma arquitetura de simulador especificada neste capítulo.

Figura 21: Máquina de estados da plataforma de simulação. Todas as etapas descritas são feitas de forma automática baseado em parâmetros iniciais de simulação.

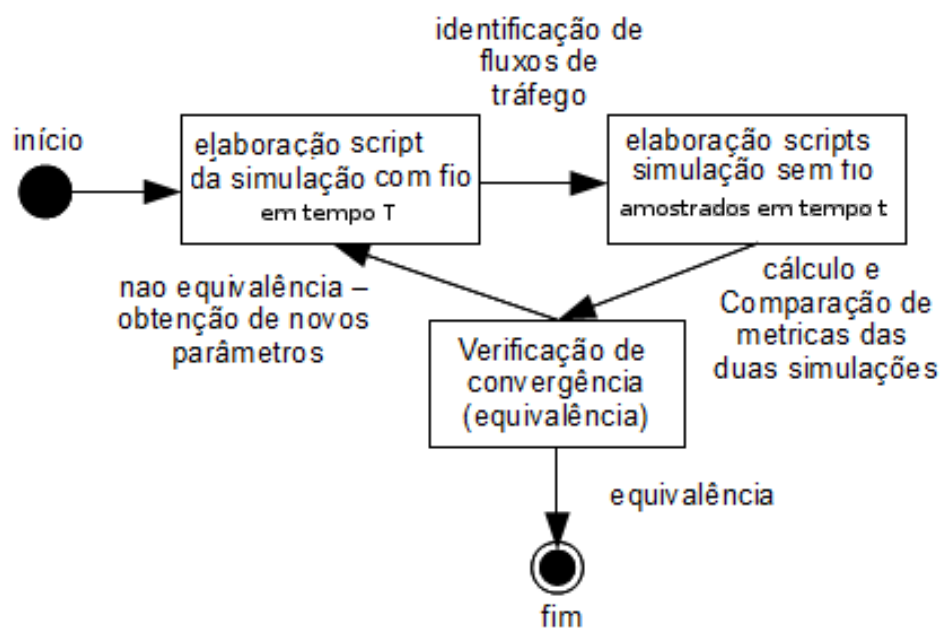

A idéia geral é aproximar-se ao máximo do paradigma emergente das WiNoCs, aproveitando-se das interfaces e conceitos existentes no ns-2. Dessa forma, propõe-se um ambiente de co-simulação no qual há a execução de uma simulação com fio principal e simulações sem fio amostradas equivalentes a simulação com fio principal. Por meio deste ambiente misto de simulação é possível conseguir um maior nível de detalhe do comportamento das redes 
em chip sem fio no nível físico, abordando aspectos como o alcance do canal sem fio, do acesso ao meio, o que possibilita o uso de abordagens de acesso ao meio como a IEEE 802.11 trabalhada preliminarmente por Yoon e Park (2005), e do roteamento de protocolos dinâmicos buscando-se o desligamento parcial de nós da rede para a economia de energia, conforme abordado na seção 3.3.

Além disso, as abordagens sem fio permitem também analisar o tempo de resposta e a própria dinâmica interna dos protocolos de roteamento, as quais não seriam possíveis de simular utilizando somente a simulação com fio. Dessa forma, propõe-se uma abordagem iterativa, ilustrada na Figura 21, baseada em uma simulação única com fio em um intervalo de tempo $T$ auxiliada por diversas simulações sem fio amostradas em intervalos $t<T$. Os canais da simulação com fio que possuem o papel de transmissores sem fio são alterados a fim de transmitirem os mesmos fluxos de dados e a mesma quantia de pacotes nos intervalos de tempo $t$. Em suma os canais com fio responsáveis pela transmissão de dados entre os clusters são modelados a partir dos resultados das simulações da malha sem fio. A equivalência entre as duas simulações é garantida por um módulo de convergência.

Para o desenvolvimento desta abordagem foi escolhida a linguagem de programação Java pelo fato da mesma apresentar um amplo espectro de opções e recursos de integração úteis para o desenvolvimento deste tipo de aplicação. No apêndice $A$ há um exemplo de um script de simulação com fio gerado pela plataforma de simulação. No apêndice $B$ há um exemplo de um script, o qual retrata a primeira simulação sem fio amostrada a partir dos resultados da simulação com fio anterior. Estes scripts são executados pelo ns-2 e seus arquivos de saída são lidos e analisados pela plataforma de simulação a fim de obter os dados necessários para a tomada de decisão realizada pelo módulo de convergência detalhado na seção 4.1.4.

A Figura 22 descreve a topologia simulada. Há dois tipos de switches: os dotados de canal sem fio e os que não o possuem. Os switches dotados de canais sem fio possuem arquitetura muito similar a minBD (seção 2.7.3), porém, ao invés de redirecionar os pacotes de volta ao mesmo switch, usa-se o canal sem fio como atalho para os pacotes que necessitam atravessar distâncias maiores que o tamanho de uma aresta de um cluster (em número de 
saltos). A topologia é uma estrutura hierárquica composta por clusters sendo que em cada cluster há um nó central que possui acesso sem fio destinado aos pacotes que necessitem alcançar os outros clusters da rede. Os switches sem fio são dispostos de tal forma a constituírem somente as conexões descritas na figura 22. Por meio de tal estrutura é possível reduzir o número de saltos necessários para se chegar a um destino por pacotes que necessitem viajar grandes distâncias, o que aumenta o desempenho geral da rede.

Figura 22: Diagrama da topologia simulada. A rede é dividida em unidades menores denominadas clusters. As conexões pontilhadas e switches em preto estão presentes na simulação com fio pura e nas simulações sem fio. As conexões restantes são consideradas somente na simulação com fio.

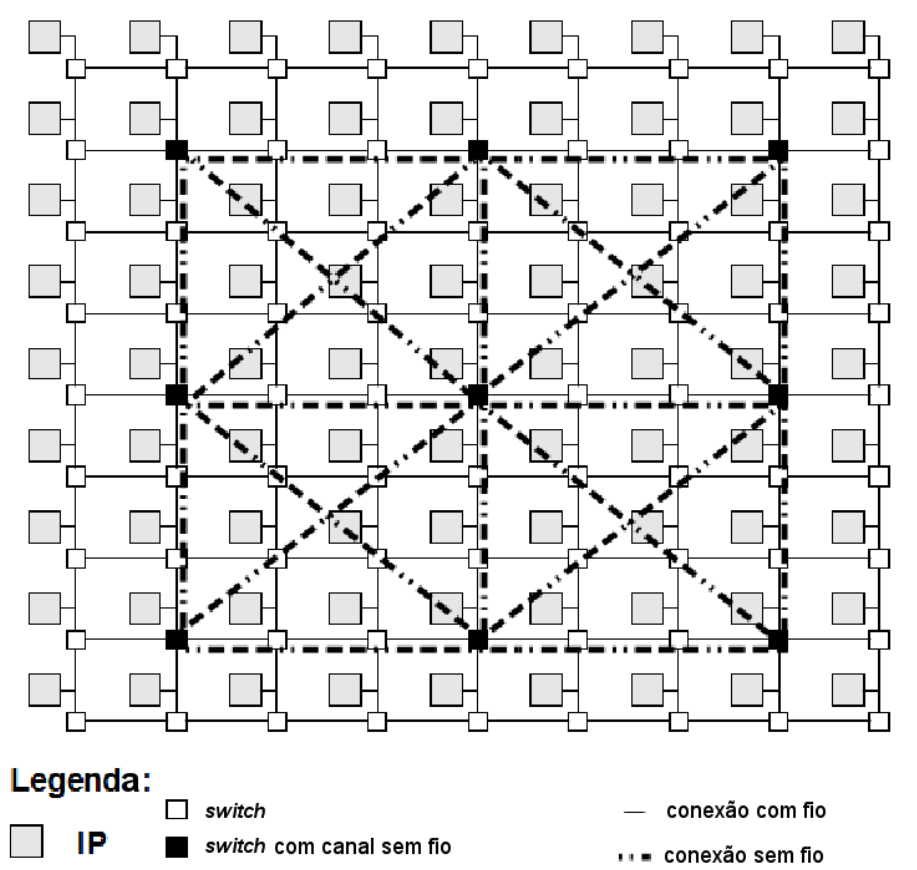

Adaptado de: Ferreira e Margi (2013)

Na plataforma de simulação, a decisão acerca do acesso aos canais sem fio é baseada no número de saltos. Dado um fluxo de tráfego, se o canal sem fio apresentar uma alternativa com menos saltos que o roteamento tradicional pela rede com fio e, se houver a possibilidade de adicionar mais um fluxo de tráfego, o canal sem fio é utilizado. No caso de não ser possível a alocação no canal sem fio, o fluxo é administrado por meio do roteamento tradicional. A seção 4.1.4 apresenta maiores detalhes acerca de como os fluxos de tráfego são gerenciados na plataforma de simulação. Além das alternativas apresentadas como suporte para a decisão de utilizar ou não o canal sem fio apresentadas 
nesta seção, há também a proposta de uma outra abordagem na seção 5.2 na qual se discute detalhadamente acerca do uso dos protocolos da seção 3.4 aplicados às WiNoCs.

\subsection{Modelagem}

Esta seção engloba os aspectos envolvidos na modelagem de uma WiNoC usando o ns-2 como base de simulação. Inicialmente descreve-se o funcionamento geral da simulação, seguido de aspectos importantes a respeito da convergência entre a simulação com fio e as simulações sem fio do ns-2, e finaliza-se com a especificação dos parâmetros e métricas envolvidas na simulação.

\subsubsection{Fluxo principal da plataforma de simulação}

O fluxo principal de simulação consiste primeiramente na simulação da arquitetura dos switches da NoC a fim de obter os dados temporais de execução médios dos switches com canal sem fio e dos que não o possuem. Estes valores obtidos podem ser integrados ao ns-2 por meio do parâmetro link delay disponível no simulador. A fim de efetuar este maior nível de detalhamento da arquitetura do switch a ferramenta Gem5 (BINKERT et al., 2011) pode ser utilizada, conforme será analisado na seção 4.2. No diagrama de fluxo de dados da Figura 23 este processo é ilustrado pelo bloco 1.

Os parâmetros temporais relacionados à arquitetura do switch (bloco 2 da Figura 23) são agregados aos parâmetros de simulação (seção 4.1.2) por meio de um arquivo XML de entrada (respectivamente blocos 3 e 4 da Figura 23). A partir deste conjunto de parâmetros, elabora-se um script tcl (Tool Command Language) para a simulação da topologia da Figura 22 composta apenas por conexões com fio em um intervalo de tempo $T$ no ns-2 (bloco 5). Após o término da simulação com fio executada no ns-2 (bloco 6), o arquivo de saída é analisado e amostrado (bloco 7) em intervalos de tempo $t<T$ gerando $T / t$ scripts de simulação da malha sem fio simulando os nós em negrito na Figura 22 (bloco 8). 
Figura 23: Fluxo principal de simulação.

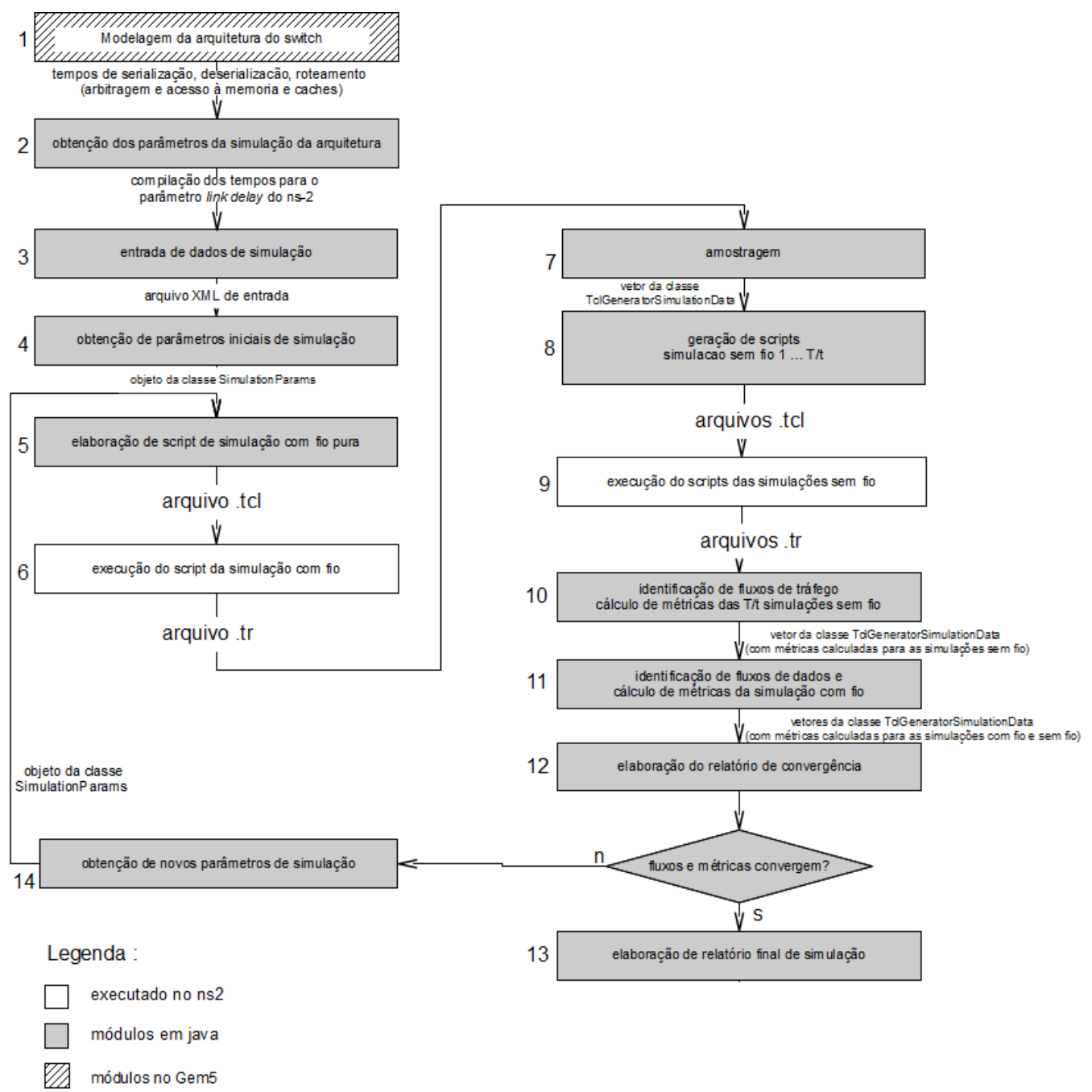

Após a execução do conjunto de scripts das simulações sem fio (bloco 9), os resultados de cada simulação da malha sem fio são analisados, conforme as abordagens de convergência da seção 4.1.4, e comparados com os resultados da simulação com fio (respectivamente blocos 10, 11 e 12). Se o grau de similaridade for satisfatório com os valores mínimos ajustados na entrada (seção 4.1.2) o algoritmo de convergência (seção 4.1.4) termina e a simulação está concluída (bloco 13). Caso contrário, calculam-se novos parâmetros de simulação, repetindo-se o processo a fim de buscar métricas convergentes entre a simulação com fio e as simulações sem fio (bloco 14 da Figura 23). A figura 24 ilustra um exemplo de configuração de topologia gerado pelos scripts das simulações com fio e sem fio. 
Figura 24: Exemplo de topologia com fio e sua topologia sem fio equivalente. Trata-se de uma configuração de fluxos de tráfego detectada em um intervalo de amostragem $t$ na simulação com fio (a) a qual será reproduzida em uma simulação sem fio em (b). Os nós na cor preta são os emissores e receptores envolvidos na comunicação durante este intervalo de tempo $t$.

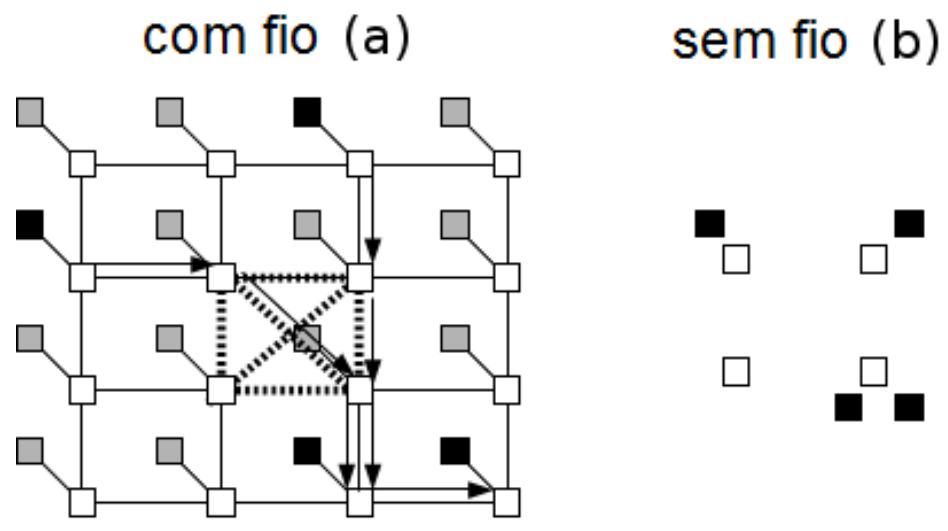

\subsubsection{Parâmetros}

Os parâmetros utilizados na plataforma de simulação (seção 4.1.2) foram dimensionados de tal forma a simular aspectos dos cenários de tráfego na NoC. O throughput das IPs é modelado por meio da aplicação CBR (Constant Bit Rate) disponível no simulador ns-2. É importante ressaltar que outros parâmetros como a modelagem das antenas e os parâmetros relativos ao acesso ao meio também podem ser modificados. Tais mudanças podem ser configuradas pelo usuário nas classes de geração dos scripts TCL do ns-2. Os parâmetros do arquivo XML de entrada do simulador incluem:

- número de switches por clusters;

- número de clusters;

- tamanho do pacote;

- intervalo de amostragem $t$ para a simulação sem fio;

- throughput da aplicação;

- largura da banda da simulação com fio;

- atraso para a camada de enlace; 
- tamanho da fila para a simulação com fio;

- tamanho da fila do switch da simulação sem fio;

- erro relativo máximo para a taxa de entrega e para o atraso médio;

- tempo de simulação $T$;

- coeficiente de tráfego interno (tráfego dentro de um cluster);

- coeficiente de tráfego externo (tráfego entre clusters);

- número de saltos predominante para o tráfego interno;

- número de saltos predominante para o tráfego externo;

- abordagem de convergência.

É importante ressaltar que, por meio dos parâmetros que especificam o número desejável de saltos, é possível simular diferentes perfis de tráfego com origens e destinos mais próximos ou mais distantes. Tais fluxos de tráfego são escolhidos aleatoriamente no início da simulação. $O$ uso da palavra predominante justifica-se pelo fato que, dependendo do tamanho da topologia e da quantia de fluxos de tráfego, não há como garantir que todos os fluxos tenham exatamente o número de saltos passado como parâmetro. $\mathrm{O}$ simulador, no caso de não encontrar alternativas de fluxos de tráfego de acordo com o passado como parâmetro, decrementa no número de saltos até que as porcentagens de tráfego interno e externos sejam satisfeitas.

O conceito de tráfego interno é definido como o número de nós fontes e destinos os quais são empregados no tráfego de pacotes dentro de um cluster. O tráfego externo é definido como o número de nós fontes e destinos os quais são empregados entre clusters. A figura 25 ilustra os dois conceitos.

Para a modelagem do canal sem fio foi utilizada o padrão IEEE 802.11 (IEEE, 1997), que inclusive possui um estudo de caso de seu emprego no contexto de WiNoCs (YOON; PARK, 2005). Dessa forma, a taxa máxima de transferência do canal sem fio é de $54 \mathrm{Mbps}$. A posição dos nós sem fio é ajustada de acordo com os padrões de comunicação desejados. Nos experimentos da seção 5.1, por exemplo, a topologia é ajustada para que a comunicação seja possível de acordo com a topologia da Figura 22. 
Figura 25: llustração dos conceitos de nós em tráfego interno e externo: há dois pares de nós do cluster no canto superior esquerdo envolvidos em tráfego interno ao passo que há um par de nós no cluster superior esquerdo envolvido na comunicação com outros clusters.
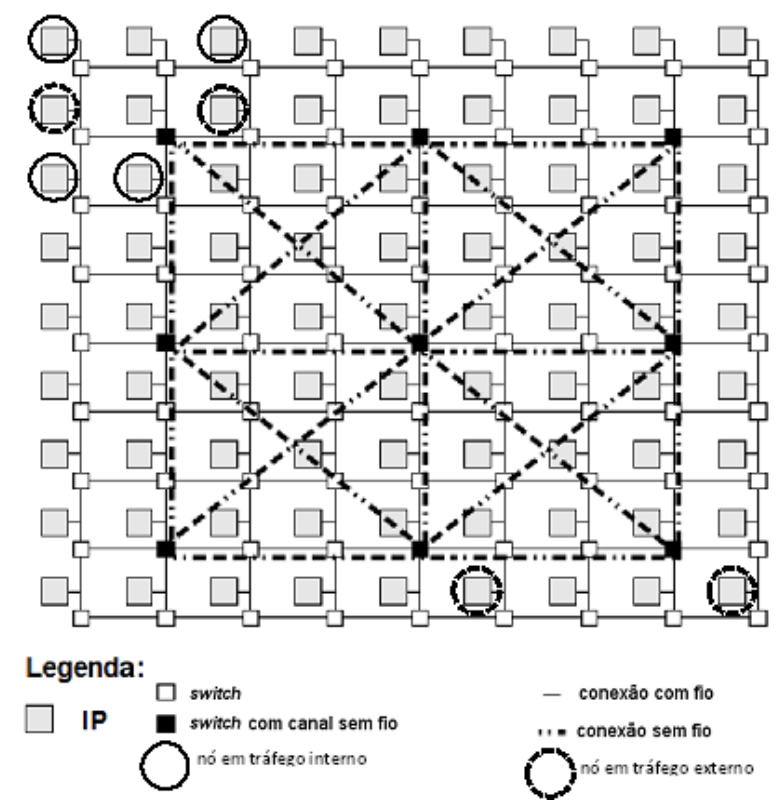

O apêndice $C$ ilustra um exemplo de como os parâmetros de entrada da ferramenta são ajustados. Nota-se que é possível inserir mais de um perfil de simulação, o que facilita a execução em série de diferentes tipos de experimentos.

\subsubsection{Métricas}

As métricas utilizadas na avaliação de convergência de simulação são:

- fluxos de tráfego: origem e destino na malha da simulação sem fio;

- throughput: número de pacotes transmitidos no intervalo de tempo $t$ para cada fluxo sem fio;

- taxa de entrega: quantidade de pacotes efetivamente recebidos dividida pela quantidade de pacotes enviados;

- atraso médio: intervalo de tempo médio de percurso da origem até ao destino dos pacotes. 
O cálculo do throughput e do atraso médio dos fluxos de tráfego utilizados no fluxo principal ferramenta de simulação descrito na seção 4.1.1 é efetuado conforme especificado na seção 2.4.

\subsubsection{Algoritmo de convergência}

Esta seção detalha os aspectos relacionados ao algoritmo de convergência utilizado no processo de simulação descrito na seção 4.1.1. $O$ aspecto mais relevante acerca da convergência é que se trata de uma abordagem iterativa baseada na detecção dos fluxos de tráfego tanto na simulação de nós com fio quanto nas simulações com os nós sem fio, conforme ilustrado na Figura 23.

Os fluxos de tráfego da simulação com fio entre clusters são detectados a partir dos arquivos de trace do ns-2. Tais fluxos são amostrados e especificados em simulações sem fio com o mesmo throughput de aplicação medidos em cada intervalo de amostragem da simulação com fio. As métricas empregadas na análise das simulações com o objetivo de verificar convergência são as especificadas na seção 4.1.3.

$O$ apêndice $D$ ilustra parte do algoritmo de convergência. A plataforma de simulação utiliza o erro médio entre a simulação com fio e as simulações sem fio amostradas para verificar o quão similares são (linhas 167 a 219). O processo iterativo pára no momento em que a convergência é conseguida, ou seja, quando os mesmos fluxos de tráfego transportam pacotes com taxa de entrega e atraso médio com erros relativos abaixo dos valores dados nos parâmetros de simulação (linhas 211 a 218). No simulador, a valor da taxa de entrega é ajustado como sendo 1.0, o que significa taxa nula de perda de pacotes. No caso da convergência não ser conseguida, o simulador modifica alguns parâmetros de acordo com os resultados obtidos na última análise de convergência e inicia um novo processo de simulação e amostragem (linhas 259 a 469) . O simulador utiliza duas abordagens de conjuntos de parâmetros a serem modificados em cada iteração a fim de realizar a abordagem de convergência, apresentados a seguir:

- throughput da aplicação CBR e tamanho da banda da simulação com fio 
(linhas 259 a 320) - este caso é utilizado a fim de conhecer o tamanho de banda da simulação sem fio ideal para um determinado conjunto de experimentos. A banda da simulação com fio depende do número total de nós da topologia e do throughput da aplicação. O simulador analisa a taxa de entrega e os dados de atraso médio e, com estes resultados, modifica respectivamente o throughput da aplicação CBR e o comprimento da banda com fio a fim de se obter uma solução convergente.

- throughput da aplicação CBR e atraso da camada de enlace (linhas 322 a 392) - este caso é empregado após a descoberta de uma banda com fio própria para um dado conjunto de perfis de simulação. O processo de análise é similar ao da abordagem anterior na qual o throughput da aplicação (usando a análise de resultados da taxa de entrega) e o atraso da camada de enlace (usando os dados de atraso médio) são modificados a fim de se obter uma solução convergente.

O algoritmo 1 descreve de maneira generalizada o procedimento de convergência empregado na plataforma de simulação. Os máximos aceitáveis para os erros relativos são ajustados nos parâmetros de entrada conforme especificado na seção 4.1.2.

\subsection{Desenvolvimento}

O sistema implementado pode ser resumido a partir do diagrama de componentes da Figura 26.

O subsistema de entrada consiste nas estruturas necessárias para interpretação dos parâmetros de entrada (seção 4.1.2). O framework engloba as funcionalidades necessárias para a integração com o simulador ns-2, bem como os componentes que elaboram os scripts de simulação. Além disso, no framework estão incluídas as estruturas necessárias para a identificação dos fluxos de tráfego e de cálculo das métricas especificadas na seção 4.1.3. O sistema de controle é composto pelos componentes de amostragem e de verificação de convergência. $O$ componente de amostragem é responsável por dividir a simulação com fio pura em intervalos de tempo $t$ menores que $T$, e 


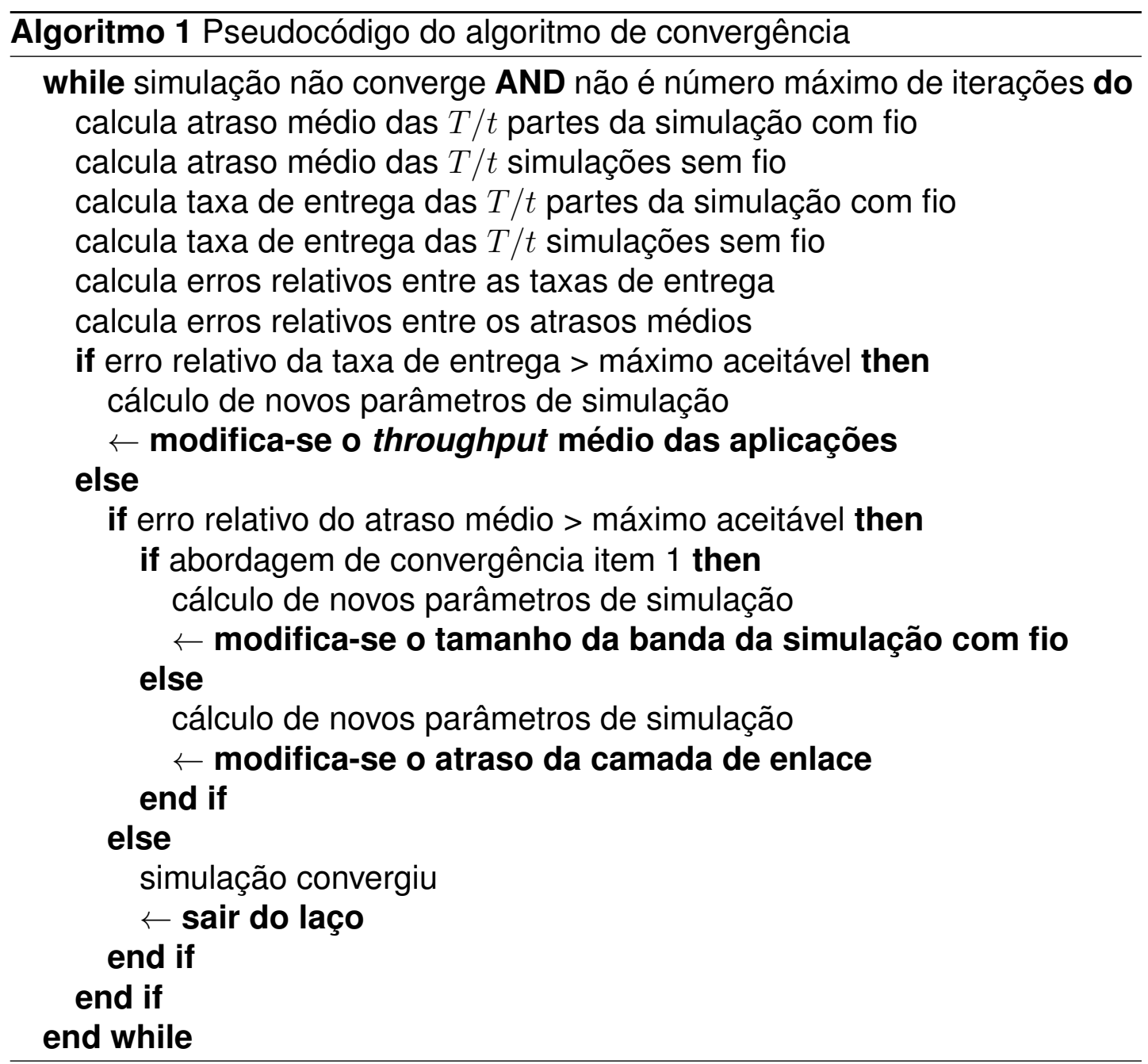

também por elaborar os scripts de simulação sem fio para o tráfego extra cluster em cada intervalo de tempo $t$. O módulo de convergência verifica se os resultados das métricas originadas pela simulação com fio pura são compatíveis com os das simulações sem fio. Finalmente o módulo de saída engloba a elaboração do relatório final de simulação. Além disso, também há as estruturas necessárias para a identificação dos fluxos de tráfego e cálculos de métricas conforme especificado na seção 4.1.4.

Como um passo final o subsistema de detalhamento do hardware é usado para o refinamento do simulador, reunindo dados relativos à dinâmica temporal da arquitetura do switch direcionada ao silício. Entre os os dados temporais destaca-se o tempo tomado para a transmissão de pacotes no caso do switch necessitar mudá-los de eixo (por exemplo: entrada pela porta leste e saída pela porta norte) ou simplesmente encaminhá-los ao próximo canal de transmissão. Há também o cálculo do ciclo de execução no caso em que o switch 
Figura 26: Diagrama de componentes do simulador de redes em chip sem fio destacado-se os cinco principais subsistemas.

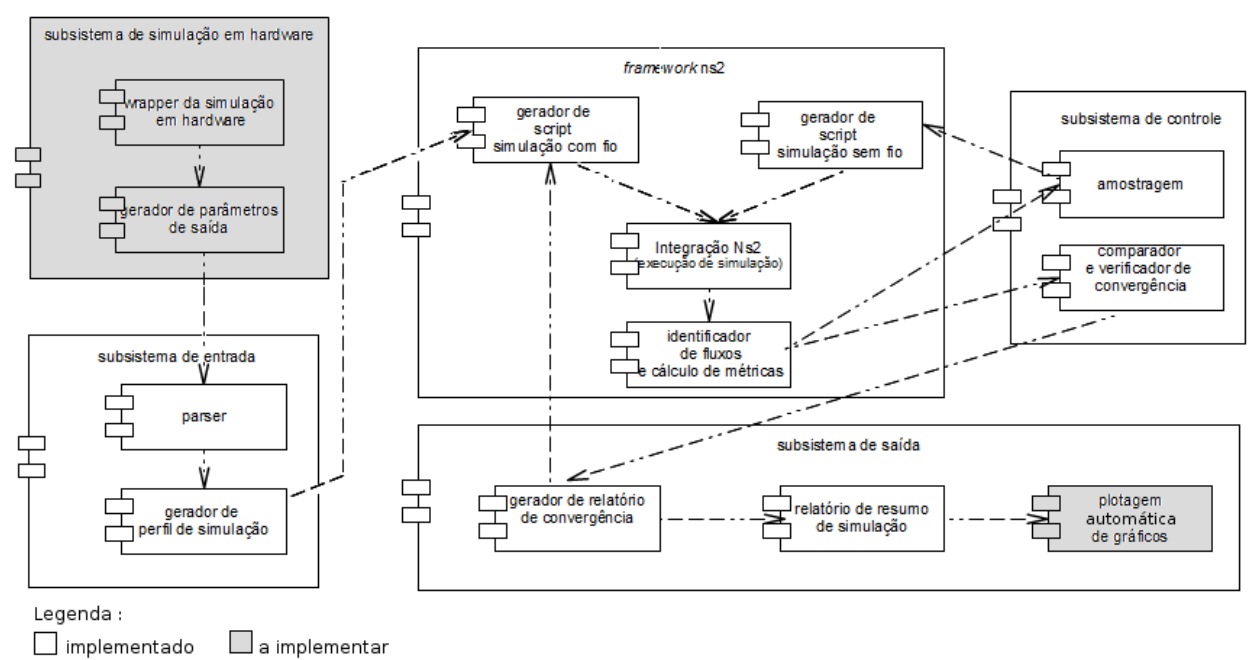

Adaptado de: Ferreira e Margi (2013)

encaminha os pacotes para o canal sem fio. A fim de realizar esta modelagem, ferramentas de modelagem arquiteturas de sistemas computacionais como o Gem5 (BINKERT et al., 2011) podem ser utilizadas. É possível modelar a arquitetura dos switches usando os modelos de CPU do Gem5 e agregar tempos associados ao roteamento e de acesso à memória, aos caches, às latências de serialização e transmissão (conforme descrito na seção 2.4) e, com isso, aferir sua influência no desempenho geral do switch e na simulação da dinâmica dos nós em rede. O trecho de código 4.1 (SAIDI; HANSSON, 2012) ilustra como instanciar e configurar componentes no Gem5 permitindo um ambiente no qual é possível modelar e conectar componentes chaves de uma plataforma em hardware.

Trecho de Código 4.1: exemplo de configuração de modelo de CPU do Gem5.

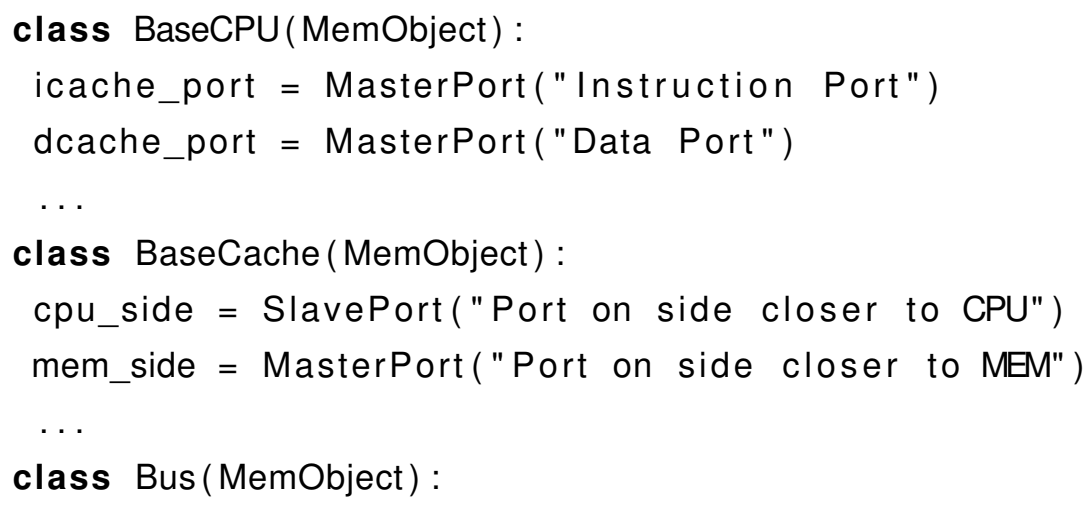




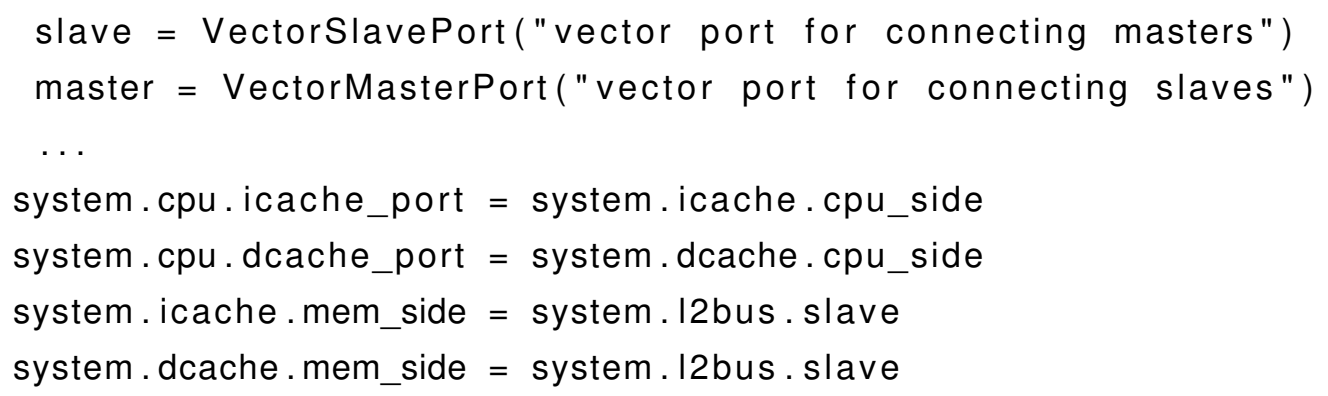

Associando-se o simulador Gem5 a traces de debugging conforme ilustrado na figura 27 é possível obter um arquivo de saída com os valores temporais do sistema configurado em hardware. Estes valores podem ser agregados à plataforma de simulação por meio do parâmetro link delay do ns-2. A integração com a plataforma de simulação é feita por meio do subsistema de entrada conforme ilustrado na Figura 26.

Figura 27: Exemplo de trace de um modelo de CPU no Gem5.

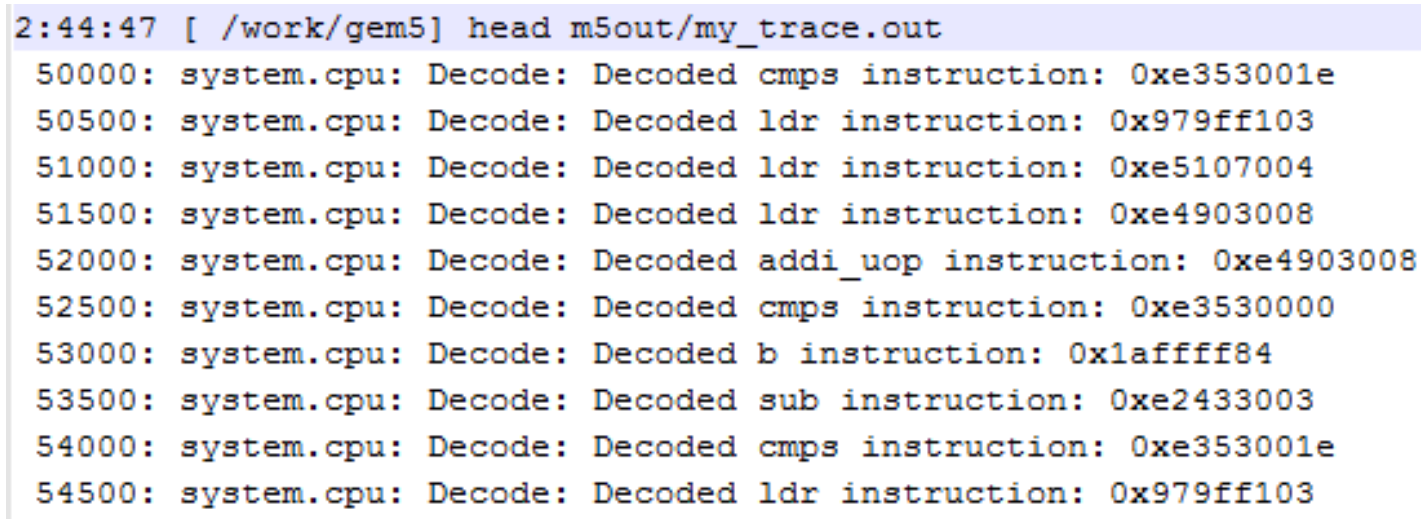

Fonte: Saidi e Hansson (2012)

A análise de consumo energético pode ser realizada por meio do emprego do simulador Orion (WANG et al., 2002) empregando um framework parecido com o utilizado para integrar o ns-2. Por meio do Orion é possível utilizar um conjunto de modelos energéticos que foram desenvolvidos para diversos componentes de redes em chip. Por meio destes modelos é possível estimar o consumo energético da arquitetura do switch. A figura 28 ilustra alguns dos componentes com os quais é possível modelar um switch no Orion.

A primeira versão do Orion data de 2002 e era constituída de uma arquitetura padrão a partir de modelos da estrutura dos circuitos de cada componente do switch (seção 2.2). Em 2009 foi lançada a segunda versão a qual adicionou novos modelos de consumo energético para flip-flops e para os canais. 
Figura 28: Componentes (crossbar, arbitragem e buffers de entrada e saída) da arquitetura do switch modelado no Orion.

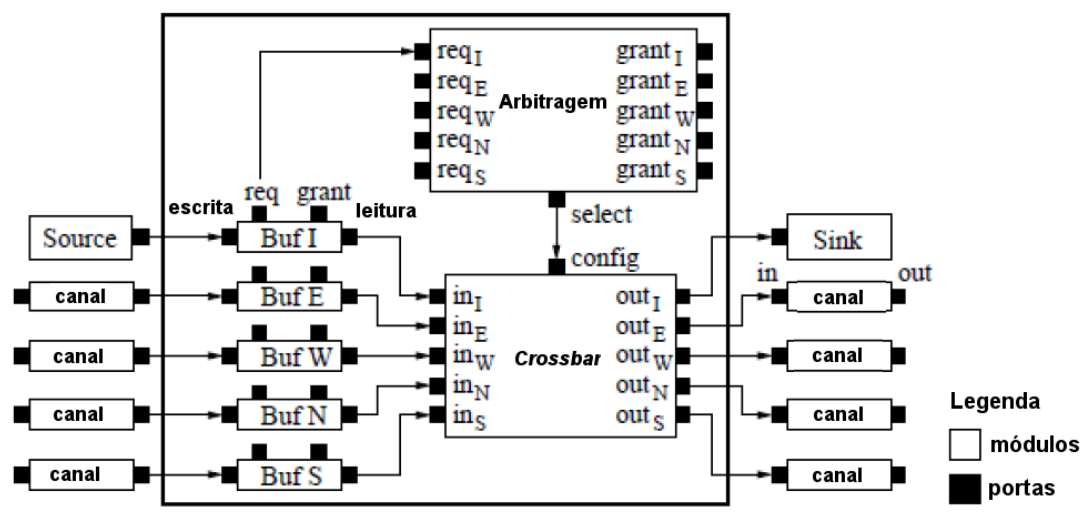

Adaptado de: Wang et al. (2002)

Finalmente a terceira versão do Orion engloba mecanismos de refinamento do consumo energético tomados a partir de layouts de Place and Routing dos circuitos de cada componente os quais podem ser parametrizados com o objetivo de se aproximar o máximo possível de uma biblioteca específica de componentes em hardware na qual o chip será posteriormente projetado. É importante ressaltar que Orion também suporta modelagem não paramétrica conforme descrito por Kahng, Lin e Samadi (2010).

A arquitetura do switch sem fio pode ser especificada por meio dos arquivos de cabeçalho do Orion obtendo a contribuição energética de cada um das estruturas do switch, conforme descrito na seção 2.3. O canal sem fio, por exemplo, pode ser modelado por meio de um buffer central e a especificação da arquitetura de um novo crossbar. O consumo energético total da rede pode ser estimado por meio de experimentos com topologias conforme também especificado por Wang et al. (2002). Para isto deve ser implementado um módulo no Orion baseado no design pattern do tipo factory com o objetivo de decodificar entre os diferentes modelos de topologias.

\subsection{Sinopse}

A tabela 8 seção resume as principais características da plataforma de simulação descrita neste capítulo. 
Tabela 8: Plataforma de simulação - principais aspectos

\begin{tabular}{|c|c|}
\hline Aspecto & Descrição \\
\hline fluxo principal & $\begin{array}{l}\text { uso do ns-2 pela ferramenta de simulação por meio de um } \\
\text { algoritmo de convergência de uma simulação com fio e } \\
\text { um conjunto de simulações sem fio. }\end{array}$ \\
\hline parâmetros & $\begin{array}{c}\text { entrada de parâmetros feita por meio de um arquivo } \\
\text { XML no qual se pode especificar aspectos relacionados } \\
\text { ao tamanho da topologia, perfis de tráfego e aspectos } \\
\text { relativos à arquitetura do switch. }\end{array}$ \\
\hline métricas & $\begin{array}{l}\text { fluxos de tráfego, throughput, taxa de entrega } \\
\text { e atraso médio. }\end{array}$ \\
\hline $\begin{array}{l}\text { algoritmo de } \\
\text { convergência }\end{array}$ & $\begin{array}{l}\text { Iterativo, possuindo duas abordagens configuráveis. Consiste } \\
\text { em transmitir a mesma quantidade de pacotes das mesmas } \\
\text { fontes e destinos nos mesmos intervalos de tempo. }\end{array}$ \\
\hline
\end{tabular}




\section{EXPERIMENTOS E ANÁLISE DE RESULTADOS}

Este capítulo apresenta os experimentos realizados, descrevendo os cenários e resultados obtidos com a plataforma de simulação especificada no capítulo 4. Avaliou-se o desempenho dos protocolos ad hoc de roteamento sem fio na seção 5.1 em diferentes cenários de tráfego interno e externo bem como em termos de número de saltos entre os emissores e receptores de dados. Além disso, na seção 5.2, há uma análise de como implementar os protocolos estudados neste trabalho em hardware, visando o uso em WiNoCs.

\subsection{Desempenho de protocolos}

Os experimentos envolvendo a análise de desempenho de protocolos foram feitos utilizando a topologia da Figura 22 descrita no capítulo 4 . Foram feitos dois experimentos principais: um para avaliar o desempenho dos protocolos em diferentes configurações de fluxos de tráfego e o segundo para avaliar a influência do número total de nós no desempenho geral da NoC. Para a escolha da largura de banda da simulação com fio foi executado um conjunto de dez simulações (abrangendo perfis de topologia e tráfego dos experimentos principais), adotando-se a abordagem de convergência a qual modifica em cada iteração o throughput da aplicação CBR e tamanho da banda da simulação com fio (seção 4.1.4). Dessa forma foi possível obter uma largura de banda compatível com a topologia simulada, cujo valor foi de 0.25MB. A partir disso, utilizou-se a abordagem de convergência que modifica em cada iteração o throughput da aplicação CBR e atraso da camada de enlace para os experimentos principais (seção 4.1.4). 


\subsubsection{Perfis de tráfego interno e externos}

No primeiro experimento os protocolos DSR, DSDV e AODV (seção 3.4) foram utilizados em uma topologia hierárquica composta por 9 clusters com 16 nós em cada um deles. No experimento, os perfis aleatórios de tráfego interno (dentro de um cluster) e externo (entre clusters) são variados ${ }^{1}$. Duas métricas foram avaliadas: o throughput e o atraso médio (seção 4.1.3). O número de nós intermediários foi ajustado para ser o maior possível. Em outras palavras, os emissores e receptores foram ajustados de tal forma a ficarem o mais longe possível. O tamanho de pacote adotado foi de 512 bytes transmitidos em um ritmo constante utilizando uma abordagem UDP. A distância entres os nós dotados de canal sem fio é ajustada de forma a estabelecer os padrões de comunicação na Figura 22. Para o acesso ao meio utilizou-se a especificação IEEE 802.11. Os nós com fio possuem uma fila de 2 nós e cada nó sem fio tem uma fila de 64 pacotes.

A Figura 29-a resume os resultados das simulação para protocolos de roteamento. Os resultados mostram que o throughput dos fluxos do canal sem fio é muito sensível ao tráfego externo sobre os canais sem fio e o desempenho da rede é significativamente afetado em cenários de alto tráfego externo, conforme esperado. Isso acontece porque o tempo de resposta do protocolo de roteamento sem fio é maior do que o roteamento fixo empregado no mecanismo com fio. Os resultados também mostram que protocolos reativos são mais indicados para cenários com baixo tráfego externo nos quais há poucos fluxos, dessa forma, sendo mais fáceis de ser gerenciados usando estratégias de roteamento sob demanda. O protocolo DSDV, o qual usa uma estratégia de roteamento ativa com envio periódico de mensagens contendo dados para as tabelas dos nós, demonstra um desempenho mais estável em todos os

\footnotetext{
${ }^{1}$ Para se obter o número de nós em tráfego interno e externo a partir de suas respectivas porcentagens, basta multiplicar a porcentagem pelo número total de nós em um cluster. Após a multiplicação, aplicar a função piso. Divide-se o resultado da operação anterior por dois e aplica-se a função piso novamente. O resultado indica a quantidade de pares de nós engajados em tráfego interno ou externo. No cenário de tráfego interno de $10 \%$ e $80 \%$, por exemplo, o número de pares de nós em tráfego interno é dado por $0.1^{*} 16=1.6$. O menor inteiro mais próximo de 1.6 é 1.0. Dividindo-se 1.0 por 2, obtém-se 0.5 . Dessa forma não há pares de nós em tráfego interno, pois $\lfloor 0.5\rfloor=0$. Semelhantemente $80 \%$ de tráfego externo equivale dizer que há $\left\lfloor\frac{\lfloor 0.8 * 16\rfloor}{2}\right\rfloor=6$ pares de nós envolvidos em tráfego externo (seis nós fontes e seis nós destinos). Os nós centrais com canal sem fio em um cluster não estão configurados para serem emissores ou receptores de um determinado fluxo de tráfego, logo não é possível empregar $100 \%$ dos nós nos experimentos.
} 
Figura 29: Resultados das métricas para os três procolos simulados em diferentes perfis de fluxos de tráfego usando uma topologia de 16 nós $\times 9$ clusters

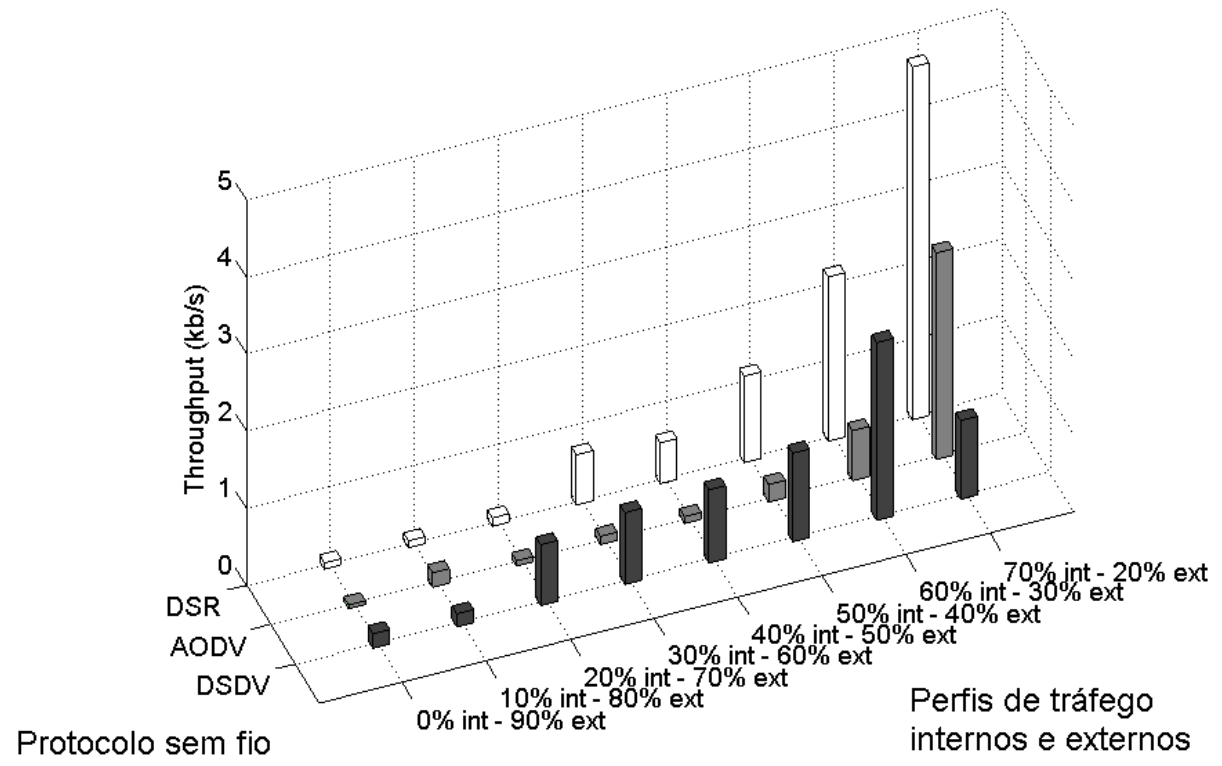

(a) throughput médio nos canais sem fio $x$ perfis de tráfego dentro dos clusters (interno) e entre clusters (externo) para cada protocolo sem fio

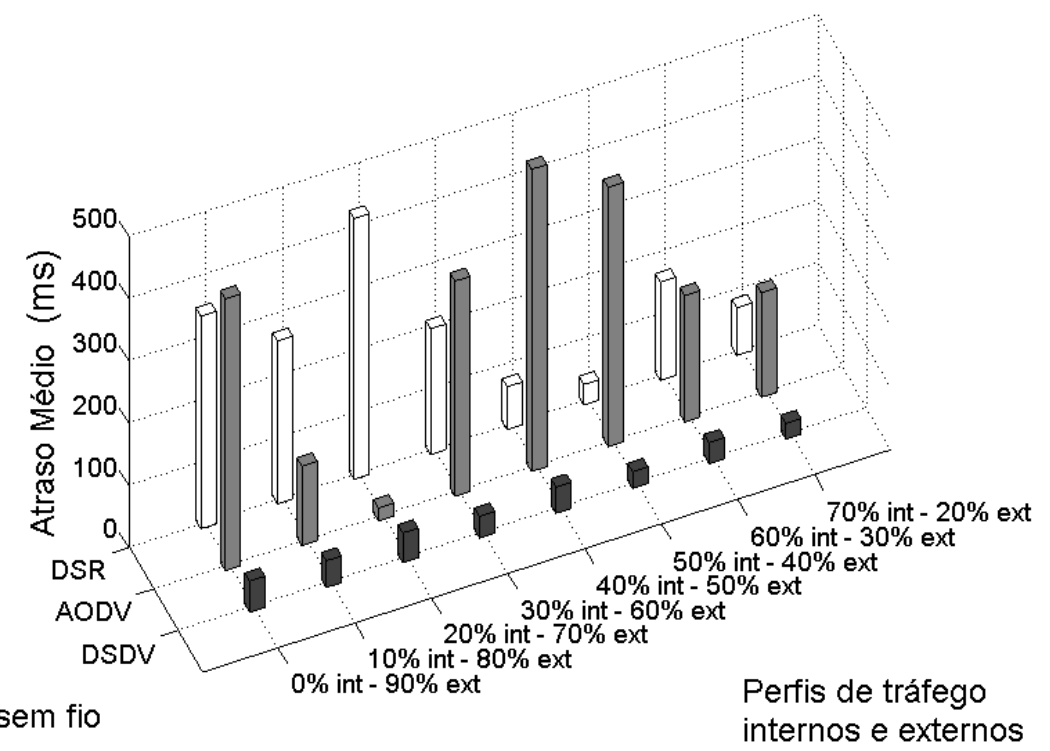

Protocolo sem fio internos e externos

(b) atraso médio nos canais sem fio $\mathrm{x}$ perfis de tráfego dentro dos clusters (interno) e entre clusters (externo) para cada protocolo sem fio 
cenários de tráfego, apesar de inferior ao dos outros dois protocolos. Os resultados também apontam que o desempenho da rede é sensivelmente inferior para cenários com mais de $60 \%$ de fluxos externos, isto é, os canais sem fio conseguem gerenciar com melhor eficácia até oito fluxos externos para cada cluster em uma topologia de 16 nós $\times 9$ clusters $^{2}$.

A Figura 29-b resume o atraso médio para diferentes configurações de fluxos de tráfego interno e externo. O protocolo DSR demonstra que seu atraso médio é maior quando há maior tráfego externo, conforme esperado. Em cenários de tráfego externo elevado, as mensagens de controle de rota do protocolo DSR levam mais tempo para chegar aos seus destinos, afetando o desempenho geral dos fluxos. O AODV leva mais tempo para entregar os pacotes em cenários de elevado tráfego externo, como também em cenários de balanceados de tráfego externo e interno. A inflexão no protocolo AODV acontece por conta do protocolo ser mais sensível às mudanças nos fluxos de tráfego. Nos cenários de tráfego externo maior que $80 \%$, o nó dotado de canal sem fio atua como gargalo, chaveando os fluxos de tráfego para fora do canal sem fio, o que aumenta o atraso médio. No cenário "20\% int - $70 \%$ ext", não há este chaveamento frequente, diminuindo o atraso médio. Por outro lado, à medida que os fluxos de tráfego interno e externam se aproximam de uma configuração balanceada, há uma quantidade maior de fluxos de tráfego dentro do cluster, aumentando o overhead de gerenciamento. À medida que os fluxos de tráfego externo diminuem, os canais sem fio ficam menos ocupados e mais estáveis, ocasionando uma nova baixa no atraso médio. O protocolo DSDV exibe constância no atraso médio em todos os cenários de tráfego demonstrando que protocolos de roteamento ativos possuem desempenho estável em topologias hierárquicas de WiNoCs.

\subsubsection{Tamanho da rede e número de saltos}

Para o experimento de tamanho da rede foram simulados diferentes configurações de topologias com perfis de tráfego internos e externos balanceados,

\footnotetext{
${ }^{2} 60 \%$ de 16 nós engajados em tráfego externo é igual a $\left\lfloor\frac{\lfloor 0.6 * 16\rfloor}{2}\right\rfloor=4$. Dessa forma, dentro de um cluster, há quatro nós fontes e quatro nós destinos comunicando-se com outros clusters, totalizando um total de oito nós envolvidos em tráfego externo por cluster para a topologia simulada.
} 
isto é, $50 \%$ do total de nós que podem receber fluxos de tráfego em um emphcluster engajados em tráfego interno e 50\% engajados em tráfego externo. $\mathrm{O}$ perfil de número de saltos é analisado por meio da variação do número desejável de saltos para os fluxos internos e externos, conforme especificado na seção 4.1.2. Há três cenários de comunicação entre nós: clusters e comunicação interna de nós adjacentes, clusters separados por dois saltos e comunicação interna de nós separados por dois saltos e número máximo de saltos dentro e fora dos clusters.

Figura 30: Resultados das métricas em diferentes configurações de clusters em cenários balanceados de tráfego interno e externo

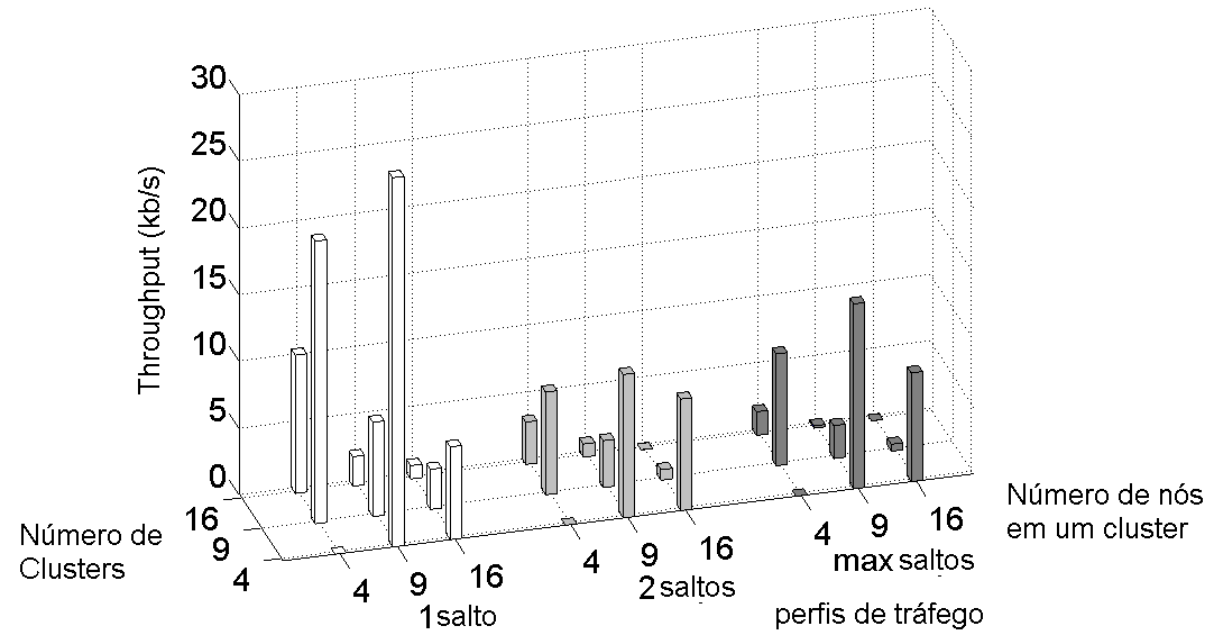

(a) throughput médio nos canais sem fio $\mathrm{x}$ tamanho da topologia em um cenário balanceado de tráfego dentro dos clusters (interno) e entre clusters (externo)

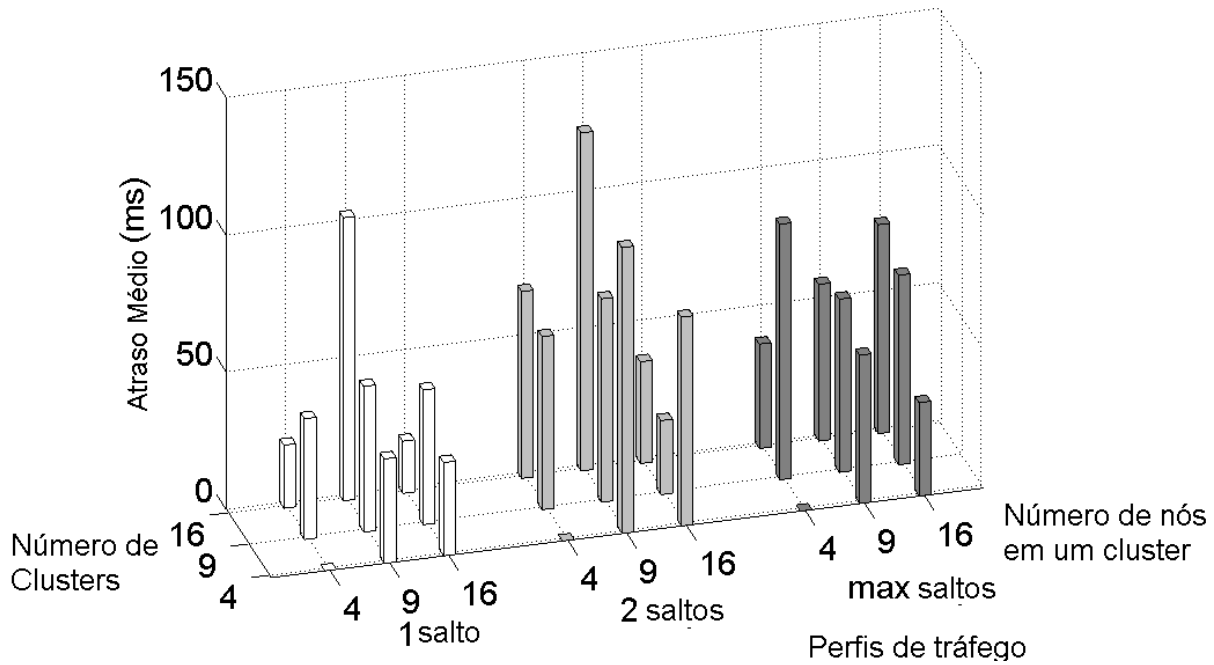

(b) Atraso médio dos fluxos de tráfego nos canais sem fio $x$ tamanho da topologia em um cenário balanceado de tráfego dentro dos clusters (interno) e entre clusters (externo) 
Os resultados exibidos na Figura 30 avaliam os efeitos do tamanho da rede em uma WiNoC com diferentes estratégias de roteamento. As topologias são simuladas usando o protocolo DSR por ser mais simples e de mais facilidade para implementação do roteamento dinâmico em chip. É importante ressaltar que a topologia $4 \times 4$ tem throughput zero porque é muito pequena para se beneficiar dos efeitos dos canais sem fio. Como o número de saltos é similar em canais com fio e sem fio, é conveniente utilizar somente o roteamento com fio. A Figura 30-a exibe não somente os efeitos do tamanho da topologia sobre os canais sem fio como também o impacto sobre a distância, em saltos, entre a fonte e o destino dos fluxos. Quando a comunicação é predominante entre clusters adjacentes (1-hop) o throughput médio sobre os canais sem fio é superior. As diferenças entre os perfis de tráfego com dois saltos e com o máximo número de saltos não são expressivas para topologias pequenas, contudo, é possível perceber que o throughput da aplicação é sensivelmente menor em topologias com mais de 81 nós por conta do aumento do número de requisições de acesso ao meio dos canais sem fio.

A Figura 30-b exibe os resultados do atraso médio para topologias e fluxos de tráfego distintos. Nota-se o efeito visível do número de saltos no desempenho geral do atraso do canal sem fio.

\subsection{Empregando protocolos ad hoc sem fio em WiNoCs}

Implementações em hardware de protocolos clássicos podem ser encontradas para o AODV (RAMAKRISHNAN; SHANMUGAVEL, 2006a) e para o DSDV (RAMAKRISHNAN; SHANMUGAVEL, 2006b). Contudo, os requisitos envolvendo o uso de tais protocolos para WiNoC são mais simples uma vez que os nós não se movimentam, o que simplifica sua concepção e complexidade. $O$ acesso ao canal sem fio é primeiramente decidido por meio da análise se as posições de origem e destino são maiores que a aresta de um cluster. Em segundo lugar, um pacote é aceito no canal sem fio quando: o seu buffer não está cheio o suficiente para admitir outro fluxo de tráfego e há uma rota para o cluster de destino. Esta decisão é feita por meio da consulta de uma tabela principal na qual há todos os nós inativos e ocupados. No momento em 
que os nós tornam-se gargalos devido ao excessivo tráfego entre os clusters ou quando uma rota para o cluster de destino não está disponível, o tráfego flui apenas pelos canais com fio. Além disso esta tabela principal é usada para ligar os nós baseado em um número mínimo de nós ativos com o objetivo de evitar que todos os nós sem fio sejam desligados com o decorrer do tempo.

Com uma abordagem similar à adotada por Zhao e Wang (2008) para desenvolver um protocolo de acesso ao meio, é possível estabelecer duas fases principais para o funcionamento dos protocolos: recalculo de rota e transferência de dados. O recalculo de rota é ativado quando qualquer nó sem fio é ligado ou quando um buffer sem fio está ocupado, o que significa que o nó em questão não é capaz de admitir mais fluxos de tráfego. O deadlock pode ser evitado por meio de uma ordenação de buffers simples conforme explicado por Zhao e Wu (2012).

A transferência periódica de tabelas no DSDV poderia ser desativada. Para a sua aplicação em WiNoC, a atualização das tabelas de roteamento é somente necessária na fase de recalculo de rota, seguida por atualizações parciais quando os nós são desligados ou ligados. O uso do protocolo DSR em WiNoC necessita somente de um mecanismo de descoberta de rotas a ser realizado durante o recalculo de rotas. As mensagens RREP retornarão a rota para o nó emissor a qual será armazenada em tabelas de cache de rotas, ativando a comunicação subsequente.

Similarmente para o emprego do protocolo AODV em WiNoC somente há a necessidade das mensagens RREQ e RREP, pois os nós são estacionários no chip. As tabelas de roteamento do AODV necessitam ser atualizadas somente durante a fase de recalculo de rota, sendo que as rotas serão utilizadas até a ocorrência de um novo evento que ative o recalculo de rota.

\subsection{Sinopse}

Esta seção resume os aspectos principais discutidos neste capítulo.

A Tabela 9 sintetiza os pontos principais acerca da análise de resultados.

A Tabela 10 sintetiza os pontos principais discutidos para o emprego de 
Tabela 9: Análise de resultados - pontos principais

\begin{tabular}{|c|c|}
\hline Aspecto & Análise \\
\hline $\begin{array}{l}\text { protocolos } \\
\text { de roteamento } \\
\text { reativo } \\
(\mathrm{DSR} \text { e AODV) }\end{array}$ & $\begin{array}{c}\text { são mais indicados em cenários com baixo } \\
\text { tráfego entre clusters. Desempenho do AODV } \\
\text { revelou-se sensível à frequência das mudanças } \\
\text { dos fluxos de tráfego }\end{array}$ \\
\hline $\begin{array}{l}\text { protocolo } \\
\text { de roteamento } \\
\text { ativo } \\
\text { (DSDV) }\end{array}$ & $\begin{array}{l}\text { demonstrou desempenho inferior, contudo estável, } \\
\text { para os diferentes perfis de tráfego simulados }\end{array}$ \\
\hline canais sem fio & $\begin{array}{l}\text { desempenho é menor quando o tráfego externo } \\
\text { supera } 60 \% \text { do total de nós do cluster }\end{array}$ \\
\hline tamanho da rede & $\begin{array}{l}\text { redes com mais de } 81 \text { nós possuem } \\
\text { throughput sensivelmente menor por conta } \\
\text { do elevado número de requisições de acesso ao meio }\end{array}$ \\
\hline
\end{tabular}

protocolos ad hoc sem fio em WiNoCs.

Tabela 10: Emprego de protocolos ad hoc sem fio em WiNoCs - pontos principais

\begin{tabular}{cc}
\hline Aspecto & Descrição \\
\hline simplificações & $\begin{array}{c}\text { aspectos relativos à mobilidade característicos dos protocolos } \\
\text { devem ser ignorados em WiNoCs, pois os nós não se movem }\end{array}$ \\
$\begin{array}{c}\text { roteamento em } \\
\text { duas fases }\end{array}$ & recálculo de rota e transferência de dados \\
$\begin{array}{c}\text { tabela pricipal } \\
\text { de roteamento }\end{array}$ & $\begin{array}{c}\text { reúne informações acerca da atividade dos nós com canal } \\
\text { sem fio. Também é util para ajudar a manter um } \\
\text { número mínimo de nós com canal sem fio em atividade }\end{array}$ \\
\hline
\end{tabular}




\section{CONSIDERAÇÕES FINAIS}

Este trabalho forneceu um panorama geral acerca do paradigma das redes em chip sem fio (WiNoCs), abordando conceitos acerca da arquitetura dos switches, da modelagem e da simulação de NoCs e WiNoCs como também a respeito da disposição dos nós com canal sem fio na rede.

Além disso, foi possível elaborar cenários de simulação de WiNoCs utilizando protocolos ativos e reativos no ns-2, conforme proposto. Também foi possível abordar aspectos de simulação relativos ao acesso ao meio, ao tamanho da rede e ao roteamento em topologias hierárquicas de WiNoCs. As partir dos dados das simulações foi possível obter visão geral da dinâmica das redes em chip sem fio usando protocolos ad hoc de roteamento dinâmico.

Além das discussões acerca da topologia e do número de saltos relatadas no capítulo 5 , os resultados também demonstraram que os clusters de WiNoC com oito ou mais nós engajados em comunicação entre clusters (60\% ou mais de tráfego externo em um cluster de 16 nós) possuem seu desempenho geral significativamente degradados. Na figura 29 , percebe-se que em cenários cujo tráfego externo entre clusters excede $60 \%$, há queda no desempenho do DSR seguida pela queda do DSDV. O protocolo DSDV mostrou-se com um desempenho superior, comparado ao DSR e ao AODV, para o roteamento em redes em chip sem fio hierárquicas. Tal protocolo obteve desempenho estável em diferentes perfis de tráfego e tamanhos de topologias. Os pacotes do protocolo DSDV também demonstraram um menor atraso médio, se comparados com os pacotes dos protocolos DSR e AODV.

Em um contexto de uso de simuladores próprios e de aplicação específica em redes em chip sem fio, este trabalho abre as portas para uma plataforma flexível a qual permite a modelagem da dinâmica dos nós em rede a partir de um aparato consolidado e muito difundido na literatura. Associada a ferramen- 
tas de modelagem de arquiteturas em hardware (BINKERT et al., 2011) e de consumo energético (WANG et al., 2002) é possível realizar estudos com um aprofundado nível de detalhe abrangendo todos os aspectos não somente da dinâmica da rede como de aspectos individuais dos switches da rede.

\subsection{Publicações}

O artigo científico publicado com informações acerca desta pesquisa de mestrado foi:

- Ferreira, J. C.; Margi, Cíntia B.. Simulação de redes em chip sem fio. In: IV Escola Regional de Alto Desempenho de São Paulo (ERAD-SP 2013). São Carlos - SP: Sociedade Brasileira de Computação, 2013. p. 74-77;

Um segundo artigo encontra-se em elaboração para submissão para periódico, e destaca os resultados obtidos com a ferramenta proposta.

\subsection{Trabalhos futuros}

Os trabalhos futuros incluem uma comparação entre o simulador proposto no capítulo 4, cujo código-fonte pode ser baixado no link (FERREIRA, 2014), com diferentes propostas de WiNoC e abordagens de topologias (YOON; PARK, 2005; WU; WANG; ZHAO, 2010; ZHAO; WU, 2012), elaborando mais cenários para explorar futuros aspectos na simulação de WiNoC, Alguns exemplos de simulação são camadas sem-fio totalmente conectadas, topologias smallworld incompletas e a desativação de nós sem fio para economia de energia.

Há também a expansão do simulador para sua integração com ferramentas de análise de consumo energético, muito importantes para a avaliação de desempenho de uma NoC (seção 2.4). Com a ferramenta de simulação consolidada, abre-se a possibilidade de usar a plataforma de simulação para modelar e avaliar um mecanismo de roteamento baseado no protocolo DSDV do ns-2, o qual obteve o desempenho mais estável nos experimentos do capítulo 
5. Tal mecanismo, abordado seção 5.2, possui como principal objetivo de guiar implementações em hardware (FPGA) de switches dotados de roteamento dinâmico com o objetivo de poupar energia (seção 3.3) em um ambiente de co-simulação. 


\section{REFERÊNCIAS}

ADDISON, P. Fractals and Chaos: An illustrated course. Abingdon, Oxford, Reino Unido: Taylor \& Francis, 1997. ISBN 9780849384431.

ALBERT, R.; JEONG, H.; BARABÁSI, A.-L. Error and attack tolerance of complex networks. Nature, v. 406, n. 6794, p. 378-382, 2000.

BALIARDA, C. P.; ROMEU, J.; CARDAMA, A. The koch monopole: A small fractal antenna. Transactions on Antennas and Propagation, IEEE, Los Alamitos, CA, EUA, v. 48, n. 11, p. 1773-1781, 2000.

BENINI, L.; MICHELI, G. D. Networks on chips: A new soc paradigm. Computer, IEEE Computer Society Press, Los Alamitos, CA, EUA, v. 35, n. 1, p. 70-78, janeiro 2002.

BINKERT, N.; BECKMANN, B.; BLACK, G.; REINHARDT, S. K.; SAIDI, A.; BASU, A.; HESTNESS, J.; HOWER, D. R.; KRISHNA, T.; SARDASHTI, S.; SEN, R.; SEWELL, K.; SHOAIB, M.; VAISH, N.; HILL, M. D.; WOOD, D. A. The gem5 simulator. SIGARCH Computer Architecture News, ACM, Nova lorque, NY, EUA, v. 39, n. 2, p. 1-7, 2011.

BUECHLER, J.; KASPER, E.; RUSSER, P.; STROHM, K. M. Silicon highresistivity-substrate millimeter-wave technology. Transactions on Microwave Theory and Techniques, IEEE, Los Alamitos, CA, EUA, v. 34, n. 12, p. 1516-1521, 1986.

BURKE, P.; YU, Z.; RUTHERGLEN, C. Carbon nanotubes for rf and microwaves. In: Gallium Arsenide and Other Semiconductor Application Symposium. Los Alamitos, CA, EUA: IEEE, 2005. p. 1-4.

CHANG, K.; DEB, S.; GANGULY, A.; YU, X.; SAH, S. P.; PANDE, P. P.; BELZER, B.; HEO, D. Performance evaluation and design trade-offs for wireless network-on-chip architectures. Journal on Emerging Technologies in Computing Systems, ACM, Nova lorque, NY, EUA, p. 23:1-23:25, 2012.

CRAIK, C. J.; MUTLU, O. Investigating the Viability of Bufferless NoCs in Modern Chip Multi-processor Systems. Pittsburgh, EUA, 2011.

DALLY, W. Virtual-channel flow control. IEEE Transactions on Parallel and Distributed Systems, Los Alamitos, CA, EUA, v. 3, n. 2, p. $194-205,1992$.

DALLY, W. J. Express cubes: Improving the performance of k-ary n-cube interconnection networks. Transactions on Computers, IEEE, Los Alamitos, CA, EUA, v. 40, n. 9, p. 1016-1023, 1991. 
DEB, S.; GANGULY, A.; PANDE, P.; BELZER, B.; HEO, D. Wireless noc as interconnection backbone for multicore chips: Promises and challenges. Journal on Emerging and Selected Topics in Circuits and Systems, IEEE, v. 2, n. 2, p. 228-239, 2012.

ERBAS, C. System-level modeling and design space exploration for multiprocessor embedded System-on-Chip architectures. Tese (Doutorado) — Informatics Institute, Univ. of Amsterdam, Nov. 2006.

FALLIN, C.; CRAIK, C.; MUTLU, O. Chipper: A low-complexity bufferless deflection router. In: 17th International Conference on High-Performance Computer Architecture. Los Alamitos, CA, EUA: IEEE Computer Society, 2011. p. 144-155.

FALLIN, C.; NAZARIO, G.; YU, X.; CHANG, K.; AUSAVARUNGNIRUN, R.; MUTLU, O. Minbd: Minimally-buffered deflection routing for energy-efficient interconnect. In: Sixth International Symposium on Networks on Chip (NoCS). Los Alamitos, CA, EUA: IEEE/ACM, 2012. p. $1-10$.

FERREIRA, J. C. WiNoC simulator source code. juin 2014. Disponível em: <https://github.com/jefchavesfer/ns2-int>. Acesso em: 14 jun. 2014.

FERREIRA, J. C.; MARGI, C. B. Simulação de redes em chip sem fio. In: Escola Regional de Alto Desempenho de São Paulo. Porto Alegre, RS, Brasil: Sociedade Brasileira de Computação, 2013.

FLOYD, B. A CMOS Wireless Interconnect System for Multigigahertz Clock Distribution. Flórida, EUA: University of Florida, 2001.

GANGULY, A.; CHANG, K.; DEB, S.; PANDE, P.; BELZER, B.; TEUSCHER, C. Scalable hybrid wireless network-on-chip architectures for multicore systems. Transactions on Computers, IEEE, Los Alamitos, CA, EUA, v. 60, n. 10, p. 1485-1502, 2011.

GANGULY, A.; WETTIN, P.; CHANG, K.; PANDE, P. Complex network inspired fault-tolerant noc architectures with wireless links. In: Fifth International Symposium on Networks on Chip (NoCS). Los Alamitos, CA, EUA: IEEE, 2011. p. 169-176.

GROT, B.; HESTNESS, J.; KECKLER, S. W.; MUTLU, O. Express cube topologies for on-chip interconnects. In: 15th International Symposium on High Performance Computer Architecture. Los Alamitos, CA, EUA: IEEE, 2009. p. 163-174.

GUERRIER, P.; GREINER, A. A generic architecture for on-chip packetswitched interconnections. In: Design, Automation and Test in Europe Conference and Exhibition. Los Alamitos, CA, EUA: IEEE, 2000. p. 250-256. 
HUANG, Y.; YIN, W.-Y.; LIU, Q. H. Performance prediction of carbon nanotube bundle dipole antennas. Transactions on Nanotechnology, IEEE, Los Alamitos, CA, EUA, v. 7, n. 3, p. 331-337, May 2008.

IEEE. leee standard for information technology- telecommunications and information exchange between systems-local and metropolitan area networks-specific requirements-part 11: Wireless lan medium access control (mac) and physical layer (phy) specifications. IEEE Std 802.11-1997, p. i-445, 1997.

ISI. Creating Wired-cum-Wireless and MobileIP Simulations in ns. novembro 2011. Disponível em: <http://www.isi.edu/nsnam/ns/tutorial/ nsscript 6.html>. Acesso em: 27 jun. 2013.

. The Network Simulator - ns-2. novembro 2011. Disponível em: <http://www.isi.edu/nsnam/ns/>. Acesso em: 27 jun. 2013.

JOHNSON, D. B.; MALTZ, D. A. Dynamic source routing in ad hoc wireless networks. In: Mobile Computing. Dordrecht, Países Baixos: Kluwer Academic Publishers, 1996. p. 153-181.

JUNG, W. Op Amp Applications Handbook. San Francisco, Califórnia, Estados Unidos: Newnes/Elsevier, 2005. (Analog Devices series). ISBN 9780750678445.

KAHNG, A.; LIN, B.; SAMADI, K. Improved on-chip router analytical power and area modeling. In: 15th Asia and South Pacific Design Automation Conference (ASP-DAC). Los Alamitos, CA, EUA: IEEE, 2010. p. 241-246.

KEMPA, K.; RYBCZYNSKI, J.; HUANG, Z.; GREGORCZYK, K.; VIDAN, A.; KIMBALL, B.; CARLSON, J.; BENHAM, G.; WANG, Y.; HERCZYNSKI, A.; REN, Z. Carbon nanotubes as optical antennae. Advanced Materials, WILEY-VCH Verlag, v. 19, n. 3, p. 421-426, 2007.

KESHAV, S. REAL 5.0 Overview. agosto 1997. Disponível em: <http: //www.cs.cornell.edu/skeshav/real/overview.html>. Acesso em: 4 ago. 2013.

KIM, J. Low-cost router microarchitecture for on-chip networks. In: Proceedings of the 42nd Annual International Symposium on Microarchitecture. Nova Iorque, NY, EUA: IEEE/ACM, 2009. (MICRO 42), p. 255-266.

KIM, J.; BALFOUR, J.; DALLY, W. J. Flattened butterfly topology for on-chip networks. Computer Architecture Letters, IEEE Computer Society, Los Alamitos, CA, EUA, v. 6, n. 2, p. 37-40, 2007.

KIM, J.; DALLY, W. J.; ABTS, D. Flattened butterfly: A cost-efficient topology for high-radix networks. SIGARCH Compututer Architecture News, ACM, New York, NY, USA, v. 35, n. 2, p. 126-137, 2007. 
KIMOTO, K.; WATANABE, S.; KIKKAWA, T.; HALL, P.; YUAN, V. Characteristics of fractal dipole antennas integrated on si for ulsi wireless interconnects. In: Antennas and Propagation Society International Symposium. Los Alamitos, CA, EUA: IEEE, 2004. v. 4, p. 3437-3440.

KOKSAL, C. E.; EKICI, E. Applications and performance of a nanoreceiver with a carbon nanotube antenna forest. Wireless Communications, IEEE, v. 19, n. 5 , p. 52-57, 2012.

KUMAR, A.; KUNDU, P.; SINGH, A. P.; PEH, L. shiuan; JHA, N. K. A 4.6tbits/s $3.6 \mathrm{ghz}$ single-cycle noc router with a novel switch allocator in $65 \mathrm{~nm} \mathrm{cmos}$. In: 25th International Conference on Computer Design. Los Alamitos, CA, EUA: IEEE, 2007. p. 63-70.

KUMAR, R.; GAIKWAD, S. On the design of nano-arm fractal antenna for uwb wireless applications. Journal of Microwaves, Optoelectronics and Electromagnetic Applications, scielo, São Paulo, Brasil, v. 12, p. 158 -171, 2013.

KUMAR, S.; JANTSCH, A.; SOININEN, J.-P.; FORSELL, M.; MILLBERG, M.; OBERG, J.; TIENSYRJA, K.; HEMANI, A. A network on chip architecture and design methodology. In: Annual Symposium on VLSI, 2002. Proceedings. Los Alamitos, CA, EUA: IEEE, 2002. p. 105-112.

LIN, J.; WU, H.-T.; O, K. K. Compact on-chip monopole antennas on 20-/spl omega/-cm silicon substrates for operation in the 5.8-ghz ism band. In: International Electron Devices Meeting, 2005. IEDM Technical Digest. Los Alamitos, CA, EUA: IEEE, 2005. p. 947-950.

LIN, J.; WU, H.-T.; SU, Y.; GAO, L.; SUGAVANAM, A.; BREWER, J.; O, $\mathrm{K}$. Communication using antennas fabricated in silicon integrated circuits. Journal of Solid-State Circuits, IEEE, Los Alamitos, CA, EUA, v. 42, n. 8, p. 1678-1687, 2007.

MANOHAR, R.; ; MANOHAR, R.; KELLY, C. Network on a chip: Modeling wireless networks with asynchronous vlsi. Communications Magazine, IEEE, Los Alamitos, CA, EUA, v. 39, p. 149-155, 2001.

MEDHI, D.; RAMASAMY, K. Network routing - algorithms, protocols, and architectures. Burlington, EUA: Morgan Kaufmann, 2007. ISBN 978-0-12-088588-6.

MOSCIBRODA, T.; MUTLU, O. A case for bufferless routing in on-chip networks. SIGARCH Computer Architecture News, ACM, Nova lorque, NY, EUA, p. 196-207, 2009.

MOTAMEDI, K.; IOANNIDES, N.; RÜMMELI, M.; SCHAGAEV, I. Reconfigurable network on chip architecture for aerospace applications. In: Proc. of the 30th IFAC Workshop on Real-Time Programming and 4th International Workshop on Real-Time Software. Varsóvia, Polônia: Polish Information Processing Society, 2009. p. 131-136. 
NA, Y.; XIAO-WEI, S. Analysis of the multiband behavior on sierpinski carpet fractal antennas. In: Microwave Conference Proceedings, 2005. APMC 2005. Asia-Pacific Conference Proceedings. Los Alamitos, CA, EUA: IEEE, 2005. v. 4 , p. 4 pp.-.

$\mathrm{NI}$, L. M.; MCKINLEY, P. K. A survey of wormhole routing techniques in direct networks. Computer, IEEE, Los Alamitos, CA, EUA, v. 26, n. 2, p. 62-76, 1993.

NYCHIS, G. P.; FALLIN, C.; MOSCIBRODA, T.; MUTLU, O.; SESHAN, S. On-chip networks from a networking perspective: congestion and scalability in many-core interconnects. In: Proceedings of the SIGCOMM conference on Applications, technologies, architectures, and protocols for computer communication. Nova lorque, NY, EUA: ACM, 2012. p. 407-418.

O., K. K.; KIM, K.; FLOYD, B.; MEHTA, J.; YOON, H.; HUNG, C.-M.; BRAVO, D.; DICKSON, T.; GUO, X.; LI, R.; TRICHY, N.; CASERTA, J.; BOMSTAD W.R., I.; BRANCH, J.; YANG, D.-J.; BOHORQUEZ, J.; SEOK, E.; GAO, L.; SUGAVANAM, A.; LIN, J.-J.; CHEN, J.; BREWER, J. On-chip antennas in silicon ics and their application. IEEE Transactions on Electron Devices, Los Alamitos, CA, EUA, p. 1312 - 1323, 2005.

OGRAS, U.; MARCULESCU, R. "it's a small world after all": Noc performance optimization via long-range link insertion. Transactions on Very Large Scale Integration (VLSI) Systems, Los Alamitos, CA, EUA, v. 14, n. 7, p. 693-706, 2006.

OGRAS, U. Y.; HU, J.; MARCULESCU, R. Key research problems in noc design: a holistic perspective. In: Proceedings of the 3rd international conference on Hardware/software codesign and system synthesis. Nova Iorque, NY, EUA: IEEE/ACM/IFIP, 2005. p. 69-74.

PERKINS, C. E.; BHAGWAT, P. Highly dynamic destination-sequenced distance-vector routing (dsdv) for mobile computers. In: ACM. SIGCOMM Computer Communication Review. Nova Iorque, NY, EUA, 1994. v. 24, n. 4, p. 234-244.

PERKINS, C. E.; ROYER, E. M. Ad-hoc on-demand distance vector routing. In: IEEE. Second Workshop on Mobile Computing Systems and Applications. Los Alamitos, CA, EUA, 1999. p. 90-100.

PUENTE, C.; ROMEU, J.; POUS, R.; RAMIS, J.; HIJAZO, A. Small but long koch fractal monopole. Electronics Letters, IEEE, Los Alamitos, CA, EUA, v. 34, n. 1, p. 9-10, Jan 1998.

RAMAKRISHNAN, M.; SHANMUGAVEL, S. Fpga implementation of aodv routing protocol in manet. In: First International Conference on Industrial and Information Systems. Los Alamitos, CA, EUA: IEEE, 2006. p. 470-473.

Fpga implementation of dsdv based router in mobile adhoc network. In: Annual India Conference. Los Alamitos, CA, EUA: IEEE, 2006. p. 1-5. 
RAZAVI, B.; AYTUR, T.; LAM, C.; YANG, F.-R.; LI, K.-Y.; YAN, R.-H.; KANG, H.-C.; HSU, C.-C.; LEE, C.-C. A uwb cmos transceiver. Journal of Solid-State Circuits, IEEE, Los Alamitos, CA, EUA, v. 40, n. 12, p. 2555-2562, 2005.

REBEIZ, G.; KATEHI, L.; ALI-AHMAD, W.; ELEFTHERIADES, G.; LING, C. Integrated horn antennas for millimeter-wave applications. Antennas and Propagation Magazine, IEEE, Los Alamitos, CA, EUA, v. 34, n. 1, p. 7-16, 1992.

RICE. The Rice University Monarch Project. outubro 2004. Disponível em: <http://www.monarch.cs.rice.edu/>. Acesso em: 4 ago. 2013.

SAHA, P.; SASAKI, N.; KIKKAWA, T. A single-chip gaussian monocycle pulse transmitter using $0.18 / \mathrm{spl} \mathrm{m} / \mathrm{m}$ cmos technology for intra/interchip uwb communication. In: 2006 Symposium on VLSI Circuits, 2006. Digest of Technical Papers. Los Alamitos, CA, EUA: IEEE, 2006. p. $204-205$.

SAIDI, A.; HANSSON, A. Simulating Systems, not Benchmarks. 2012. Disponível em: <http://gem5.org/dist/tutorials/hipeac2012/ gem5_hipeac.pdf>. Acesso em: 30 jan. 2015.

SASAKI, N.; KIMOTO, K.; MORIYAMA, W.; KIKKAWA, T. A single-chip ultra-wideband receiver with silicon integrated antennas for inter-chip wireless interconnection. Journal of Solid-State Circuits, IEEE, Los Alamitos, CA, EUA, v. 44, n. 2, p. 382-393, 2009.

SCHAFER, M.; HOLLSTEIN, T.; ZIMMER, H.; GLESNER, M. Deadlock-free routing and component placement for irregular mesh-based networks-on-chip. In: International Conference on Computer-Aided Design. ICCAD. New York, NY, USA: ACM, 2005. p. 238-245.

SHI, Z.; BURNS, A. Real-time communication analysis for on-chip networks with wormhole switching. In: Proceedings of the Second International Symposium on Networks-on-Chip. Los Alamitos, CA, EUA: IEEE Computer Society, 2008. p. 161-170.

USC. VINT Project Overview. outubro 1997. Disponível em: $<$ http: //www.isi.edu/nsnam/vint/project_overview.htm>. Acesso em: 4 ago. 2013.

WANG, H.-S.; ZHU, X.; PEH, L.-S.; MALIK, S. Orion: a power-performance simulator for interconnection networks. In: 35th Annual International Symposium on Microarchitecture. Los Alamitos, CA, EUA: IEEE/ACM, 2002. p. 294-305.

WANG, Y.; KEMPA, K.; KIMBALL, B.; CARLSON, J. B.; BENHAM, G.; LI, W. Z.; KEMPA, T.; RYBCZYNSKI, J.; HERCZYNSKI, A.; REN, Z. F. Receiving and transmitting light-like radio waves: Antenna effect in arrays of aligned carbon nanotubes. Applied Physics Letters, v. 85, n. 13, p. 2607-2609, 2004. 
WATANABE, S.; KIMOTO, K.; KIKKAWA, T. Transient characteristics of integrated dipole antennas on silicon for ultra wideband wireless interconnects. In: Antennas and Propagation Society International Symposium. Los Alamitos, CA, EUA: IEEE, 2004. v. 3, p. $2277-2280$.

WATTS, D. J.; STROGATZ, S. H. Collective dynamics of 'small-world' networks. Nature, v. 393, n. 6684, p. 409-10, 1998.

WENTWORTH, S. Eletromagnetismo aplicado: Abordagem antecipada das linhas de transmissão. Porto Alegre, RS, Brasil: Bookman, 2008. ISBN 9788577804269.

WILTON, S. J. E.; SALEH, R. Programmable logic ip cores in soc design: opportunities and challenges. In: Conference on Custom Integrated Circuits. Los Alamitos, CA, EUA: IEEE, 2001. p. 63-66.

WU, R.; WANG, Y.; ZHAO, D. A low-cost deadlock-free design of minimal-table rerouted xy-routing for irregular wireless nocs. In: Fourth International Symposium on Networks-on-Chip (NOCS). Los Alamitos, CA, EUA: ACM/IEEE, 2010. p. $199-206$.

YOON, S.-R.; PARK, S.-C. Simulation and analysis of network on chip architecture for wireless communication system. In: Proceedings of the Fifth International Workshop on System-on-Chip for Real-Time Applications. Los Alamitos, CA, EUA: IEEE Computer Society, 2005. (IWSOC '05), p. 471-475.

ZHAO, D.; WANG, Y. Sd-mac: Design and synthesis of a hardwareefficient collision-free qos-aware mac protocol for wireless network-on-chip. Transactions on Computers, IEEE, Los Alamitos, CA, EUA, v. 57, n. 9, p. 1230-1245, 2008.

ZHAO, D.; WANG, Y.; LI, J.; KIKKAWA, T. Design of multi-channel wireless noc to improve on-chip communication capacity. In: Fifth International Symposium on Networks on Chip (NoCS). [S.I.: s.n.], 2011.

ZHAO, D.; WU, R. Overlaid mesh topology design and deadlock free routing in wireless network-on-chip. In: Proceedings of the 2012 Sixth International Symposium on Networks-on-Chip. Los Alamitos, CA, EUA: IEEE Computer Society, 2012. p. 27-34. 


\section{APÊNDICE A - EXEMPLO DE SCRIPT DA SIMULAÇÃO COM FIO}

Trecho de Código A.1: script TCL da simulação com fio gerado automaticamente pela plataforma de simulação do capítulo 4 .

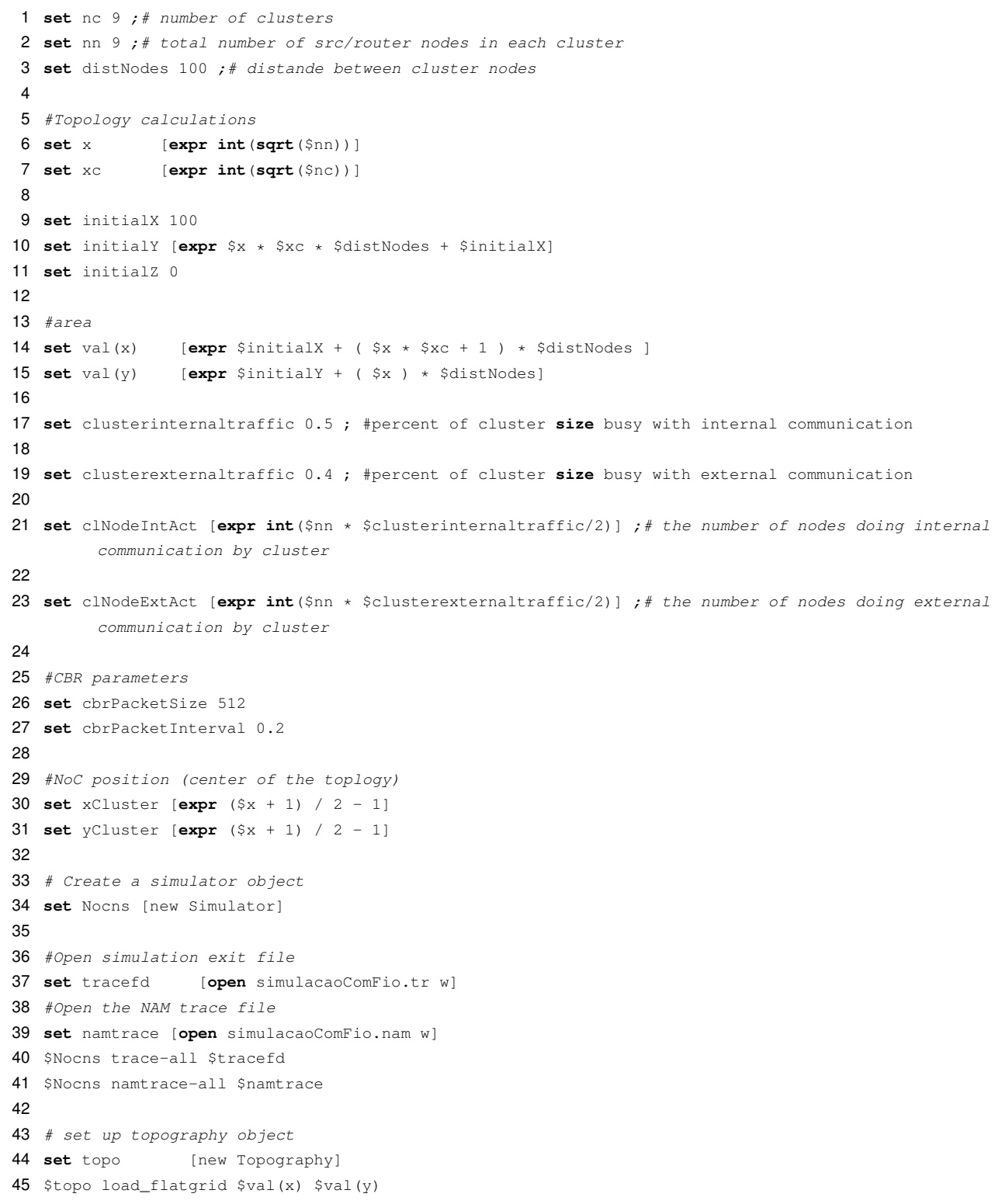




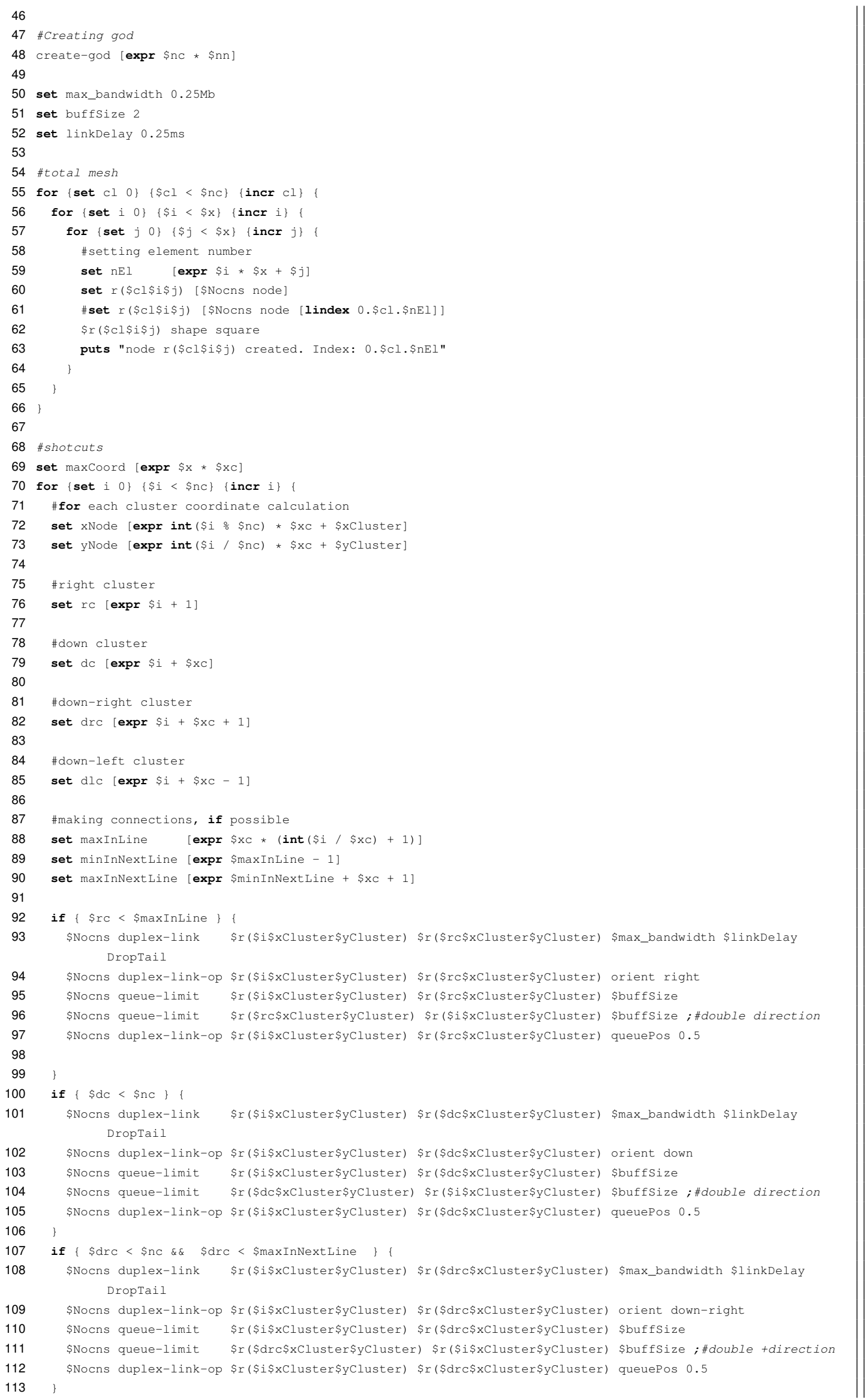




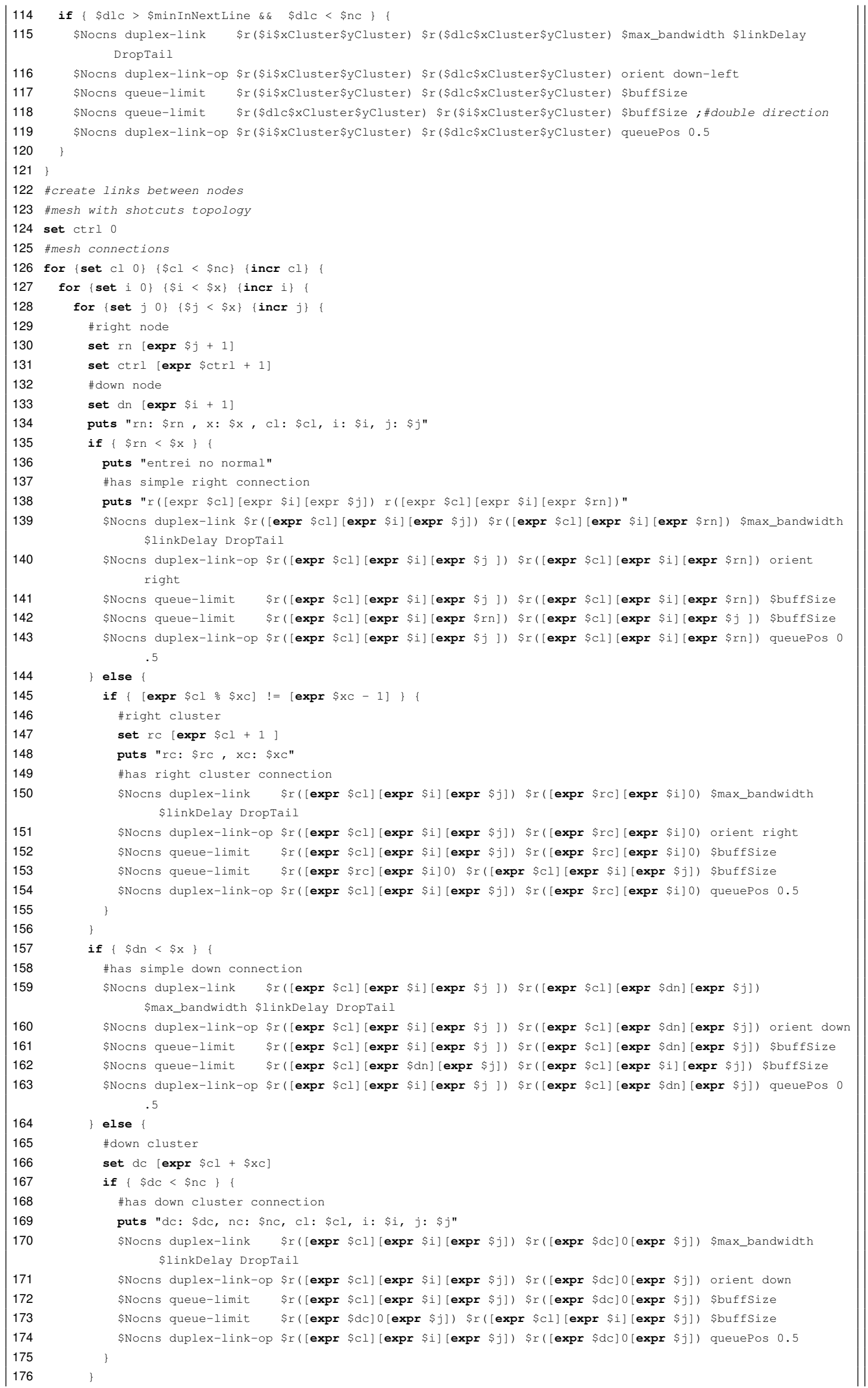


\#Create a UDP agent and attach it to node $s(0)$

puts "Creating udp_(0)"

set udp_(0) [new Agent/UDP]

\$udp_(0) set class_ 2

puts "Attaching $r(820)$ udp_(0)"

\$Nocns attach-agent $\$ r(820)$ \$udp_(0)

\# Create a CBR traffic source and attach it to udp (0)

puts "Creating cbr(0)"

puts "Attaching cbr(0) udp (0)"

set cbr(0) [new Application/Traffic/CBR]

$\$ c b r(0)$ set packetSize_ \$cbrPacketSize

$\$ c b r(0)$ set interval_ \$cbrPacketInterval

$\$ c b r(0)$ attach-agent $\$ u d p_{-}(0)$

puts "Creating sink_(0)"

set sink_(0) [new Agent/Null]

puts "Attaching $r(802)$ sink_(0)"

\$Nocns attach-agent $\$ r(802)$ \$sink_(0)

puts "Connecting udp (0) $\operatorname{sink}(0) "$

\$Nocns connect \$udp_(0) \$sink_(0)

puts "cbr(0) starting at 0 * $0.2962963 "$

\$Nocns at 0.0 "\$cbr(0) start"

\$Nocns at 210.01 "\$cbr(0) stop"

\#Create a UDP agent and attach it to node $\mathrm{s}(1)$

puts "Creating udp_(1)"

set udp_(1) [new Agent/UDP]

\$udp_(1) set class_ 2

puts "Attaching $r(322)$ udp_(1)"

\$Nocns attach-agent $\$$ (322) \$udp_(1)

\# Create a CBR traffic source and attach it to udp(1)

puts "Creating cbr(1)"

puts "Attaching cbr(1) udp(1)"

set cbr(1) [new Application/Traffic/CBR]

$\$ c b r(1)$ set packetSize_ \$cbrPacketSize

\$cbr(1) set interval_ \$cbrPacket Interval

\$cbr(1) attach-agent \$udp_(1)

puts "Creating sink_(1)"

set sink_(1) [new Agent/Null]

puts "Attaching $r(300)$ sink_(1)"

\$Nocns attach-agent $\$ r(300)$ \$sink_(1)

puts "Connecting udp(1) sink(1)"

\$Nocns connect \$udp_(1) \$sink_(1)

puts "cbr(1) starting at $1 * 0.2962963 "$

$\$$ Nocns at 0.2962963 "\$cbr(1) start"

\$Nocns at 210.01 "\$cbr(1) stop"

\#Create a UDP agent and attach it to node s(2)

puts "Creating udp_(2)"

set udp_(2) [new Agent/UDP]

\$udp_(2) set class_ 2

puts "Attaching $r(320)$ udp_(2)"

\$Nocns attach-agent $\$$ (320) \$udp_(2)

\# Create a CBR traffic source and attach it to udp(2)

puts "Creating cbr(2)"

puts "Attaching cbr(2) udp(2)"

set $\mathrm{cbr}(2)$ [new Application/Traffic/CBR]

$\$ c b r(2)$ set packetSize_ \$cbrPacketSize

\$cbr(2) set interval_ \$cbrPacket Interval

$\$ c b r(2)$ attach-agent $\$$ udp_(2)

puts "Creating sink_(2)"

set sink_(2) [new Agent/Null]

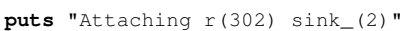

\$Nocns attach-agent \$r(302) \$sink $(2)$

puts "Connecting udp(2) sink(2) "

\$Nocns connect \$udp_(2) \$sink_(2) 
puts "cbr(2) starting at $2 * 0.2962963 "$

\$Nocns at $0.5925926 "$ "\$cbr(2) start"

\$Nocns at 210.01 "\$cbr(2) stop"

\#Create a UDP agent and attach it to node s(3)

puts "Creating udp_(3)"

set udp_(3) [new Agent/UDP]

\$udp_(3) set class_ 2

puts "Attaching r(002) udp_(3)"

\$Nocns attach-agent $\$ r(002)$ \$udp_(3)

\# Create a CBR traffic source and attach it to udp (3)

puts "Creating cbr(3)"

puts "Attaching cbr(3) udp(3) "

set cbr(3) [new Application/Traffic/CBR]

$\$ c b r(3)$ set packetSize_ \$cbrPacketSize

\$cbr(3) set interval_ \$cbrPacketInterval

\$cbr (3) attach-agent \$udp_(3)

puts "Creating sink_(3)"

set sink_(3) [new Agent/Null]

puts "Attaching $r(020)$ sink_(3)"

\$Nocns attach-agent $\$ r(020)$ \$sink_(3)

puts "Connecting udp (3) sink (3)"

\$Nocns connect \$udp_(3) \$sink_(3)

puts "cbr(3) starting at $3 * 0.2962963 "$

\$Nocns at 0.8888889 "\$cbr(3) start"

\$Nocns at 210.01 "\$cbr(3) stop"

\#Create a UDP agent and attach it to node s(4)

puts "Creating udp_(4)"

set udp_(4) [new Agent/UDP]

\$udp_(4) set class_ 2

puts "Attaching $r(622)$ udp_(4)"

\$Nocns attach-agent $\$ r(622)$ \$udp_(4)

\# Create a CBR traffic source and attach it to udp(4)

puts "Creating cbr(4)"

puts "Attaching cbr(4) udp(4)"

set cbr(4) [new Application/Traffic/CBR]

\$cbr (4) set packetSize_\$cbrPacketSize

\$cbr (4) set interval_ \$cbrPacketInterval

$\$ c b r(4)$ attach-agent $\$$ udp_ $(4)$

puts "Creating sink_(4)"

set sink_(4) [new Agent/Null]

puts "Attaching $r(600)$ sink_(4)"

\$Nocns attach-agent $\$ r(600)$ \$sink_(4)

puts "Connecting udp(4) sink(4)"

\$Nocns connect \$udp_(4) \$sink_(4)

puts "cbr(4) starting at 4 * $0.2962963 "$

\$Nocns at 1.1851852 "\$cbr (4) start"

\$Nocns at 210.01 "\$cbr(4) stop"

\#Create a UDP agent and attach it to node s(5)

puts "Creating udp_(5)"

set udp_(5) [new Agent/UDP]

\$udp_(5) set class_ 2

puts "Attaching $r(800)$ udp_(5)"

\$Nocns attach-agent $\$ r(800) \quad \$ u d p \_(5)$

\# Create a CBR traffic source and attach it to udp (5)

puts "Creating cbr(5)"

puts "Attaching cbr(5) udp(5)"

set cbr(5) [new Application/Traffic/CBR]

$\$ c b r(5)$ set packetSize_ \$cbrPacketSize

$\$ c b r(5)$ set interval_ \$cbrPacketInterval

$\$ c b r(5)$ attach-agent $\$$ udp_(5)

puts "Creating sink_(5)"

set sink_(5) [new Agent/Null]

puts "Attaching r(822) sink_(5)"

\$Nocns attach-agent \$r(822) \$sink_(5)

puts "Connecting udp (5) sink(5)"

\$Nocns connect \$udp_(5) \$sink_ (5)

puts "cbr(5) starting at $5 * 0.2962963 "$

\$Nocns at 1.4814816 "\$cbr(5) start" 


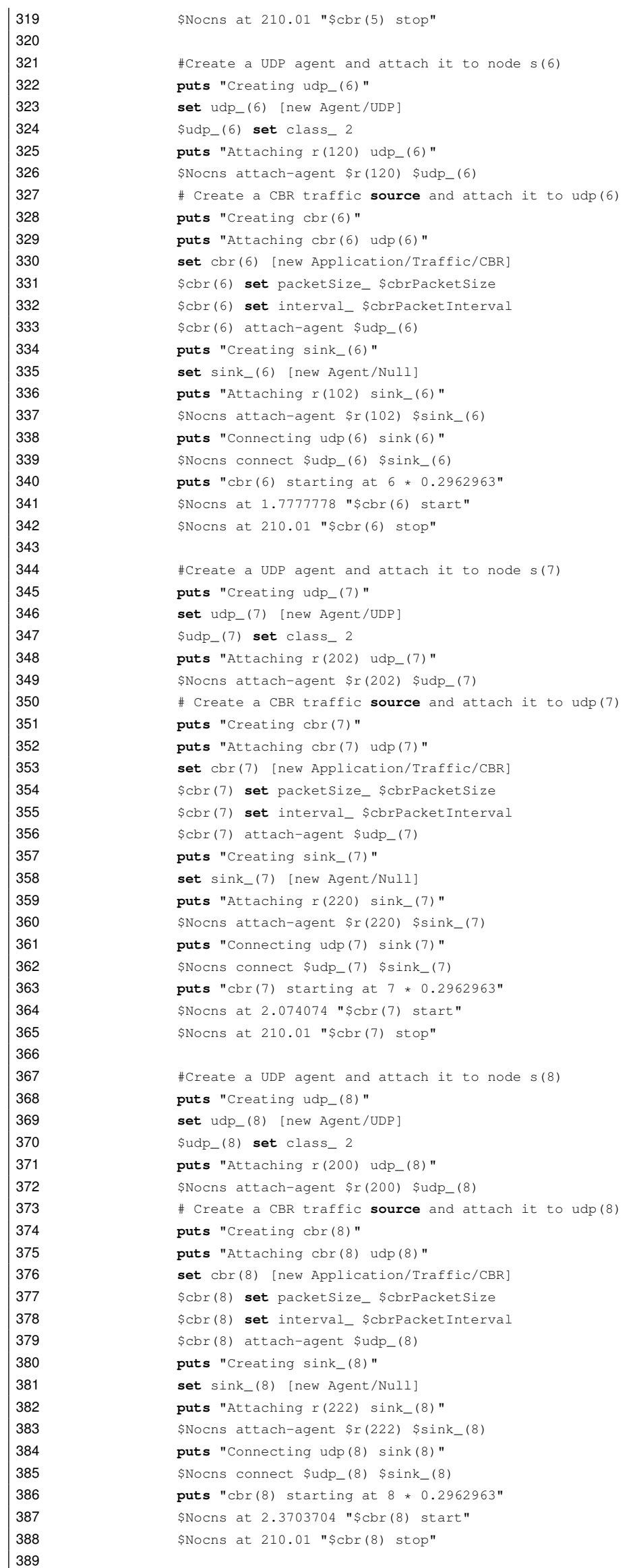


\#Create a UDP agent and attach it to node $\mathrm{s}(9)$

puts "Creating udp_(9)"

set udp_(9) [new Agent/UDP]

\$udp_(9) set class_ 2

puts "Attaching $r(500)$ udp_(9)"

\$Nocns attach-agent $\$ r(500)$ \$udp_(9)

\# Create a CBR traffic source and attach it to udp (9)

puts "Creating cbr(9)"

puts "Attaching cbr(9) udp(9)"

set cbr (9) [new Application/Traffic/CBR]

\$cbr(9) set packetSize \$cbrPacketSize

\$cbr(9) set interval_ \$cbrPacketInterval

\$cbr (9) attach-agent \$udp_(9)

puts "Creating sink_(9)"

set sink_(9) [new Agent/Null]

puts "Attaching $r(522)$ sink_(9)"

\$Nocns attach-agent \$r(522) \$sink_(9)

puts "Connecting udp (9) sink (9)"

\$Nocns connect \$udp_(9) \$sink_(9)

puts "cbr(9) starting at 9 * $0.2962963 "$

\$Nocns at 2.6666667 "\$cbr $(9)$ start"

\$Nocns at 210.01 "\$cbr(9) stop"

\#Create a UDP agent and attach it to node s(10)

puts "Creating udp_(10)"

set udp_(10) [new Agent/UDP]

\$udp_(10) set class_ 2

puts "Attaching $r(520)$ udp_(10)"

\$Nocns attach-agent $\$ r(520)$ \$udp_(10)

\# Create a CBR traffic source and attach it to udp(10)

puts "Creating cbr(10)"

puts "Attaching cbr(10) udp(10)"

set cbr(10) [new Application/Traffic/CBR]

$\$ c b r(10)$ set packetSize \$cbrPacketSize

\$cbr(10) set interval_ \$cbrPacketInterval

\$cbr(10) attach-agent \$udp_(10)

puts "Creating sink_(10)"

set sink_(10) [new Agent/Null]

puts "Attaching $r(502)$ sink_(10)"

\$Nocns attach-agent \$r(502) \$sink_(10)

puts "Connecting udp(10) sink(10)"

\$Nocns connect \$udp_(10) \$sink_(10)

puts "cbr(10) starting at 10 * $0.2962963 "$

\$Nocns at 2.962963 "\$cbr(10) start"

\$Nocns at 210.01 "\$cbr(10) stop"

\#Create a UDP agent and attach it to node s(11)

puts "Creating udp_(11)"

set udp_(11) [new Agent/UDP]

\$udp_(11) set class_ 2

puts "Attaching $r(602)$ udp_(11)"

\$Nocns attach-agent \$r(602) \$udp_(11)

\# Create a CBR traffic source and attach it to udp(11)

puts "Creating cbr(11)"

puts "Attaching cbr(11) udp(11)"

set cbr(11) [new Application/Traffic/CBR]

\$cbr(11) set packetSize_ \$cbrPacketSize

\$cbr(11) set interval_ \$cbrPacketInterval

\$cbr(11) attach-agent \$udp_(11)

puts "Creating sink_(11)"

set sink_(11) [new Agent/Null]

puts "Attaching $r(620)$ sink_(11)"

\$Nocns attach-agent \$r(620) \$sink_(11)

puts "Connecting udp(11) sink(11)"

\$Nocns connect \$udp_(11) \$sink_(11)

puts "cbr(11) starting at $11 * 0.2962963 "$

\$Nocns at 3.2592592 "\$cbr(11) start"

\$Nocns at 210.01 "\$cbr(11) stop"

\#Create a UDP agent and attach it to node s(12)

puts "Creating udp_(12)" 
set udp_(12) [new Agent/UDP]

\$udp_(12) set class_ 2

puts "Attaching $r(420)$ udp_(12)"

\$Nocns attach-agent $\$ r(420)$ \$udp_(12)

\# Create a CBR traffic source and attach it to udp(12)

puts "Creating cbr(12)"

puts "Attaching cbr(12) udp(12)"

set cbr(12) [new Application/Traffic/CBR]

\$cbr(12) set packetSize_\$cbrPacketSize

\$cbr(12) set interval_ \$cbrPacketInterval

\$cbr(12) attach-agent \$udp_(12)

puts "Creating sink_(12)"

set sink_(12) [new Agent/Null]

puts "Attaching $r(402)$ sink_(12)"

\$Nocns attach-agent \$r(402) \$sink_(12)

puts "Connecting udp(12) sink(12)"

\$Nocns connect \$udp_(12) \$sink_(12)

puts "cbr(12) starting at 12 * $0.2962963 "$

\$Nocns at 3.5555556 "\$cbr(12) start"

\$Nocns at 210.01 "\$cbr(12) stop"

\#Create a UDP agent and attach it to node s(13)

puts "Creating udp_(13)"

set udp_(13) [new Agent/UDP]

\$udp_(13) set class_ 2

puts "Attaching $r(000)$ udp_(13)"

\$Nocns attach-agent $\$ r(000)$ \$udp_(13)

\# Create a CBR traffic source and attach it to udp(13)

puts "Creating cbr(13)"

puts "Attaching cbr(13) udp(13)"

set cbr(13) [new Application/Traffic/CBR]

\$cbr(13) set packetSize_ \$cbrPacketSize

\$cbr(13) set interval_ \$cbrPacketInterval

$\$ c b r(13)$ attach-agent \$udp_(13)

puts "Creating sink_(13)"

set sink_(13) [new Agent/Null]

puts "Attaching $r(022)$ sink_(13)"

\$Nocns attach-agent \$r(022) \$sink_(13)

puts "Connecting udp(13) sink(13)"

\$Nocns connect \$udp_(13) \$sink_(13)

puts "cbr(13) starting at 13 * $0.2962963 "$

\$Nocns at 3.851852 "\$cbr(13) start"

\$Nocns at 210.01 "\$cbr(13) stop"

\#Create a UDP agent and attach it to node s(14)

puts "Creating udp_(14)"

set udp_(14) [new Agent/UDP]

\$udp_(14) set class_ 2

puts "Attaching $r(100)$ udp_(14)"

\$Nocns attach-agent \$r(100) \$udp_(14)

\# Create a CBR traffic source and attach it to udp(14)

puts "Creating cbr(14)"

puts "Attaching cbr(14) udp(14)"

set cbr(14) [new Application/Traffic/CBR]

\$cbr(14) set packetSize_ \$cbrPacketSize

\$cbr(14) set interval_ \$cbrPacketInterval

\$cbr(14) attach-agent \$udp_(14)

puts "Creating sink_(14)"

set sink_(14) [new Agent/Null]

puts "Attaching $r(122)$ sink_(14)"

\$Nocns attach-agent \$r(122) \$sink_(14)

puts "Connecting udp(14) sink(14)"

\$Nocns connect \$udp_(14) \$sink_(14)

puts "cbr(14) starting at 14 * $0.2962963 "$

\$Nocns at 4.148148 "\$cbr(14) start"

\$Nocns at 210.01 "\$cbr(14) stop"

\#Create a UDP agent and attach it to node s(15)

puts "Creating udp_(15)"

set udp_(15) [new Agent/UDP]

\$udp_(15) set class_ 2 
puts "Attaching $r(702)$ udp_(15)"

\$Nocns attach-agent $\$ r(702)$ \$udp_(15)

\# Create a CBR traffic source and attach it to udp(15)

puts "Creating cbr(15)"

puts "Attaching cbr(15) udp(15)"

set $c b r(15)$ [new Application/Traffic/CBR]

\$cbr(15) set packetSize_\$cbrPacketSize

\$cbr(15) set interval_ \$cbrPacketInterval

\$cbr(15) attach-agent \$udp_(15)

puts "Creating sink_(15)"

set sink_(15) [new Agent/Null]

puts "Attaching $r(720)$ sink_(15)"

\$Nocns attach-agent \$r(720) \$sink_(15)

puts "Connecting udp(15) sink(15)"

\$Nocns connect \$udp_(15) \$sink_(15)

puts "cbr(15) starting at $15 * 0.2962963 "$

\$Nocns at 4.4444447 "\$cbr(15) start"

\$Nocns at 210.01 "\$cbr(15) stop"

\#Create a UDP agent and attach it to node s(16)

puts "Creating udp_(16)"

set udp_(16) [new Agent/UDP]

\$udp_(16) set class_ 2

puts "Attaching $r(700)$ udp_(16)"

\$Nocns attach-agent $\$ r(700)$ \$udp_(16)

\# Create a CBR traffic source and attach it to udp(16)

puts "Creating cbr(16)"

puts "Attaching cbr(16) udp(16)"

set cbr(16) [new Application/Traffic/CBR]

\$cbr(16) set packetSize_ \$cbrPacketSize

\$cbr(16) set interval_ \$cbrPacketInterval

\$cbr(16) attach-agent \$udp_(16)

puts "Creating sink_(16)"

set sink_(16) [new Agent/Null]

puts "Attaching $r(722)$ sink_(16)"

\$Nocns attach-agent \$r(722) \$sink_(16)

puts "Connecting udp(16) sink(16)"

\$Nocns connect \$udp_(16) \$sink_(16)

puts "cbr(16) starting at 16 * $0.2962963 "$

\$Nocns at 4.740741 "\$cbr(16) start"

\$Nocns at 210.01 "\$cbr(16) stop"

\#Create a UDP agent and attach it to node s(17)

puts "Creating udp_(17)"

set udp_(17) [new Agent/UDP]

\$udp_(17) set class_ 2

puts "Attaching $r(400)$ udp_(17)"

\$Nocns attach-agent $\$ r(400)$ \$udp_(17)

\# Create a CBR traffic source and attach it to udp(17)

puts "Creating cbr(17)"

puts "Attaching cbr(17) udp(17)"

set cbr(17) [new Application/Traffic/CBR]

\$cbr(17) set packetSize \$cbrPacketSize

\$cbr(17) set interval_ \$cbrPacketInterval

\$cbr(17) attach-agent \$udp_(17)

puts "Creating sink_(17)"

set sink_(17) [new Agent/Null]

puts "Attaching $r(422)$ sink_(17)"

\$Nocns attach-agent \$r(422) \$sink_(17)

puts "Connecting udp(17) sink(17)"

\$Nocns connect \$udp_(17) \$sink_(17)

puts "cbr(17) starting at 17 * $0.2962963 "$

\$Nocns at 5.037037 "\$cbr(17) start"

\$Nocns at 210.01 "\$cbr(17) stop"

\#EXTERNAL FLOWS

\#Create a UDP agent and attach it to node s(18)

puts "Creating udp_(18)"

set udp_(18) [new Agent/UDP]

\$udp_(18) set class_ 2 
puts "Attaching $r(501)$ udp_(18)"

\$Nocns attach-agent $\$ r(501)$ \$udp_(18)

\# Create a CBR traffic source and attach it to udp(18)

puts "Creating cbr(18)"

puts "Attaching cbr(18) udp(18)"

set $\mathrm{cbr}(18)$ [new Application/Traffic/CBR]

\$cbr(18) set packetSize_ \$cbrPacketSize

\$cbr(18) set interval_ \$cbrPacketInterval

\$cbr(18) attach-agent $\$$ udp_(18)

puts "Creating sink_(18)"

set sink_(18) [new Agent/Null]

puts "Attaching $r(321)$ sink_(18)"

\$Nocns attach-agent \$r(321) \$sink_(18)

puts "Connecting udp(18) sink(18)"

\$Nocns connect \$udp_(18) \$sink_(18)

puts "cbr(18) starting at 18 * $0.2962963 "$

\$Nocns at 5.3333335 "\$cbr(18) start"

\$Nocns at 210.01 "\$cbr(18) stop"

\#Create a UDP agent and attach it to node s(19)

puts "Creating udp_(19)"

set udp_(19) [new Agent/UDP]

\$udp_(19) set class_ 2

puts "Attaching $r(801)$ udp_(19)"

\$Nocns attach-agent $\$ r(801)$ \$udp_(19)

\# Create a CBR traffic source and attach it to udp(19)

puts "Creating cbr(19)"

puts "Attaching cbr(19) udp(19)"

set cbr(19) [new Application/Traffic/CBR]

\$cbr(19) set packetSize_ \$cbrPacketSize

\$cbr(19) set interval_ \$cbrPacketInterval

\$cbr (19) attach-agent \$udp_(19)

puts "Creating sink_(19)"

set sink_(19) [new Agent/Null]

puts "Attaching $r(310)$ sink_(19)"

\$Nocns attach-agent \$r(310) \$sink_(19)

puts "Connecting udp(19) sink(19)"

\$Nocns connect \$udp_(19) \$sink_(19)

puts "cbr(19) starting at 19 * $0.2962963 "$

\$Nocns at 5.6296296 "\$cbr(19) start"

\$Nocns at 210.01 "\$cbr(19) stop"

\#Create a UDP agent and attach it to node s (20)

puts "Creating udp_(20)"

set udp_(20) [new Agent/UDP]

\$udp_(20) set class_ 2

puts "Attaching $r(012)$ udp_(20)"

\$Nocns attach-agent \$r(012) \$udp_(20)

\# Create a CBR traffic source and attach it to udp(20)

puts "Creating cbr(20)"

puts "Attaching cbr(20) udp (20)"

set cbr(20) [new Application/Traffic/CBR]

$\$ c b r(20)$ set packetSize \$cbrPacketSize

\$cbr(20) set interval_ \$cbrPacketInterval

$\$ c b r(20)$ attach-agent $\$$ udp_ $(20)$

puts "Creating sink_(20)"

set sink_(20) [new Agent/Null]

puts "Attaching $r(712)$ sink_(20)"

\$Nocns attach-agent \$r(712) \$sink_(20)

puts "Connecting udp(20) sink(20)"

\$Nocns connect \$udp_(20) \$sink_(20)

puts "cbr(20) starting at $20 * 0.2962963 "$

$\$$ Nocns at $5.925926 "$ "\$cbr (20) start"

\$Nocns at 210.01 "\$cbr(20) stop"

\#Create a UDP agent and attach it to node s(21)

puts "Creating udp_(21)"

set udp_(21) [new Agent/UDP]

\$udp_(21) set class_

puts "Attaching $r(010)$ udp_(21)"

\$Nocns attach-agent $\$ r(010)$ \$udp_(21) 
\# Create a CBR traffic source and attach it to udp(21)

puts "Creating cbr(21)"

puts "Attaching cbr(21) udp (21)"

set cbr(21) [new Application/Traffic/CBR]

$\$ c b r(21)$ set packetSize_ \$cbrPacketSize

\$cbr(21) set interval_ \$cbrPacketInterval

\$cbr(21) attach-agent \$udp_(21)

puts "Creating sink_(21)"

set sink_(21) [new Agent/Null]

puts "Attaching $r(212)$ sink_(21)"

\$Nocns attach-agent \$r(212) \$sink_(21)

puts "Connecting udp(21) sink(21)"

\$Nocns connect \$udp_(21) \$sink_(21)

puts "cbr(21) starting at $21 * 0.2962963 "$

\$Nocns at 6.2222223 "\$cbr(21) start"

\$Nocns at 210.01 "\$cbr(21) stop"

\#Create a UDP agent and attach it to node s(22)

puts "Creating udp_(22)"

set udp_(22) [new Agent/UDP]

\$udp_(22) set class_ 2

puts "Attaching $r(621)$ udp_(22)"

\$Nocns attach-agent $\$ r(621)$ \$udp_(22)

\# Create a CBR traffic source and attach it to udp (22)

puts "Creating cbr(22)"

puts "Attaching cbr(22) udp (22)"

set $\mathrm{cbr}(22)$ [new Application/Traffic/CBR]

$\$ c b r(22)$ set packetSize_\$cbrPacketSize

\$cbr (22) set interval_ \$cbrPacketInterval

\$cbr(22) attach-agent \$udp_(22)

puts "Creating sink_(22)"

set sink_(22) [new Agent/Null]

puts "Attaching $r(810)$ sink_(22)"

\$Nocns attach-agent $\$ r(810)$ \$sink_(22)

puts "Connecting udp (22) sink(22)"

\$Nocns connect \$udp_(22) \$sink_(22)

puts "cbr(22) starting at 22 * $0.2962963 "$

\$Nocns at 6.5185184 "\$cbr(22) start"

\$Nocns at 210.01 "\$cbr(22) stop"

\#Create a UDP agent and attach it to node s(23)

puts "Creating udp_(23)"

set udp_ (23) [new Agent/UDP]

\$udp_(23) set class_ 2

puts "Attaching $r(021)$ udp_(23)"

\$Nocns attach-agent $\$$ r(021) \$udp_(23)

\# Create a CBR traffic source and attach it to udp (23)

puts "Creating cbr(23)"

puts "Attaching cbr(23) udp (23)"

set $\mathrm{cbr}(23)$ [new Application/Traffic/CBR]

\$cbr (23) set packetSize_ \$cbrPacketSize

\$cbr(23) set interval_ \$cbrPacketInterval

\$cbr (23) attach-agent \$udp_(23)

puts "Creating sink_(23)"

set sink_(23) [new Agent/Null]

puts "Attaching $r(601)$ sink_(23)"

\$Nocns attach-agent \$r(601) \$sink_(23)

puts "Connecting udp (23) sink (23)"

\$Nocns connect \$udp_(23) \$sink_(23)

puts "cbr(23) starting at $23 * 0.2962963 "$

\$Nocns at 6.814815 "\$cbr(23) start"

$\$$ Nocns at 210.01 "\$cbr(23) stop"

\#Create a UDP agent and attach it to node s (24)

puts "Creating udp_(24)"

set udp_(24) [new Agent/UDP]

\$udp_(24) set class_ 2

puts "Attaching $r(001)$ udp_(24)"

\$Nocns attach-agent $\$ r(001)$ \$udp_(24)

\# Create a CBR traffic source and attach it to udp (24)

puts "Creating cbr(24)" 
puts "Attaching cbr(24) udp (24)"

set cbr(24) [new Application/Traffic/CBR]

$\$ c b r(24)$ set packetSize_ \$cbrPacketSize

\$cbr(24) set interval_ \$cbrPacketInterval

\$cbr(24) attach-agent \$udp_(24)

puts "Creating sink_(24)"

set sink_(24) [new Agent/Null]

puts "Attaching $r(710)$ sink_(24)"

\$Nocns attach-agent \$r(710) \$sink_(24)

puts "Connecting udp(24) sink(24)"

\$Nocns connect \$udp_(24) \$sink_(24)

puts "cbr(24) starting at $24 * 0.2962963 "$

\$Nocns at 7.111111 "\$cbr(24) start"

\$Nocns at 210.01 "\$cbr(24) stop"

\#Create a UDP agent and attach it to node s(25)

puts "Creating udp_(25)"

set udp_(25) [new Agent/UDP]

\$udp_(25) set class_ 2

puts "Attaching $r(221)$ udp_(25)"

\$Nocns attach-agent \$r(221) \$udp_(25)

\# Create a CBR traffic source and attach it to udp(25)

puts "Creating cbr(25)"

puts "Attaching cbr(25) udp(25)"

set cbr(25) [new Application/Traffic/CBR]

$\$ c b r(25)$ set packetSize_ \$cbrPacketSize

\$cbr(25) set interval_ \$cbrPacket Interval

\$cbr(25) attach-agent \$udp_(25)

puts "Creating sink_(25)"

set sink_(25) [new Agent/Null]

puts "Attaching $r(612)$ sink_(25)"

\$Nocns attach-agent \$r(612) \$sink_(25)

puts "Connecting udp(25) sink (25)"

\$Nocns connect \$udp_(25) \$sink_(25)

puts "cbr(25) starting at $25 * 0.2962963 "$

\$Nocns at 7.4074073 "\$cbr(25) start"

\$Nocns at 210.01 "\$cbr(25) stop"

\#Create a UDP agent and attach it to node s(26)

puts "Creating udp_(26)"

set udp_(26) [new Agent/UDP]

\$udp_(26) set class_ 2

puts "Attaching $r(210)$ udp_(26)"

\$Nocns attach-agent \$r(210) \$udp_(26)

\# Create a CBR traffic source and attach it to udp(26)

puts "Creating cbr(26)"

puts "Attaching cbr(26) udp(26)"

set cbr(26) [new Application/Traffic/CBR]

$\$ c b r(26)$ set packetSize_ \$cbrPacketSize

\$cbr (26) set interval_ \$cbrPacket Interval

\$cbr(26) attach-agent \$udp_(26)

puts "Creating sink_(26)"

set sink_(26) [new Agent/Null]

puts "Attaching $r(301)$ sink_(26)"

\$Nocns attach-agent \$r(301) \$sink_(26)

puts "Connecting udp(26) sink (26)"

\$Nocns connect \$udp_(26) \$sink_(26)

puts "cbr(26) starting at 26 * $0.2962963 "$

\$Nocns at 7.703704 "\$cbr(26) start"

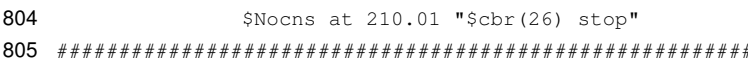

806 \#

807 \# Tell nodes when the simulation ends

808 \#

809 for $\{$ set $i 0\}\{\$ i<\$ n c\}$ incr $i\}\{$

810 for $\{$ set $j 0\}\{\$ j<\$ x\}$ incr $j\}$

for $\{$ set $k 0\}\{\$ k<\$ x\}$ incr $k\}\{$

\$Nocns at 210.01 "\$r([expr \$i] [expr \$j] [expr \$k]) reset"

\}

$815\}$ 
816 Nocns rtproto Static; \# Static routing strategy

817 \$Nocns at 210.02 "stop"

818 \$Nocns at 210.03 "puts \"NS EXITING... \" ; \$Nocns halt"

819 proc stop \{\} \{

820 global Nocns tracefd namtrace

821 \$Nocns flush-trace

822 close $\$$ tracefd

823 close snamtrace; \# Close the NAM trace file

824 \# Print some info.

825 puts "Run nam..."

826 \# exec nam simulacaoComFio.nam

$827\}$

828

829 \#wired nodes to be turned off

830 \$Nocns rtmodel-at 50.0 down $\$ r(011)$ \$r(311)

831 \$Nocns rtmodel-at 80.0 up $\$ r(011) \quad \$ r(311)$

832 \$Nocns rtmodel-at 50.0 down $\$ r(011)$ \$r(411)

833 \$Nocns rtmodel-at 80.0 up $\$ r(011) \quad \$ r(411)$

834 \$Nocns rtmodel-at 50.0 down $\$ r(011)$ \$r(111)

835 \$Nocns rtmodel-at 80.0 up $\$ r(011) \quad$ \$r(111)

836

837 \#wired nodes to be turned off

838 \$Nocns rtmodel-at 40.0 down $\$ r(111)$ \$r(411)

839 \$Nocns rtmodel-at 90.0 up $\$ r(111) \quad \$ r(411)$

840 \$Nocns rtmodel-at 40.0 down $\$ r(111)$ \$r(311)

841 \$Nocns rtmodel-at 90.0 up $\$ r(111) \quad \$ r(311)$

842 \$Nocns rtmodel-at 40.0 down $\$ r(111) \quad \$ r(511)$

843 \$Nocns rtmodel-at 90.0 up $\$ r(111) \quad \$ r(511)$

844 \$Nocns rtmodel-at 40.0 down $\$ r(111) \quad \$ r(011)$

845 \$Nocns rtmodel-at 90.0 up $\$ r(111) \quad \$ r(011)$

846 \$Nocns rtmodel-at 40.0 down $\$ r(111)$ \$r(211)

847 \$Nocns rtmodel-at 90.0 up $\$ r(111) \quad \$ r(211)$

848

849 \#run the simulation

850 \$Nocns run 


\section{APÊNDICE B - EXEMPLO DE SCRIPT DE SIMULAÇÃO SEM FIO}

Trecho de Código B.1: script TCL de uma simulação sem fio gerado automaticamente pela plataforma de simulação do capítulo 4 . Neste caso trata-se da primeira simulação sem fio amostrada a partir dos resultados da simulação com fio cujo script está no apêndice $A$

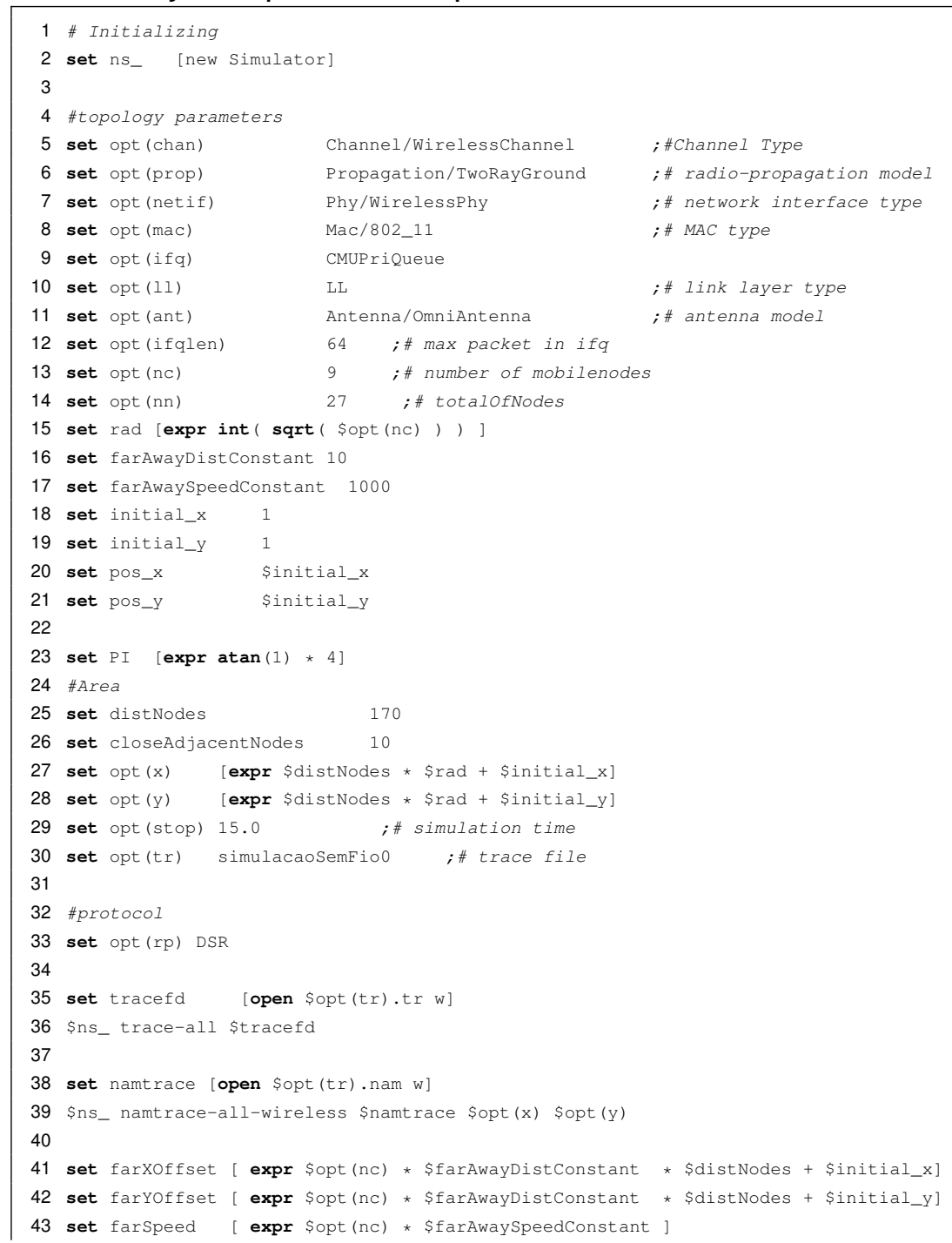




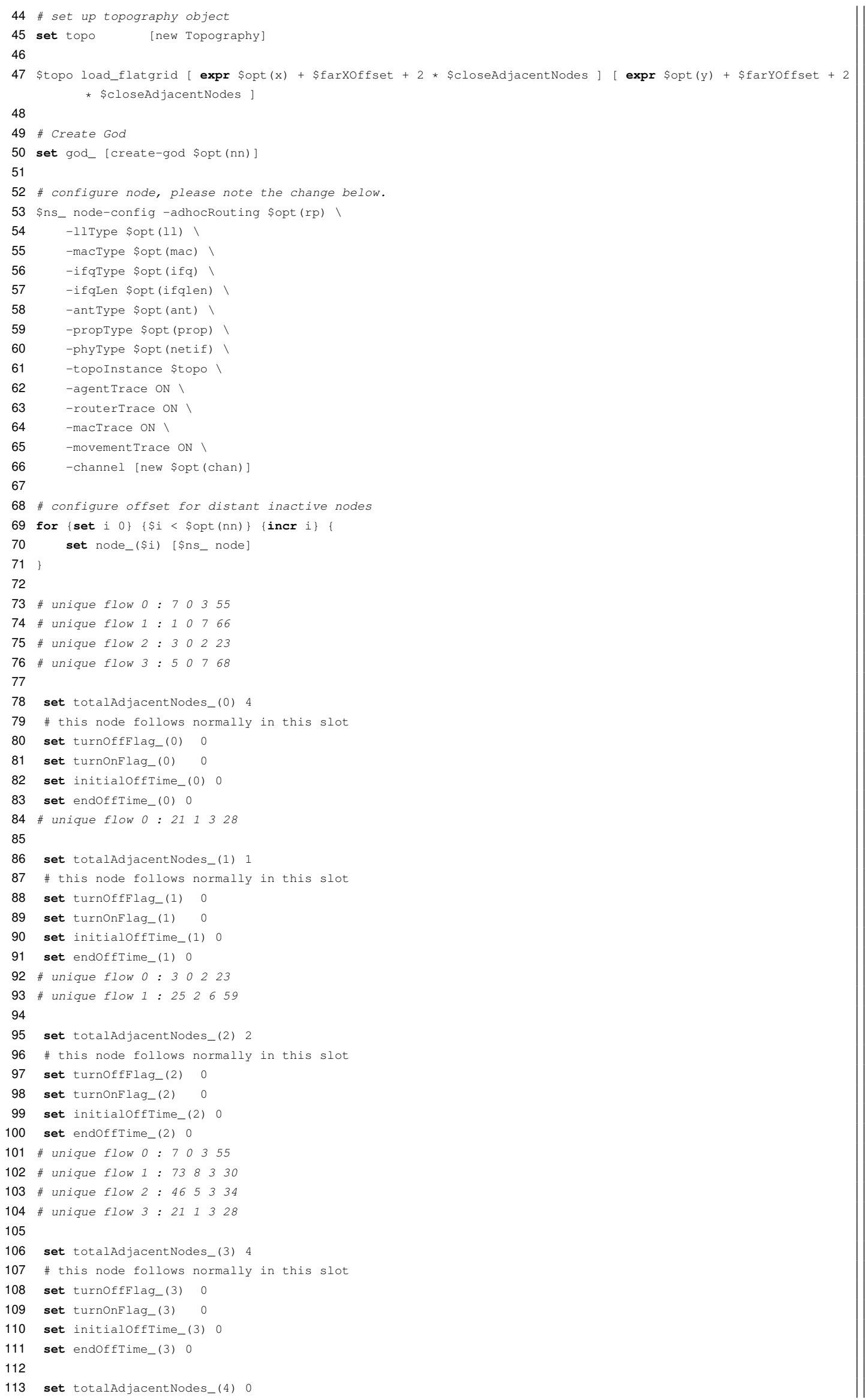




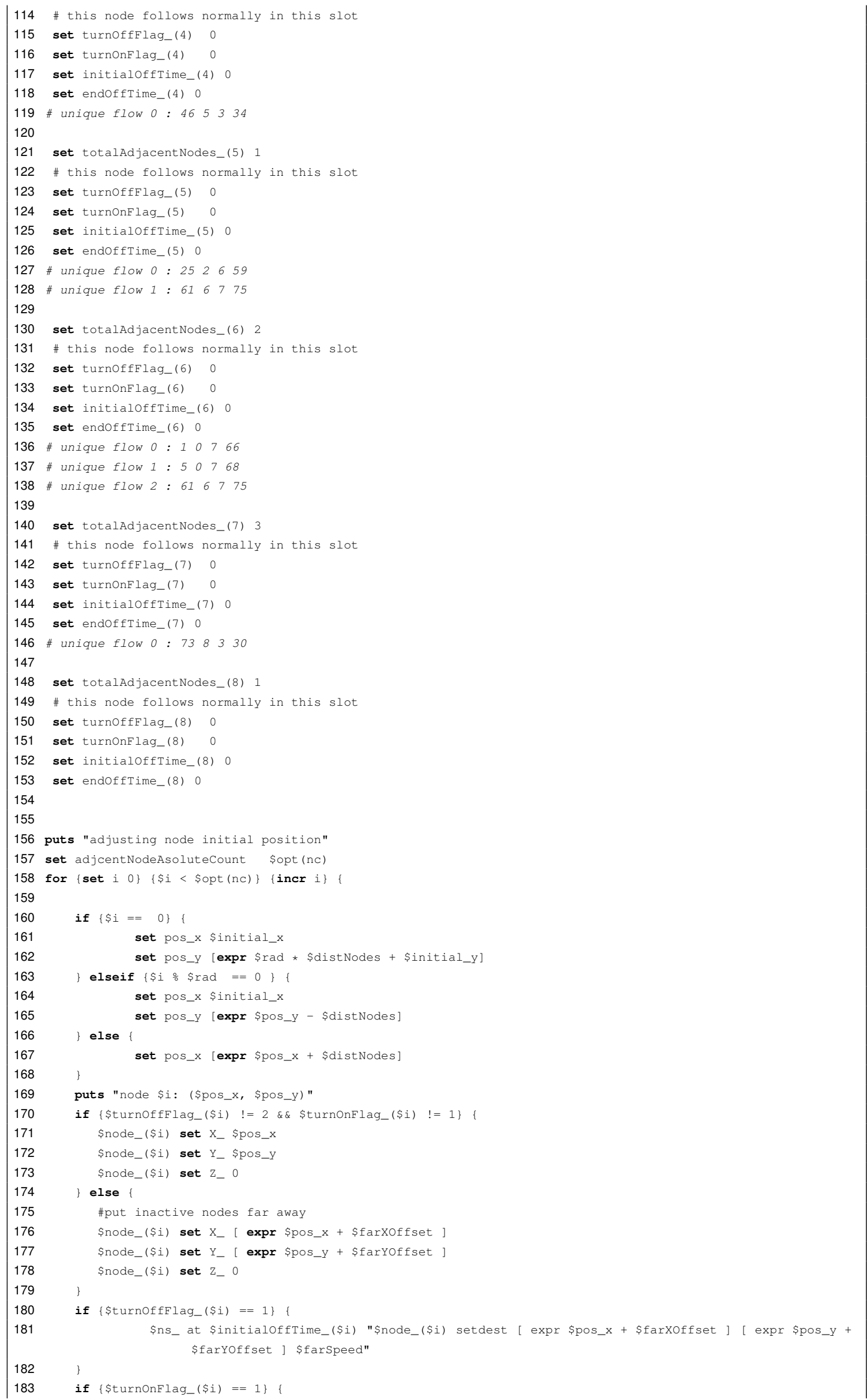




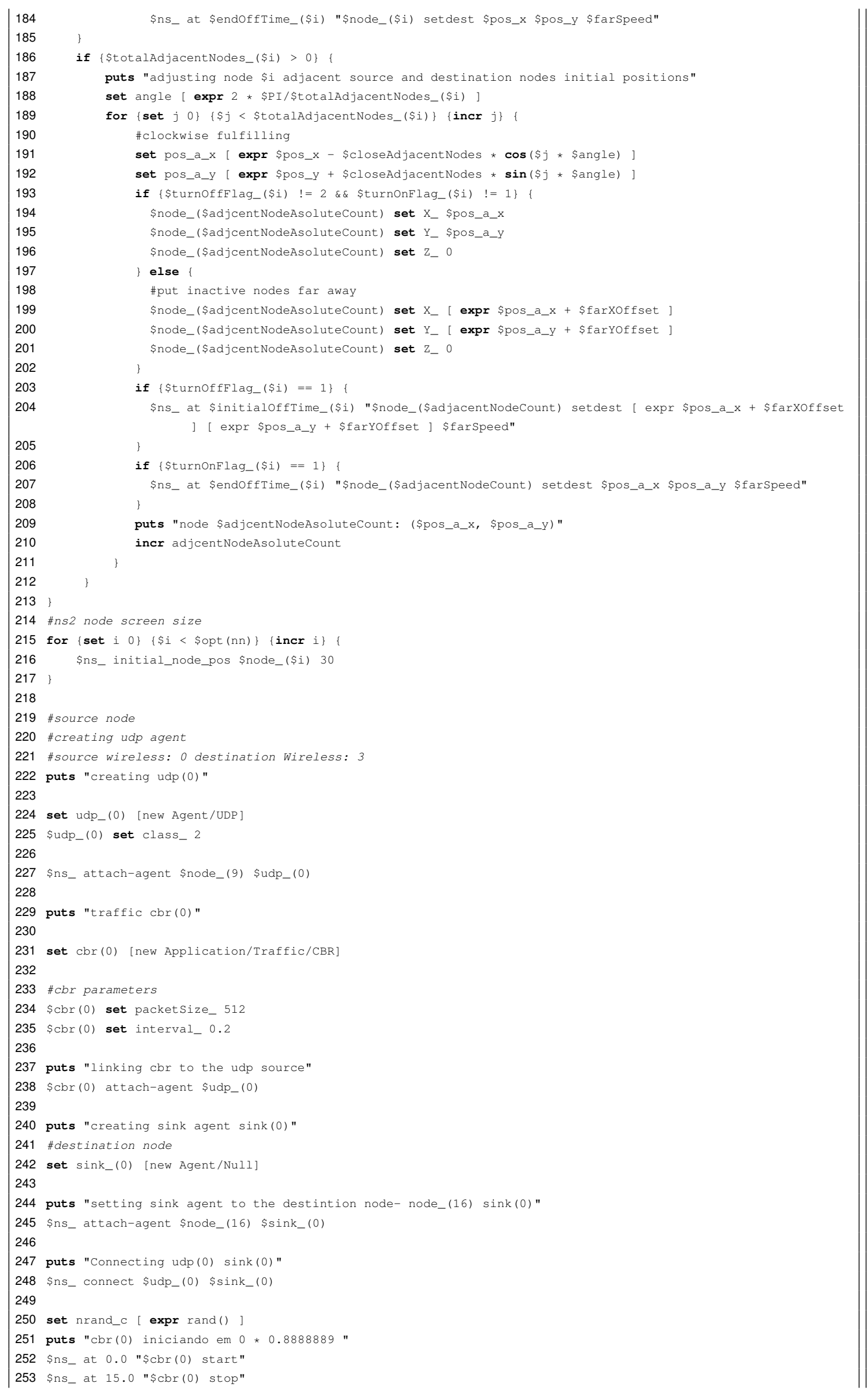




\section{4}

255 \#source node

256 \#creating udp agent

257 \#source wireless: 8 destination Wireless: 3

258 puts "creating udp (1)"

259

260 set udp_(1) [new Agent/UDP]

261 \$udp_(1) set class_ 2

262

263 \$ns_attach-agent \$node_(26) \$udp_(1)

264

265 puts "traffic cbr(1)"

266

267 set cbr(1) [new Application/Traffic/CBR]

268

269 \#cbr parameters

270 \$cbr(1) set packetSize_ 512

271 \$cbr(1) set interval_ 0.2

272

273 puts "linking cbr to the udp source"

274 \$cbr(1) attach-agent \$udp_(1)

275

276 puts "creating sink agent sink(1)"

277 \#destination node

278 set sink_(1) [new Agent/Null]

279

280 puts "setting sink agent to the destintion node- node_(17) sink(1)"

281 \$ns_attach-agent \$node_(17) \$sink_(1)

282

283 puts "Connecting udp(1) sink(1)"

284 \$ns_ connect \$udp_(1) \$sink_(1)

285

286 set nrand_c [ expr rand() ]

287 puts "cbr(1) iniciando em 1 * 0.8888889 "

288 \$ns_at 0.8888889 "\$cbr(1) start"

289 \$ns_at 15.0 "\$cbr(1) stop"

290

291 \#source node

292 \#creating udp agent

293 \#source wireless: 5 destination Wireless: 3

294 puts "creating udp (2)"

295

296 set $u_{d p}$ (2) [new Agent/UDP]

297 \$udp_(2) set class_ 2

298

299 \$ns_attach-agent \$node_(20) \$udp_(2)

300

301 puts "traffic cbr(2)"

302

303 set cbr(2) [new Application/Traffic/CBR]

304

305 \#cbr parameters

306 \$cbr(2) set packetSize_ 512

307 \$cbr(2) set interval_ 0.2

308

309 puts "linking cbr to the udp source"

310 \$cbr(2) attach-agent \$udp_(2)

311

312 puts "creating sink agent sink(2)"

313 \#destination node

314 set sink_(2) [new Agent/Null]

315

316 puts "setting sink agent to the destintion node- node_(18) sink(2)"

317 \$ns_attach-agent \$node_(18) \$sink_(2)

318

319 puts "Connecting udp(2) sink (2)"

320 \$ns_connect \$udp_(2) \$sink_(2)

321

322 set nrand_c [ expr rand() ]

323 puts "cbr(2) iniciando em 2 * 0.8888889 "

324 \$ns_at 1.7777778 "\$cbr(2) start" 


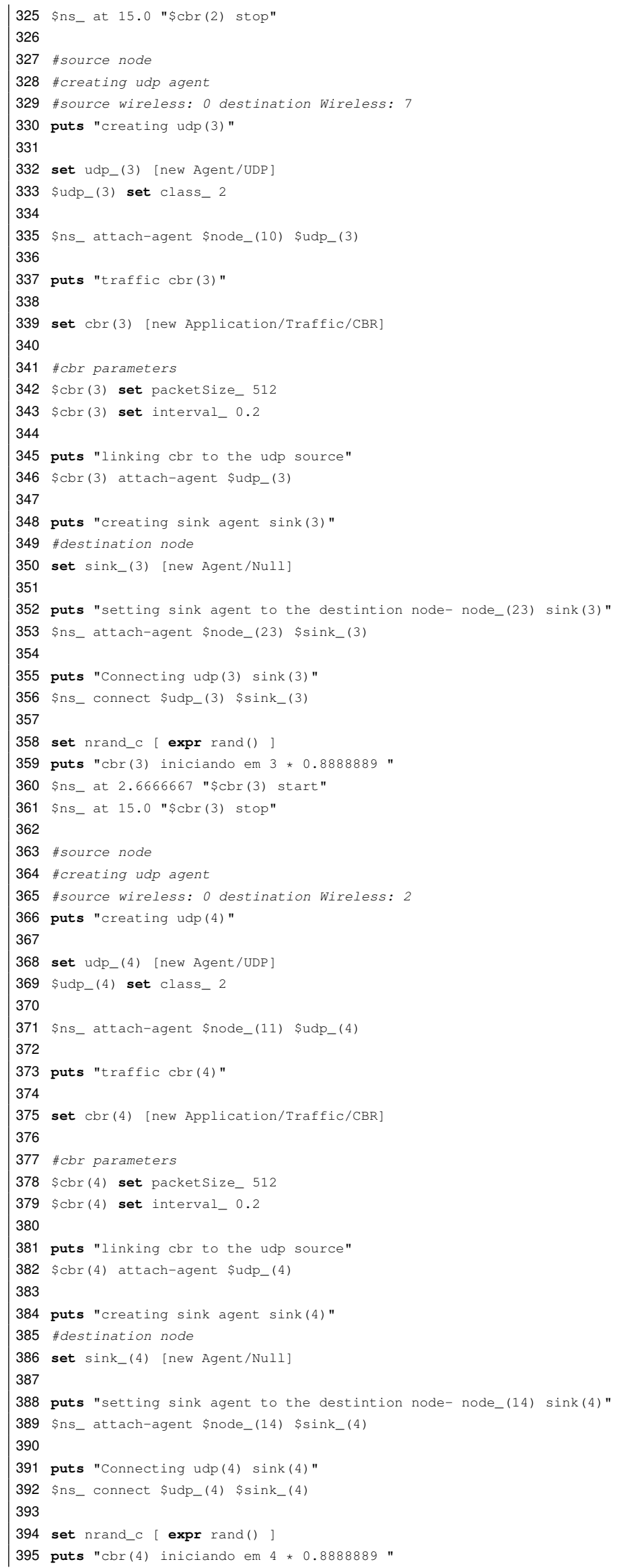




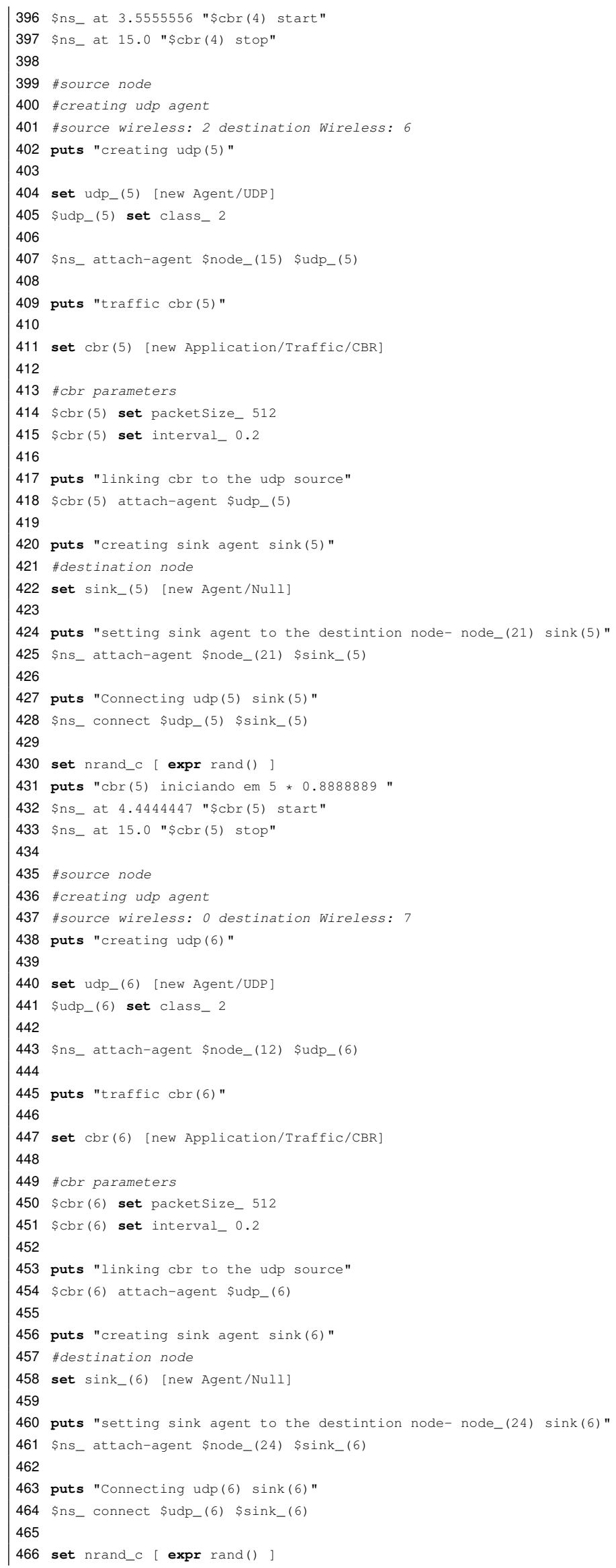


467 puts "cbr(6) iniciando em 6 * 0.8888889 "

468 \$ns_at 5.3333335 "\$cbr(6) start"

469 \$ns_at 15.0 "\$cbr(6) stop"

470

471 \#source node

472 \#creating udp agent

473 \#source wireless: 1 destination Wireless: 3

474 puts "creating udp (7) "

475

476 set udp_(7) [new Agent/UDP]

477 sudp_(7) set class_ 2

478

479 \$ns_attach-agent \$node_(13) \$udp_(7)

480

481 puts "traffic cbr(7)"

482

483 set cbr(7) [new Application/Traffic/CBR]

484

485 \#cbr parameters

486 \$cbr (7) set packetSize_ 512

487 \$cbr(7) set interval_ 0.2

488

489 puts "linking cbr to the udp source"

490 \$cbr (7) attach-agent \$udp_ (7)

491

492 puts "creating sink agent sink(7)"

493 \#destination node

494 set sink_(7) [new Agent/Null]

495

496 puts "setting sink agent to the destintion node- node_(19) sink(7)"

497 \$ns_attach-agent \$node_(19) \$sink_(7)

498

499 puts "Connecting udp (7) $\operatorname{sink}(7)$ "

500 \$ns_ connect \$udp_(7) \$sink_(7)

501

502 set nrand_c [ expr rand() ]

503 puts "cbr(7) iniciando em 7 * 0.8888889 "

504 \$ns_at 6.2222223 "\$cbr (7) start"

505 \$ns_at 15.0 "\$cbr (7) stop"

506

507 \#source node

508 \#creating udp agent

509 \#source wireless: 6 destination Wireless: 7

510 puts "creating udp (8)"

511

512 set udp_(8) [new Agent/UDP]

513 \$udp_(8) set class_ 2

514

515 \$ns_ attach-agent \$node_(22) \$udp_(8)

516

517 puts "traffic cbr(8)"

518

519 set cbr(8) [new Application/Traffic/CBR]

520

521 \#cbr parameters

522 \$cbr(8) set packetSize_ 512

523 \$cbr (8) set interval_ 0.2

524

525 puts "linking cbr to the udp source"

526 scbr (8) attach-agent \$udp_(8)

527

528 puts "creating sink agent sink(8)"

529 \#destination node

530 set sink_(8) [new Agent/Null]

531

532 puts "setting sink agent to the destintion node- node_(25) sink(8)"

533 \$ns_attach-agent \$node_(25) \$sink_(8)

534

535 puts "Connecting udp (8) $\operatorname{sink}(8) "$

536 \$ns_connect $\$$ udp_(8) $\$$ sink_(8)

537 
538 set nrand_c [ expr rand() ]

539 puts "cbr(8) iniciando em 8 * 0.8888889 "

540 \$ns_ at $7.111111 "$ \$cbr $(8)$ start"

541 \$ns_at $15.0 "$ "\$cbr(8) stop"

542

$543 \#$

544 \# finishing simulation

$545 \#$

546 for $\{$ set $i 0\} \quad\{i<\$ o p t(n n)\}$ incr i\} \{

547 \$ns_ at \$opt (stop).01 "\$node_(\$i) reset"

548

549 \# stopping nam animation

550 \$ns_at \$opt (stop).01 "\$ns_nam-end-wireless \$opt (stop)"

551 \$ns_ at \$opt(stop).01 "puts \"NS EXITING... " ; \$ns_ halt"

552 proc stop \{\} \{

553 global ns_tracefd

$554 \quad$ \$ns_flush-trace

555 close \$tracefd

$556 \quad\}$

557 puts "Starting Simulation..."

558 \$ns_ run 


\section{APÊNDICE C - EXEMPLO PARA OS PARÂMETROS DE ENTRADA}

Este apêndice ilustra um exemplo de parâmetros de entrada da plataforma de simulação descrita no capítulo 4 especificando dois experimentos. No primeiro há o desligamento de dois nós em intervalos de tempos distintos empregando o protocolo DSR ao passo que no segundo há a simulação de uma topologia empregando o protocolo AODV.

Trecho de Código C.1: exemplo de parâmetros de entrada da ferramenta de simulação

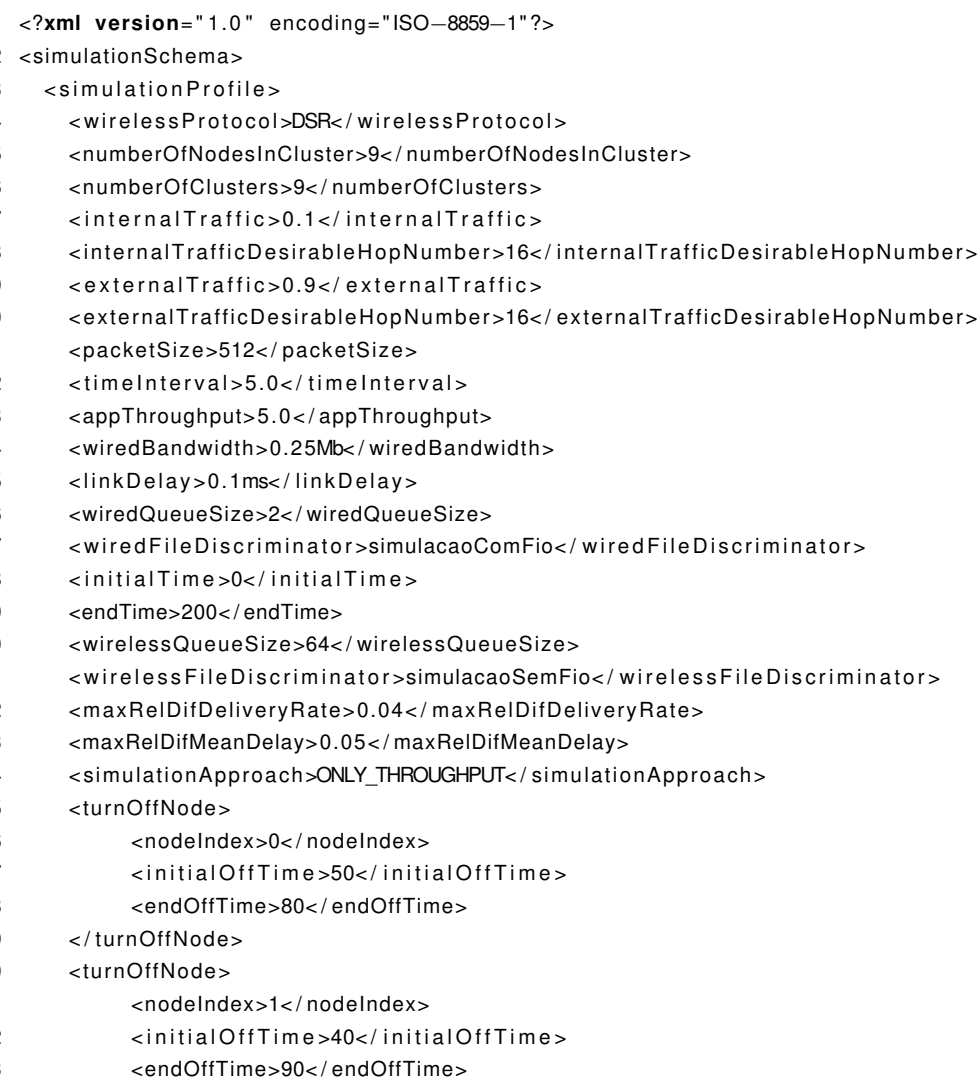


$</$ turnOffNode $>$

$</$ simulationProfile $>$

$<$ simulationProfile $>$

$<$ wireless Protocol $>A O D V</$ wirelessProtocol $>$

$<$ numberOfNodesInCluster $>16</$ numberOfNodesInCluster $>$

$<$ numberOfClusters $>9</$ numberOfClusters $>$

$<$ internalTraffic $>0.2</$ internalTraffic $>$

$<$ internalTrafficDesirableHopNumber $>16<$ / internalTrafficDesirableHopNumber $>$

$<$ externalTraffic $>0.7<$ / externalTraffic $>$

$<$ externalTrafficDesirableHopNumber $>16<$ / externalTrafficDesirableHopNumber $>$

$<$ packetSize $>512</$ packetSize $>$

$<$ timelnterval $>5.0</$ timelnterval $>$

$<$ appThroughput $>5</$ appThroughput $>$

$<$ wiredBandwidth $>0.25 \mathrm{Mb}<$ / wiredBandwidth $>$

$<$ linkDelay $>0.2 \mathrm{~ms}</$ linkDelay $>$

$<$ wiredQueueSize $>2<$ / wiredQueueSize $>$

$<$ wiredFileDiscriminator $>$ simulacaoComFio</ wiredFileDiscriminator $>$

$<$ initialTime $>0<$ initialTime $>$

$<$ endTime $>200<$ / endTime $>$

$<$ wirelessQueueSize $>64</$ wirelessQueueSize $>$

$<$ wirelessFileDiscriminator $>$ simulacaoSemFio $<$ / wirelessFileDiscriminator $>$

$<$ maxReIDifDeliveryRate $>0.04</$ maxReIDifDeliveryRate $>$

$<$ maxRelDifMeanDelay $>0.05</$ maxRelDifMeanDelay $>$

$<$ simulationApproach $>$ ONLY_THROUGHPUT</ simulationApproach $>$

$<$ simulationProfile $>$

$61</$ simulationSchema> 


\section{APÊNDICE D - CÓDIGO FONTE DAS ABORDAGENS DE CONVERGÊNCIA}

Trecho de Código D.1: código-fonte de parte do subsistema de controle ilustrado na Figura 26. Este código-fonte detalha as abordagens de convergência da seção 4.1 .4

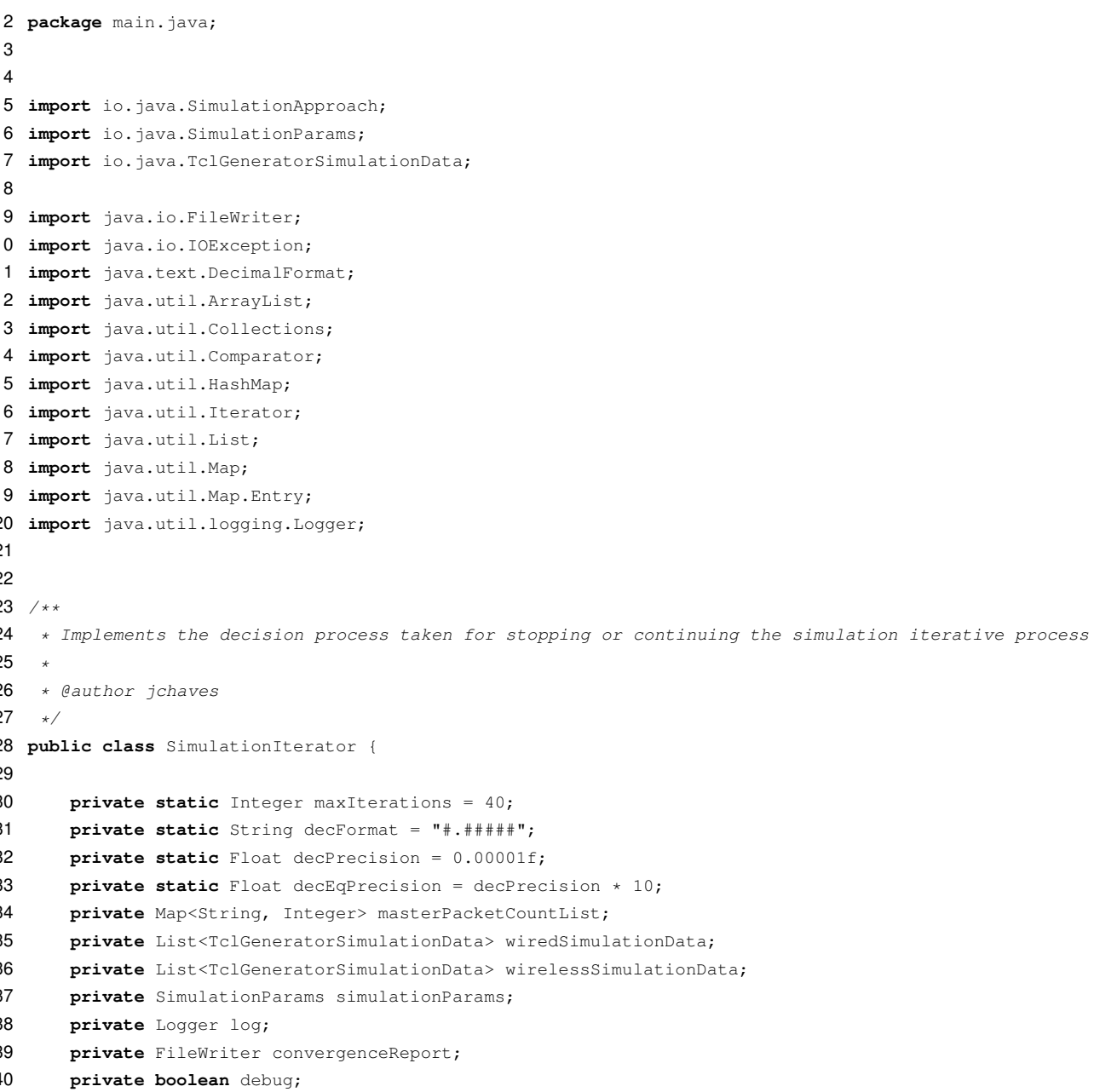




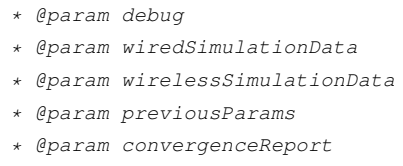


Float wiredDeliveryRate $=$ wiredSimulation.getDeliveryRate ();

Float wiredMeanDelay $=$ wiredSimulation.getMeanDelay ();

Float wirelessDeliveryRate $=$ wirelessSimulation.getDeliveryRate ();

Float wirelessMeanDelay $=$ wirelessSimulation.getMeanDelay ();

// for now it will be like this

// wirelessMeanDelay $=$ wirelessMeanDelay/2;

if (wirelessSimulation.getThroughputData().size() != wirelessSimulation.getThroughputData().size ()) \{

throw new RuntimeException("Discrepancies between wired and wireless throughput data");

I/ packet through node master count

for (Map.Entry<String, Integer> nodeCount : wirelessSimulation.getNodePacketCountData().entrySet ()) \{

Integer packetCount $=$ this.masterPacketCountList.get (nodeCount.getKey ())

if (packetcount $==$ null)

this.masterPacketCountList.put (nodeCount.getKey (), nodeCount.getValue ())

\} else

this.masterPacketCountList.put (nodeCount.getKey(), packetCount + nodeCount.getValue());

// gaps among samples are not needed in calculations

if (!wirelessSimulation.getThroughputData().isEmpty()) \{

wiredSimulationDelay $+=$ wiredMeanDelay;

wirelessimulationDelay $+=$ wirelessMeanDelay;

wirelessimulationDeliveryRate $+=$ wirelessDeliveryRate;

wiredSimulationDeliveryRate $+=$ wiredDeliveryRate;

numberofNotEmptySimulations++;

\} else \{

if (this.debug)

System.out.println ("gap") ;

,

String strLog $=$ null;

strLog $=$

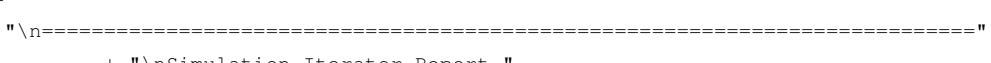

+ "InSimulation Iterator Report

$+" \backslash \mathrm{n}=$

this.log.info(strLog);

this. convergenceReport.write (strLog);

SimulationParams newSimulationParams = this.simulationParams.clone();

if (numberofNotEmptysimulations $>0)$

wirelessimulationDelay $=$ wirelessSimulationDelay / numberofNotEmptysimulations;

wiredSimulationDelay = wiredSimulationDelay / numberofNotEmptySimulations;

wirelessSimulationDeliveryRate = wirelessSimulationDeliveryRate / numberofNotEmptySimulations; wiredSimulationDeliveryRate = wiredSimulationDeliveryRate / numberofNotEmptySimulations;

Float errRelDelivery $=$

(wirelessSimulationDeliveryRate - wiredSimulationDeliveryRate) / wiredsimulationDeliveryRate;

Float errRelDelay $=$ (wirelessSimulationDelay - wiredSimulationDelay) / wiredSimulationDelay;

Float correctionfactorDelay = null;

Float correctionfactorDelivery = null;

if (this.fabs(errRelDelivery) > this.simulationParams.getMaxRelDifDeliveryRate()) strLog = "STATE: trying to balance devivery rates $\backslash \mathrm{n} "$;

this. $\log$.info(strLog);

this.convergenceReport.write (strLog);

strLog = "Tamanho erro delivery: " + this.simulationParams.getDeliveryRateError().size() + " n";

this. convergenceReport.write (strLog);

this.log.info(strLog); 


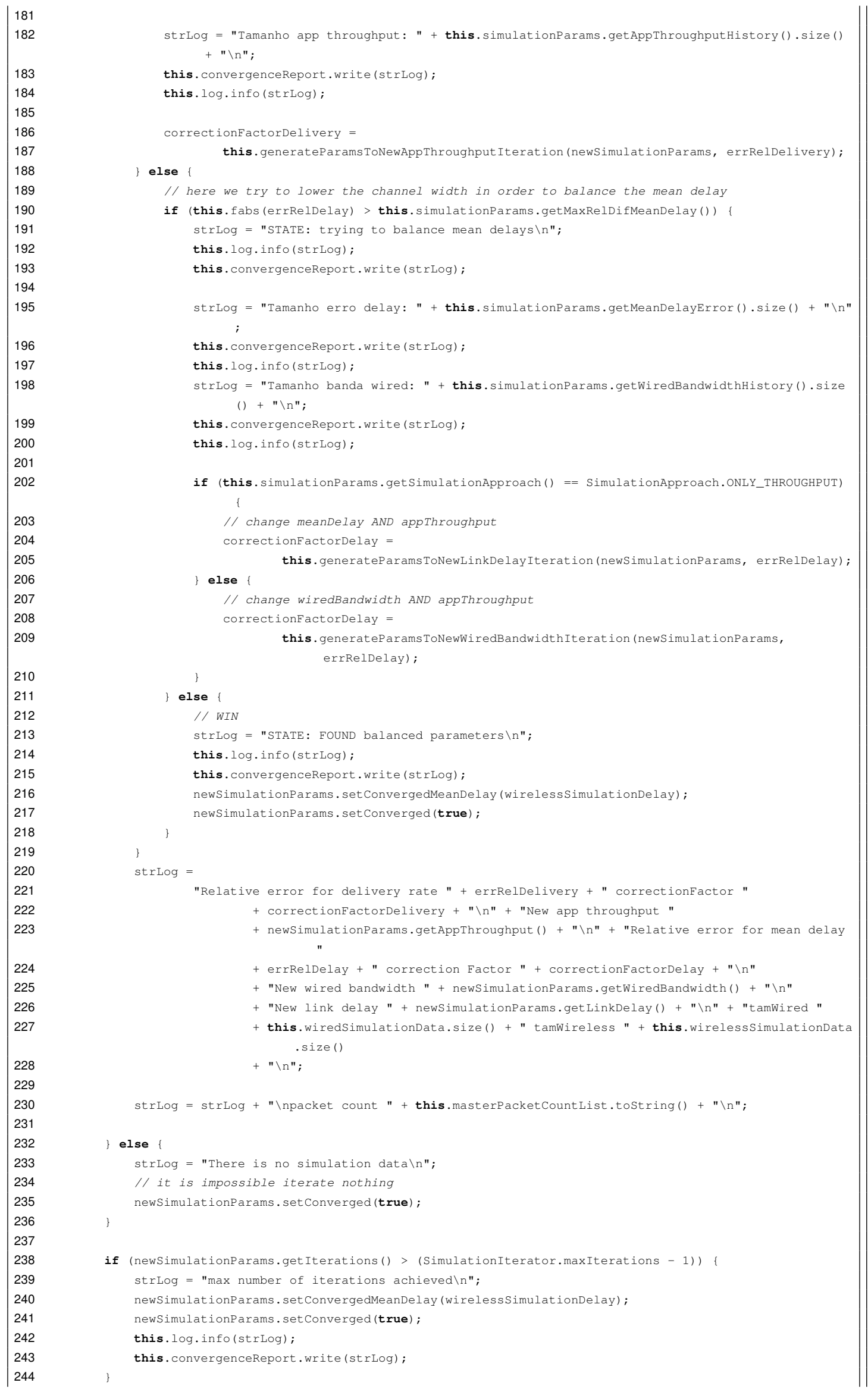


newSimulationParams.setIterations (newSimulationParams.getIterations () + 1);

this. log.info(strLog);

this. convergenceReport.write (strLog);

return newSimulationParams;

\}

$/ * *$

* eparam newSimulationParams

* eparam errReldelivery

* ereturn correctionfactordelivery

* ethrows IOException

*/

private Float generateParamsToNewAppThroughputIteration(SimulationParams newSimulationParams, Float errRelDelivery)

throws IOException

Float correctionfactorDelivery;

correctionFactorDelivery = errRelDelivery;

Float newAppThroughput $=$ null

Float appThroughput $=$ this.simulationParams.getAppThroughput ();

if (this.fabs (correctionFactorDelivery) $>(4 *$ this.simulationParams.getMaxRelDifDeliveryRate ())) (

$/ /$ correction factor is too big or small

if (correctionFactorDelivery $>0)$ i

correctionFactorDelivery $=4 *$ this.simulationParams.getMaxRelDifDeliveryRate ();

\} else \{

correctionFactorDelivery $=-4 *$ this.simulationParams.getMaxRelDifDeliveryRate () ; \}

else if (this.simulationParams.getDeliveryRateError().size() $>0$ )

Integer lastErrorIndex = this.simulationParams.getDeliveryRateError(). size() - 1;

Float lastError = this.simulationParams.getDeliveryRateError().get (lastErrorIndex);

Integer lastAppThroughputIndex = this.simulationParams.getAppThroughputHistory().size() -1 ;

if (( lastError * correctionfactorDelivery) < 0$)$ \&\& (lastAppThroughputIndex > 0)) (

Float previousAppThroughput $=$

Float.valueof (this.simulationParams.getAppThroughputHistory() . get ( lastAppThroughput Index - 1))

// errors with different signals

newAppThroughput $=$ (previousAppThroughput + appThroughput $) / 2$;

// clean history and error history

newSimulationParams.getAppThroughputHistory().clear();

newSimulationParams.getDeliveryRateError().clear();

\} else \{

// Float relerrortest $=$ (errRelDelivery - lastError) / lastError

if (this.fabs (correctionFactorDelivery) $<(2 *$ this.simulationParams.getMaxRelDifDeliveryRate ()) ) 1

if (correctionfactorDelivery $>0) \quad$ i

correctionFactorDelivery $=2$ * this.simulationParams.getMaxRelDifDeliveryRate();

\} else \{

correctionFactorDelivery $=-2$ * this.simulationParams.getMaxRelDifDeliveryRate();

DecimalFormat df = new DecimalFormat (decFormat);

if (newAppThroughput $==$ null)

newSimulationParams . setDeliveryRateError(correctionFactorDelivery);

newAppThroughput $=$ appThroughput $*(1+$ correctionFactorDelivery $) ;$

if (this.equalsfloat (newAppThroughput, appThroughput, decEqPrecision)) (

newAppThroughput $=$ appThroughput + correctionFactorDelivery;

\}

if (newAppThroughput $<0$ ) i

newAppThroughput $=$ decPrecision

Integer listSize = this.simulationParams.getAppThroughputHistory().size(),

if (listSize > 1) \{

if ((this.simulationParams.getAppThroughputHistory ().get (listSize -1$)==$ decPrecision)

\&\& (this.simulationParams.getAppThroughputHistory ().get (listSize -1$)==$ this. simulationParams

-getAppThroughputHistory() .get (listSize - 2))) (

String strLog $=$ "There is NO smaller value for throughput $\backslash n$ ";

this.log.info (strLog);

this. convergenceReport.write (strLog); 


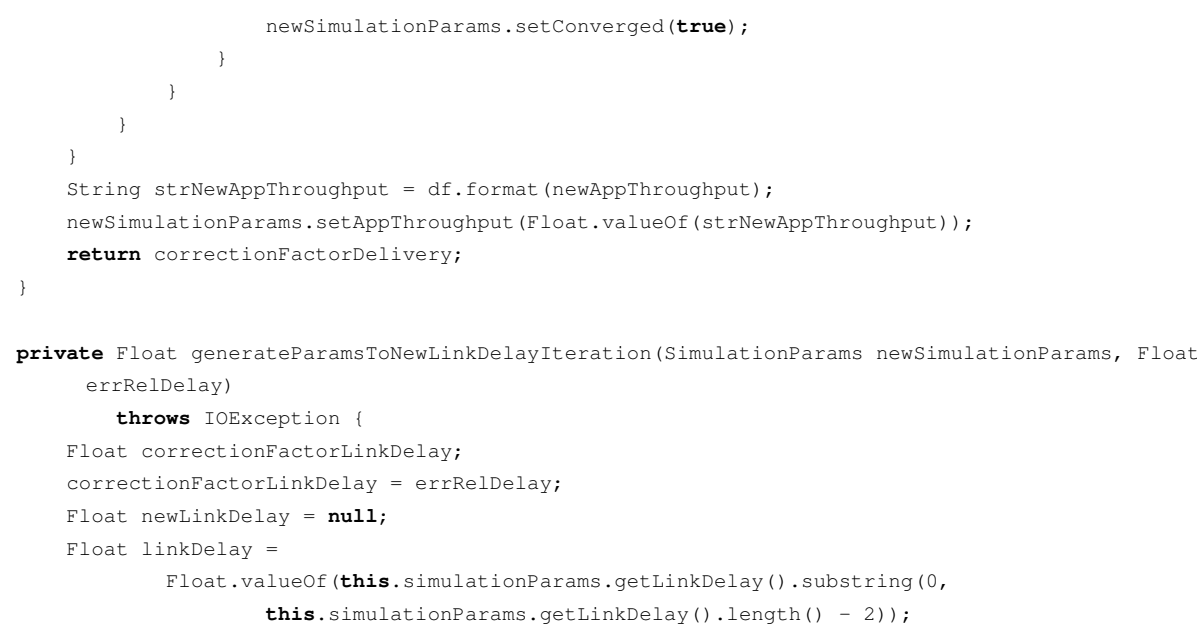

if (this.fabs (correctionFactorLinkDelay) $>(4 *$ this.simulationParams getMaxRelDifMeanDelay ()$))$ // correction factor is too big or small

if (correctionFactorLinkDelay $>0$ ) \{

correctionFactorLinkDelay $=4 *$ this.simulationParams.getMaxRelDifMeanDelay(); 
\&\& (this.simulationParams.getLinkDelayHistory() get (listSize -1$)=$ this simulationParams .getLinkDelayHistory().get(listSize - 2))) ( String strLog $=$ "There is No smaller value for linkDelay $\backslash \mathrm{n} "$; // TODO: implement the case to low throughput if wired simulation is slower than wireless

this.log.info(strLog);

this. convergenceReport.write (strLog);

newsimulationParams.setConverged (true);

\}

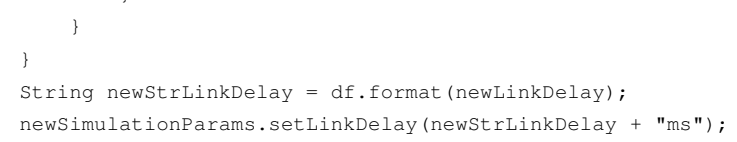




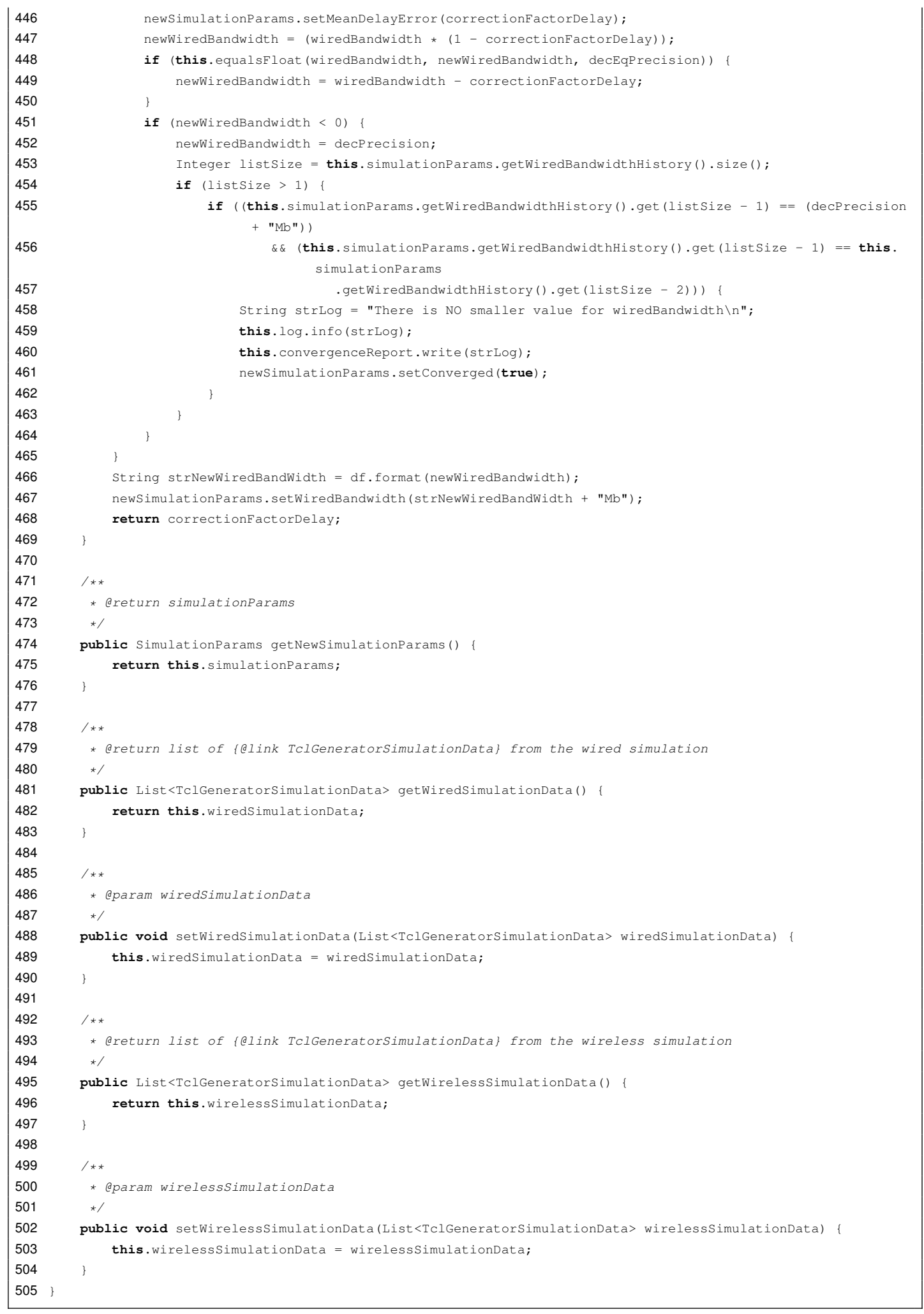

